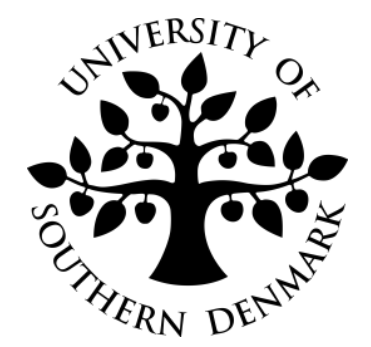

\title{
Legal Risk Premia During the Euro-Crisis: The Role of Credit and Redenomination Risk
}

\author{
by \\ Jens Nordvig \\ Discussion Papers on Business and Economics
}

No. 10/2015

FURTHER INFORMATION

Department of Business and Economics Faculty of Business and Social Sciences University of Southern Denmark Campusvej 55, DK-5230 Odense M Denmark 


\title{
Legal Risk Premia During the Euro-Crisis: The Role of Credit and Redenomination Risk
}

\author{
Jens Nordvig \\ May 18, 2015
}

\begin{abstract}
Using several new datasets, I document the role of legal risk premia in bond yields during the Euro-crisis. I find evidence of a rising premium especially in late 2011 and mid-2012 on bonds with foreign governing law relative to those with local governing law (and otherwise similar characteristics). The results illustrate that legal risk premia spiked at the height of the crisis in the Eurozone, when investors were willing to pay a premium for the additional protection offered by foreign law bonds. I show that this governing law premium can be linked to both credit risk (expected haircuts) and redenomination risk (expected currency depreciation). This paper is the first to empirically link the governing law premium to redenomination risk. I find evidence that redenomination risk is an independent driving force of governing law spreads over and above credit risk, although it is analytically challenging to separate the two risk factors. My findings, while not conclusive, are consistent with the consensus in the literature on contract law, which argues that local law financial instruments should be more susceptible to redenomination in a scenario of a country exiting the Eurozone.
\end{abstract}

JEL Classification: G1, F3, F31, K2, C58, G01

Keywords: General Financial Markets, International Finance, Foreign Exchange, Contract Law, Financial Econometrics, Financial Crisis.

The author is affiliated with Nomura Securities International, Inc. Worldwide Plaza, 309 West $49^{\text {th }}$ Street, New York, NY 10019 and the Department of Business and Economics, University of Southern Denmark, Campusvej 55, DK-5230 Odense M, Denmark. Contact details: jnordvig@me.com. The author would like to thank Thomas Barnebeck Andersen, Wouter Schmit Jongbloed and Nikolaj Malchow-Møller for helpful comments. All remaining errors are mine. 


\section{INTRODUCTION}

The Euro-crisis was a period of extreme and surprising asset price moves. Eurozone sovereign spreads widened unexpectedly. Bank stocks dropped sharply as systemic tensions erupted. Financial markets in general were highly unstable.

Behind the volatility lay increased uncertainty about the viability of the Eurozone and the emergence of sovereign credit and redenomination risk. The Euro was supposed to be an irrevocable construct; the Maastricht Treaty (and its successor treaties) was supposed to guarantee sound fiscal policy. But market tension rose in several waves in the period from 2010 to $2012 .{ }^{1}$ During these waves of tension, the debate about break up of the Euro heated up and asset pricing departed from the pre-crisis norms in many ways, Nordvig (2013).

Asset price moves were certainly driven by changing expectations about the outlook for the Eurozone economy. It is logical that currency, bond and equity markets would respond to a deteriorating outlook for the Eurozone. But under the surface, there were also certain legal issues that played an increasing role in asset pricing. The importance of specific contractual terms within bond documentation was highlighted by the Greek debt restructuring in early 2012, as documented by Zettelmeyer, Trebesch and Gulati (2013). At that time, different Greek government bonds with similar maturity and coupons, traded at widely different yields. The differentiating factor was the governing law of each bond. The majority of bonds had Greek governing law; other Greek bonds had foreign (often English) governing law. As it turned out, investors were willing to pay a significant premium (and accept lower yields) on the foreign law bonds.

This was not an issue specific to Greece. Rather, it was a regional phenomenon and ultimately a function of the different protections offered against various risks in bonds with different governing laws. Legal parameters, which were typically irrelevant to asset pricing pre-crisis, impacted asset pricing in a number of Eurozone countries during the Euro-crisis.

In this paper, I investigate the role of legal parameters in the pricing of fixed income instruments during the Euro-crisis. I focus on the role of governing law premia for various classes of Eurozone bonds; and I argue that the governing law premia during the Euro-crisis can be linked to both credit risk and redenomination risk. This finding has relevance beyond the Greek debt crisis and the Euro-crisis. It is a finding that market participants and policy makers should incorporate in risk management decisions and policy making more broadly.

\footnotetext{
1 Some would argue that the last wave of the crisis was in early 2013, when capital controls and a bailout for Cyprus were needed. I am not counting the renewed tension around Greece, observed in 2015.

${ }_{2}$ In making this statement, I am implicitly assuming that the governing law is the same as the
} 
Since I attempt to identify the underlying drivers of the legal risk premia, it is worth defining the key forces at play. The two risk concepts with which the legal parameters interact can be described as follows:

The credit risk differential between foreign law and local law bonds derives from the fact that the foreign governing law stipulation may insulate creditors from credit risk to some degree. The foreign law provisions may reduce the probability of a credit event and/or it may reduce the haircuts imposed on the creditor in a debt restructuring/default scenario. Here, credit event is defined as an event that haircuts (or delays) the creditor's coupon or principal payments. I exclude front my definition of credit risk the redenomination risk, although redenomination can constitute a CDS trigger and be deemed a credit event (for non-G7 countries), as I discuss in more detail in section 8. As such, local law bonds entail additional risks for creditors, since the sovereign has the ability to change local legislation and influence local courts in its favor. ${ }^{2}$ Both factors may increase the probability of a credit event and/or increase the haircuts imposed in the event of a credit event. In other words, the sovereign has the ability to create a more favorable outcome for itself (and other local issuers) when dealing with local law instruments. The consequence of this is of course a more adverse scenario for creditors, including foreign creditors.

The redenomination risk differential between foreign law and local law bonds derives from the fact that local law bonds may be subject to greater risk of currency redenomination in a scenario of exit from the Eurozone, as described in Nordvig (2014). In contrast, foreign law bonds will be harder to redenominate, and are more likely to stay in the original currency (i.e. Euro) irrespective of what a new legal tender law in a (former) Eurozone country stipulates. ${ }^{3}$ From this perspective, local law bonds (compared to foreign law bonds) leave creditors more exposed to the currency risk associated with exit from the Eurozone and devaluation/depreciation of a new successor currency.

There are three main contributions from this paper.

First, I highlight the role of redenomination risk in asset pricing during the Eurocrisis. Redenomination risk is an additional factor, on top of credit risk, which can help explain legal risk premia. The existing literature has paid little attention to this aspect of asset pricing. Second, to test my hypotheses empirically, I use several new

\footnotetext{
2 In making this statement, I am implicitly assuming that the governing law is the same as the jurisdiction of the instruments. I will elaborate further on this issue in section 2.2. The key point is that while the governing law of a contract is not the only legal parameter that matters, it is often 'correlated' with the other legal parameters of importance, so that whether a contract has foreign governing law matters more for redenomination risk than that parameter alone would suggest.

3 This statement applies mainly to the situation of single (or multiple) country exits from the Eurozone, i.e. partial breakup of the Eurozone. In the scenario of full-blown breakup, in which the Euro ceases to exists, there is an additional layers of complexity in the redenomination process. But this is not the most likely form of breakup, and I will analyze breakup mainly in the context of partial breakup, in which the Euro lives on in some form, even after one or more countries have exited.
} 
data sets, including both agency and corporate bonds issued in Euros by issuers residing in the Eurozone. This allows more robust conclusions on the behavior of legal risk premia compared to previous papers, which have been using only data on sovereign bonds. Third, I present two novel ways to proxy redenomination risk, which is an important but unobserved variable. I use both a method based on counting the quantity of news stories in the financial press, which mentions certain key words linked to breakup of the Euro and exit from the Eurozone, and a method based on quanto CDS (derived from CDS quotes in different currencies).

The paper is structured as follows:

In section 2, I review the empirical literature on the role of legal risk premia in bond pricing; both that literature that pre-dates the Euro-crisis and the small recent literature on the legal risk premia during the Euro-crisis. I highlight that redenomination risk is generally ignored in existing empirical work, even if this risk is conceptually as important as credit risk.

In section 3, I outline my empirical strategy. I focus on how to construct a data set that is focused on EUR denominated bonds issued by Eurozone issuers, but that is still sufficiently large to robustly identify the role of both credit risk and redenomination risk.

In section 4, I compute governing law spreads for pairs of corporate, sovereign and government-backed bonds. This gives an initial impression of the behavior over time of governing law spreads during the Euro-crisis.

In section 5, I present a regression framework to more formally derive the effect of the governing law parameter for a sample of agency bonds. I use this regression framework, including several control variables, to attempt to identify the role of both credit risk and redenomination risk as explanatory variables for the governing law premium.

In section 6, I discuss how redenomination risk could be measured in theory, and define two proxies that I will apply in the empirical analysis (a proxy based on the quantity of certain types of news stories and a another proxy based on quanto CDS). In section 7, I present my results using various specifications of the model, which emphasize both credit risk and redenomination risk.

In section 8, I discuss the special issues associated with separating the measurement of credit risk and redenomination risk, and present additional analysis, including granger causality tests.

In section 9, I summarize my main conclusions, and I highlight the importance of my results for Eurozone policy makers, who are still dealing with fragmentation of financial markets and the risk of future exits from the Eurozone. I also provide some thoughts on avenues for future research. 


\section{LEGAL RISK PREMIA: THE ROLE OF CREDIT AND REDENOMINATION RISK}

\subsection{Previous studies on legal parameters in asset pricing}

There is a body of literature, going back to at least 2000, which analyzes the role of legal parameters in asset pricing (typically in the context of bond pricing).

Historically, this literature has focused mainly on the role of Collective Action Clauses (CACs) in bond pricing. For example, Roubini (2000) argues that legal parameters (CACs) are likely to be irrelevant for asset pricing. Bolton and Jeanne (2007), on the other hand, argue that debt with CACs will be effectively senior to other debt. ${ }^{4}$ In addition, other legal parameters have occasionally been investigated. For example, Choi and Gulati (2014) investigate the pricing of bonds with government guarantees versus plain vanilla government bonds.

Recently, a branch of the literature on the role of legal parameters in asset pricing has used data from the Euro-crisis. Inspired by the events in Greece early in the crisis and around the debt restructuring in 2012, there have been a number of papers written about governing law premia on Greek bonds. The first of these papers was Choi, Gulati and Posner (2011), which noted a difference in pricing between a Greek government bond relative to a foreign-law bond.

The basic assumption in this literature is that bonds with foreign governing law offer additional protection for creditors compared to bonds with local governing law. As argued in Proctor (2010), the key incremental risk associated with local law bonds relates to the government's ability to change key provisions in the bond (or the interpretation thereof) after it has been issued. Moreover, local courts, assuming the jurisdiction and governing law coincide, may also have a certain bias to rule in favor of local debtors. In theory, the governing law provision (the underlying body of law with reference to which the contract written) and the jurisdiction specified (which defines which courts rule in the case of a dispute) can differ. On occasion, the two parameters do differ. However, in the large majority of bonds I have investigated, the governing law and the jurisdiction coincide. For example, an English law bond is highly likely to specify that English courts have jurisdiction in disputes.

This empirical analysis of the behavior of bond prices during the Euro-crisis has recently been broadened to larger samples of sovereign bonds, and analyzed in greater detail and with the use of more sophisticated statistical methods (as I will discuss in section 5).

Specifically, two papers ask similar questions to the ones I address in this paper (and have been written in parallel with this paper). Clare and Schmidlin (2014) investigate the role of the governing law parameters for a large sample of European sovereign bonds during the Euro-crisis. Chamon, Schumancher and Trebesch (2014)

\footnotetext{
$4 \quad$ For a more comprehensive review of the (pre-Euro-crisis) literature of the role of CACs in bond pricing see Häseler (2009)
} 
also focus on the role of the governing law parameter in bond pricing, and the interaction between governing law parameters and credit risk (as proxied by CDS), using a data set of Eurozone sovereign bonds.

\subsection{Redenomination risk and asset pricing in the Eurozone}

There is one aspect of bond pricing, however, that has been missing from the previous analysis of legal risk premia. That aspect is redenomination risk. This is surprising given that redenomination risk featured prominently in the policy discussion as well as in the debate in financial markets and within the legal profession during the Euro-crisis.

Back in 2012, the ECB the announced its Open Market Transaction (OMT) program, which allowed the central bank to buy unlimited amounts of bonds in certain countries (subject to a certain conditionality). The goal of the program was to eliminate redenomination risk in bond pricing, and thereby achieve lower bond yields and more accommodative financial conditions in the Eurozone (often termed 'better transmission of monetary policy').

In a speech in May 2013, ECB President Draghi summarized the issue as follows:

From the second half of 2011, we witnessed the emergence of a new source of stress, which has been defined as the risk of "redenomination," resulting from the potential exit of a country from the euro or even from the potential collapse of the single currency. A particular form of credit risk premium was associated with these possibilities, which was unrelated to the assessment of a borrower's solvency. ${ }^{5}$

The ECB was hardly the first to recognize that redenomination risk could impact asset pricing. During 2011, there was a heated debate about the issue within the legal profession (by specialists in contract law) and among financial analysts. The key question being asked was how breakup of the Euro and exit from the Eurozone would work its way though the financial system and impact various financial instruments. See Proctor (2010), Nordvig (2011) and Scott (2011) for an early discussion of this issue.

Redenomination of financial assets and liabilities is indeed a complex issue and market participants have had to learn about this entirely new risk factor in the period since 2011, when the issue first came into focus. The issue involves three main overarching dimensions.

- A political dimension: What type of breakup? Are we dealing with a single country exit (partial breakup), or a full-blown breakup, in which the Euro would cease to exist altogether? 6

- An institutional dimension: Is exit from the Eurozone done unilaterally or through a mutually agreed and legally binding arrangement?

$5 \quad$ The full speech is available here:

http://www.ecb.europa.eu/press/key/date/2013/html/sp130506.en.html

Nordvig (2013) and Nordvig (2014) elaborate on the political/institutional issues involved in redenomination linked to the various forms of breakup of the Eurozone. 
- A contractual dimension: There is a host of different legal parameters (implicit or implicit in individual contracts) that could influence the likelihood of redenomination.

This paper is focused primarily on the risk of single country exits rather than fullblown breakup. This is so because the politics of Europe would suggest that this is by far the most likely form of breakup, as argued in Nordvig (2014). From this perspective, the contractual dimension of the analysis becomes the most relevant, especially in the context of asset pricing analysis.

The list of specific legal parameters, which may be relevant to the process of redenomination includes place of payment, currency of issue, location of obligor, jurisdiction specified, and the governing law of the contract. In addition, financial instruments may have a specific redenomination clause, which may stipulate the process of redenomination even the event of Eurozone breakup. ${ }^{7}$

There is certainly a spectrum of different opinions about the details of how redenomination would work. And the nuances may be crucial in certain specific situations (a legal dispute about a specific claim). However, from a macro economic perspective, the most important distinguishing factor is the governing law parameter, as argued in Nordvig (2014).

Hence, in the context of the empirical analysis in this paper, I will focus mainly on the governing law parameter within bond documentation. A key argument for this choice is that many of the other relevant contractual legal parameters are linked to the governing law parameter. For example, the place of payment on a foreign law bond is typically outside the country in which the issuer resides. In addition, foreign courts will generally have jurisdiction in connection with a foreign law bond. As such, if a bond is issued under foreign law, making redenomination difficult, it will also embed other legal parameters, which would also render redenomination difficult. In other words, the governing law parameter is correlated with other legal parameters that also make redenomination harder.

Importantly, there is generally consensus within the legal profession that in the event of a country exiting the Eurozone and adopting a new currency, the governing law of the contract (i.e. local vs. foreign law) would be a crucial determinant of whether a financial instrument would be likely to redenominate into new currency or stay in Euro. ${ }^{8}$ As outlined in Nordvig (2014), which includes a list of eight papers

\footnotetext{
$7 \quad$ In section 3, I discuss how some Eurozone bonds issued during the Euro-crisis had such explicit 'successor currency clauses'. But that the quantity of such bonds is so small that it does not allow any formal quantitative analysis.

In the context of the debate about redenomination, the lex monetae principle is often mentioned. It states that sovereign nations have the right to determine their own currency. However, the concept is hard to apply in a clear-cut fashion in the context of the Eurozone (and specifically in a partial breakup). The reason is that there is a potential conflict between the lex monetae of the country, and the lex monetae of the EU (i.e. the Euro). Which lex monetae applies? Hence, the law of the contract becomes the determining factor, as argued by Scott (2011).
} 
published by major international law firms, the consensus within the legal profession is fairly uniform on this specific point.

The redenomination risk that Mr. Draghi was talking about back in 2012 and 2013 was particularly relevant for financial instruments governed by local laws. Such financial instruments, including most sovereign bonds, would be subject to new legislation by country level parliaments. In the exit scenario, Greece, or any country considering exit, would be able to redenominate local law assets through a new currency law (sometimes called legal tender law).

In theory, therefore, one should be able to observe the redenomination risk in the spread between local and foreign law bonds with otherwise similar characteristics (same issuer, same maturity, etc.). ${ }^{9}$ That is, when the probability of exit rises (regardless of whether the country is exiting mainly due to increased risk of insolvency or mainly due to other driving factors), and the exiting country is expected to adopt a new currency, which would depreciate in value following exit, local law bonds should trade at a discount to foreign law bonds. ${ }^{10}$ Nevertheless, this specific issue has not been sufficiently reflected in the empirical work that has been done in the area to date. ${ }^{11}$

For example, Chamon, Schumancher \& Trebesch (2014), in an otherwise thorough analysis of the premium on foreign law sovereign bonds, state:

"Our priors are that the foreign-law premium is positively correlated with the CDS spreads, since it can only make a difference in the event of a default."

It is true that there is a possible link between the foreign law premium of bonds and credit risk (as proxied by CDS spreads), due to the possibility of differential haircuts for foreign law and local law bonds (or a different probability of a credit event). But to argue that the legal parameter only matters in the event of default ignores the specific risk associated with possible redenomination, which may at least in theory happen without a default/restructuring of the bonds. For example, Germany arguably has the option of exiting the Eurozone and redenominating its currency without necessarily defaulting or restructuring its government bonds. It may not be most probably scenario from a stand-point of political analysis. But it is still a

\footnotetext{
$9 \quad$ Although in practice, it may be difficult to separate the effects from credit risk and redenomination risk, as I will discuss in more detail in sections $5,6,7$ and 8 .

For example, it is possible to imagine a political change in a country such as France that would make France pursue a return to the French Franc, without such a step coinciding in a sovereign default. The Front National is currently advocating abandoning the Euro, and the balance sheet of France remains relatively strong (i.e. balance sheet effects would be manageable), such that sovereign default and redenomination can, at least in theory, be separated. I have made this argument for France and Italy in Nordvig(2013, Chapter 13).

$11 \quad$ An exception is a very recent paper, De Santis (2015), which discusses evidence of redenomination using a very different empirical approach to mine, focusing on CDS spreads in both EUR and USD denominated contracts. I will return to this paper in section 6 .
} 
contingency to consider. ${ }^{12}$

\subsection{Bond pricing and redenomination risk}

Before I turn to the empirical analysis, it is worth outlining how redenomination risk may impact bond pricing (particularly the pricing of local law bonds).

The basic structure of the pricing equation is comparable to that used in the credit literature. Corporate bond prices can be modeled as a function of the term structure of default probabilities, expected haircuts, and discount rates (see Vrugt [2011] for an example). Inspired by this literature, I specify a bond pricing equation for Eurozone bonds as a function of the term structure of probabilities of Eurozone exit and currency depreciation/appreciation in that scenario (assumed fixed over time for simplicity).

The price of the bond is, as usual, equal to the sum of the discounted cash flows. But one has to take into account the (cumulative) probability of staying inside the Eurozone up to a given point to know whether cash flows need an FX conversion too.

Formally, the equation looks as follows:

$$
P_{0}=\sum_{n=1}^{N} d f_{n}\left[\left(C F_{n} \times S_{n}\right)+\left(1-S_{n}\right) \times\left(C F_{n} / F X\right)\right]
$$

This equation says that the price, $P_{0}$, of a given bond (measured in Euro), with cash flows $\mathrm{CF}_{\mathrm{n}}$ over $\mathrm{n}$ periods, is equal to the sum of discounted cash flow up to the point of exit in Euro and the discounted value of cash flows converted into Euro after exit, with $F X$ being the exchange rate relative to the Euro prevailing after exit. ${ }^{13}$ In this equation, $S_{n}$ is the cumulative probability of staying within the Eurozone up to period $n . S_{n}$ is logically a function of the term structure of period by period exit probabilities $\pi_{i}$ :

$$
S_{n}=\prod_{i=1}^{n}\left(1-\pi_{i}\right)
$$

12 In theory, the two risks are separate risk factors, which have the ability to impact bond pricing independently. In practice, however, there is likely to be a high correlation between the two. Risk of redenomination is likely to rise when the sovereign is under stress, for example. Linked to this, a strong correlation between the two risk factors has generally been the pattern observed during the Euro-crisis, as I also document in section 8, and this makes identification of one factor relative to the other empirically challenging.

13 In the specification used here FX is a constant, for simplicity. But a time-varying FX variable is likely to be more realistic. 
In a situation where the exiting country is expected to see its currency depreciate, it would be the case that $\mathrm{FX}>1.14$

The basic bond pricing equation could be expanded with additional terms, which capture default risk in addition to redenomination risk. A realistic empirical model would surely need both terms. Such a model would arguably combine a 'corporate finance' framework for bond pricing as a function of the term structure of default probabilities with an 'international finance' framework, which views bond pricing as a function of currency depreciation expectations. ${ }^{15}$

In the following sections, I will discuss how to analyze legal risk premia (specifically governing law premia) using a framework that recognizes that both credit risk and redenomination risk could be important drivers of the bond price (yield).

\section{IDENTIFICATION OF LEGAL RISK PREMIA IN EMPIRICAL ANALYSIS}

My goal is to establish the role of governing law parameters for the pricing of the universe of bonds issued in the Eurozone. To allow a relatively straightforward interpretation of the legal parameter, I want to narrow my focus to bonds issued by Eurozone issuers in Euros. This allows us to analyze the role of redenomination risk as well as credit risk, and it reduces the risk of other variables spuriously driving the results.

This is easier said than done, for a number of reasons.

- $\quad$ First, there is a very large amount of bonds issued in the Eurozone. I have generally looked at a total universe encompassing around four hundred thousand different bond issues. Handling this amount of data raises a number of logistical/IT issues.

- Second, the governing law variable is not always available. This is especially a problem for corporate bonds.

- $\quad$ Third, price information may be patchy, especially during the period of stress (2010-2012) that I am most interested in.

- $\quad$ Fourth, it may be difficult to directly deduce the role of the governing law parameter because certain issuers only issue in local law (Germany for example) or only in foreign law (the Spanish company Repsol for example).

\footnotetext{
14 To illustrate, most would assume that $F X>1$ in the case of Greek exit from the Eurozone. On the other hand, most would assume that $F X<1$ in the case of German exit from the Eurozone. Whether Germany would look to redenominate all instruments in such a scenario is a different issue, as I discuss further in Section 6.

$15 \quad$ I note that Vrugt (2011) constructs a model to identify implied recovery values and risk-neutral default probability term-structures from sovereign bond prices in Greece in the run-up to the debtrestructuring there. However, there is no focus on the governing law dimension of the different bonds issued by Greece or on the issue of redenomination risk.
} 
The most direct way to observe the legal risk premium is to find pairs of bonds that are identical (or close to identical) in terms of issuer and other bond characteristics (i.e. pairs of bonds that only differ in terms of their governing law parameter). This provides a clean and simple way to identify the role of the governing law parameter, without making many assumptions in the process. This is the method used in Section 4, using two different data sets.

Alternatively, when unable to find pairs of (near) identical bonds, it is possible to use a regression framework to model bond yields as a function of the governing law variable, while controlling for other variables that determine yields (such as credit rating and liquidity factors). The regression should be able to identify the role of the governing law parameter, when one appropriately controls for other variables, even if the various bonds in the sample otherwise have very different characteristics. However, such a regression framework requires a certain amount of observations (degrees of freedom) to produce statistically significant results. Importantly, since I expect that market pricing of bonds will only be sensitive to legal parameters during periods of stress, the regression framework will have to allow for time-varying regressions coefficients (hence, I cannot pool the data over time).

As mentioned, my empirical strategy entails focusing on bonds issued by Eurozone residents and in Euro only. This allows a more straightforward interpretation of the results than previous studies. Clare \& Schmidlin (2014) use a sample that includes bonds issued by non-Eurozone EU member countries. Hence, it is unclear if the results are potentially driven by country-specific differences (between Eurozone and non-Eurozone countries). Meanwhile, Chamon, Schumancher and Trebesch (2014) use a sample that includes bonds issued in currencies other than Euro. My concern is that the results may be influenced by the specifics of bond pricing in different currencies rather than the legal risk premium as such. ${ }^{16}$

In addition, a sample with bonds issued in Euros only is more suited to address the specific question about the role of redenomination risk in the legal risk premia observed. This specific issue only applies to bonds issued by Eurozone countries in Euro, and I have to constrain the selection of my sample to address this question.

To allow a look at a more narrowly defined set of bonds (along the dimensions of country of issue and currency denomination), I broaden the sample along another dimension. Specifically, I look at bonds issued by non-sovereigns (agencies and corporates). In other words, I move out the credit curve, to capture a richer sample of bonds. This is a key innovation relative to the other recent papers, which investigate the governing law premium during the Euro-crisis. Both Clare \&

\footnotetext{
16 The authors attempt to account for differences in currency of issue by converting all yields into a common space (i.e. Euro equivalent) using a risk neutral pricing equation (i.e. interest rate parity). But since the no-arbitrage assumption embedded in such relationships has been proven to fail in times of significant market stress, as shown in Coffrey, Hrung and Sankar (2009), I worry that this may play a role in driving the results. Hence, to avoid this complication and allow a simpler interpretation of results, I prefer to work on a sample that includes only bonds issued in Euros.
} 
Schmidlin (2014) and Chamon, Schumancher \& Trebesch (2014) look exclusively at sovereign bonds in their analysis.

Hence, I end up reviewing the following three sub-samples of bonds:

- A sample of observable pairs of (mainly) corporate bonds, with differing governing laws, and otherwise similar characteristics.

- A sample of foreign law government and government guaranteed bonds, which I analyze relative to specific points on local law benchmark curves. ${ }^{17}$

- A sample of agency bonds, which is sufficiently large to run a series of crosssectional and panel regressions with several control variables, allowing more formal identification of the role of the governing law parameter.

In principle, the analysis of agency bonds could be expanded to the entire universe of corporate bonds. But the challenge from an empirical perspective is that the control variables and pricing information becomes incomplete for the corporate bonds, meaning that it is harder to obtain reliable results. ${ }^{18}$

I have also tried to investigate more 'exotic' legal parameters, in order to directly identify the role of redenomination risk. During the Euro-crisis, some companies issued bonds with so-called 'currency successor clauses'. This clause is a specific stipulation about replacement currency in the event of Euro breakup ${ }^{19}$.

Conceptually, such bonds offer a way to identify redenomination risk by simply looking at the yield differential between bonds with and without the clause. In theory, this yield differential should be a function of the probability of exit and the expected currency move in the event of exit as described in section 2.3 above. But the challenge is to translate a conceptually viable avenue for identification into an empirical strategy that is workable for a reasonably large sample of financial instruments. Unfortunately, my investigations detected so few bonds with the clause embedded, that it was not a viable avenue ${ }^{20}$.

\footnotetext{
$17 \quad$ While there are no directly observable yield pairs, I essentially construct pairs by matching observable foreign law yields with an equivalent point on domestic law benchmark curves.

$18 \quad$ For example, I have crosschecked the pricing information for corporate bonds using multiple pricing sources (both from Bloomberg and Reuters). For corporate bonds, there can be considerable gaps in the data and inconsistencies between sources. Hence, a formal analysis of the broader universe of corporate bonds would likely require a comprehensive filtering exercise, which is beyond the scope of this paper.

19 For example, Volkswagen issued a bond on June 12, 2012, which stated that "References herein to a 'Specified Currency' shall include any successor currency provided for by the laws in force in the jurisdiction where the Specified Currency is issued or pursuant to intergovernmental agreement or treaty (a 'Successor Currency') to the extent that payment in the predecessor currency is no longer a legal means of payment by the Issuer on the Notes. This was a legal way to ensure that the creditors would be paid back in the currency of Germany (from time to time), not some other currency construct, with a potentially lower ${ }_{20}$ value.

20 My search ended up identifying only two bonds with the clause in the bond documentation. Namely, the bond issued by Volkswagen, and one additional bond issued by EDF (the French utility company).

Moreover, I was not able to detect any clear pricing differential on those bonds relative to other bonds issued by those companies. This is perhaps understandable since this specific clause is 'so exotic' that few people, even experts in debt capital markets, are aware of its existence. From this perspective, it is consistent with the school of thought in the literature that is arguing that legal parameters are often not fully reflected in asset pricing. For more on this topic see, for example, Choi and Gulati (2014).
} 
This is an example of the fundamental challenge in empirical work in this area. Putting together a reasonable sample of bonds, with sufficient information about both foreign law and local law bonds to robustly identify the role of the governing law parameter, is not an easy test. Against this background, I stress that a major contribution of the work embedded in this paper is the construct of suitable data set, a data set which is sufficiently rich in terms of sample size and reliable enough in terms of pricing information to allow robust identification of the governing law parameter. I believe this is the more important component of the empirical analysis, as opposed to use of sophisticated econometric techniques.

\section{OBSERVABLE GOVERNING LAW SPREADS DURING THE EURO-CRISIS}

In this section, I look at two datasets with 'observable' governing law spreads. The first dataset includes directly observable spreads from pairs of nearly identical sovereign, corporate and agency bonds (except governing law). The second dataset includes spreads constructed from matching yields on foreign law government guaranteed bonds with comparable points on local law benchmark curves.

\subsection{Observable governing law spreads}

In order to find pairs of bonds with similar characteristics, except the governing law parameters, I have scanned several hundred thousand bonds issued by Eurozone issuers. This underlying database is derived primarily from Bloomberg data on individual bonds, but the information is supplemented with data from Reuters and Dealogic. $^{21}$

For this exercise, I focus mainly on peripheral issuers (Greece, Ireland, Portugal, Spain or Italy) as well as France, since this is where one is most likely to observe sizeable legal risk premia (due to both credit risk and redenomination risk).

For several reasons, the subset of bonds satisfying the various criteria is not large. First, many individual issuers only use one governing law. Hence, even if there were a legal risk premium attached to their foreign law instruments during the Eurocrisis, I have a hard time confirming it, due to a lack of benchmark securities under local law. Second, my database does not have governing law information for all bonds issued. Third, data for bond pricing, especially for those bonds issued in smaller size, can be sporadic, and not always reliable (especially not during periods of market stress), making a robust interpretation of the reasons for spread moves subject to uncertainty. To be specific, it can be hard to differentiate between spread moves that are due to liquidity differentials (as I discuss in section 5) and those due to legal risk premia of one type or another. Hence, I have excluded bonds for which the pricing seems unreliable and discontinuous. This filtering is done based mainly on where there are many missing data points and where the recorded/prices yields

21 The methodology is discussed in more detail in Nordvig (2014). 
are implausibly discontinuous from trading day to trading day. For example, I exclude bonds for which prices are missing on more than $50 \%$ of trading days.

Nevertheless, my search resulted in 137 different pairs of bonds.

A specific example is shown in the Chart 1 below, which plots the yield of a local law and foreign law bond of Italian energy supplier Enel. Figure A.1 in the appendix shows the spread between the two bond yields in more detail.

\section{Chart 1: Individual yields of the Enel SpA bond pair}

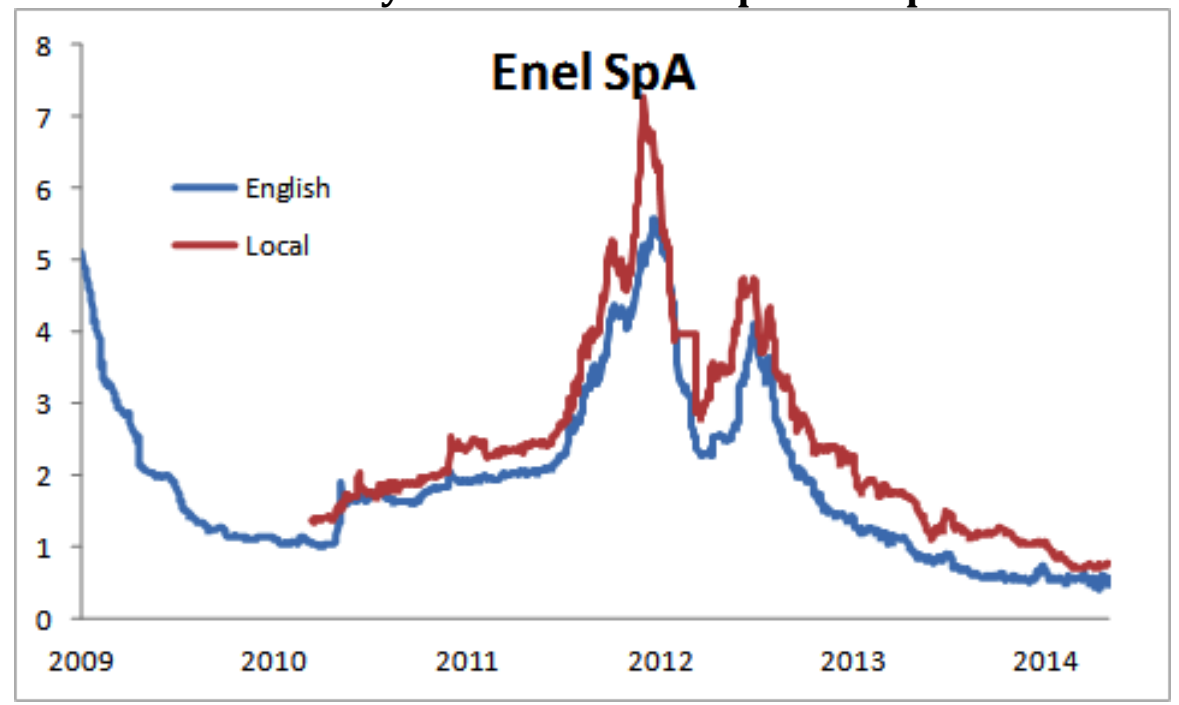

Source: Bloomberg, Nomura Securities.

Note: Chart shows the yield to maturity for two Enel SpA bonds, namely the 6/20/2014 English Law bond and the 1/14/2015 Italian law bond (both floating rate type bonds). The chart also illustrates that there is a patch of missing data for the local law bond in early 2012 (flat line in chart). This is an indication that unreliable pricing is a part of the reason for the sharp decline in the spread between the two bonds in early 2012 .

The chart provides an example of a pair of bonds from the same issuer and with similar maturity. It shows that there was little difference in the yields (close to zero spread) in the beginning of the sample (i.e. during 2010) and again towards the end of the sample (from 2014 onwards). However, during the Euro-crisis the spread becomes persistently positive. Specifically, the spread spikes towards 2 percentage points in late 2011 and it spikes again, to around 1.5 percentage points, in the middle of $2012 .{ }^{22}$

22 The chart also shows a sharp decline in the spread in early 2012 (this is even clearer in Chart A.1 in the appendix). In fact, the spread turns slightly negative for a few weeks, according to Bloomberg data. A degree of decline in the spread is understandable in the context of a dramatic improvement in market sentiment as a function of the ECB's liquidity injections in late 2011. The improvement in sentiment in early 2012 was also visible in equity prices, credit spreads and money market instruments. However, explaining that the spread should turn outright negative is not easy based on fundamentals. Since, there is evidence of missing pricing data (lack of daily pricing) just ahead of the point in time when the spreads turns temporarily negative, the temporary dip of the spread into negative is likely a function of a temporary pricing inefficiency. In section 7, when we turn to more formal modeling of governing law spread, we use monthly averaging to minimize the fact of temporary data in accuracies. 
To investigate more systematically whether the observed spreads based on my sample of 137 bond pairs track my theoretical expectation, I compute some basic descriptive statistics. First, I analyze the level of spreads over the Euro-crisis period for the sample. Second, I analyze the change in spreads around the peak of the Eurocrisis.

\subsubsection{Signs of observable governing law premia}

Table 1 below shows the distribution of spreads, between positive and negative for the 89 bond pairs I have detected in my database with a spread sign that is generally positive or negative. For the majority of the bond pairs $(72 \%)$ the spreads were positive on average as expected during the Euro-crisis (defined as the period from January 2010 to December 2012).

Table 1: Signs of observed governing law spreads

\begin{tabular}{|c|c|c|c|c|c|c|c|}
\hline & & \multicolumn{3}{|c|}{ Match Count } & \multicolumn{3}{|c|}{ Match Percentage } \\
\hline Country & Count & Positive & Negative & Not Clear & Positive & Negative & Not Clear \\
\hline Italy & 64 & 31 & 13 & 20 & $48 \%$ & $20 \%$ & $31 \%$ \\
\hline Spain & 10 & 3 & 2 & 5 & $30 \%$ & $20 \%$ & $50 \%$ \\
\hline Ireland & 2 & 1 & 0 & 1 & $50 \%$ & $0 \%$ & $50 \%$ \\
\hline Portugal & 4 & 0 & 3 & 1 & $0 \%$ & $75 \%$ & $25 \%$ \\
\hline Greece & 0 & 0 & 0 & 0 & & & \\
\hline France & 31 & 20 & 7 & 4 & $65 \%$ & $23 \%$ & $13 \%$ \\
\hline Netherlands & 26 & 11 & 7 & 8 & $42 \%$ & $27 \%$ & $31 \%$ \\
\hline Total & 137 & 66 & 32 & 39 & $48 \%$ & $23 \%$ & $28 \%$ \\
\hline
\end{tabular}

Source: Bloomberg

Note: Table shows the signs of 137 pairs of bonds with identical issuer (and similar maturity and coupon characteristics) and differing governing law (local versus foreign). Those with positive sign more than $75 \%$ of the time are deemed positive. Those with negative sign more than $75 \%$ of the time are deemed negative. Those towards the middle of the distribution are deemed 'not clear'. For example, in the total sample, there were 66 bonds with predominantly positive sign.

This was the case also at the country level, except for Portugal, where the three bond pairs I detected seemed to generate spreads with the 'wrong sign'. I define a positive spread as a situation where the spread is positive at least $75 \%$ of the time. I define a negative spread as situation where the spread is negative at least $75 \%$ of time.

Bonds that have no clear sign on the spreads (less than $75 \%$ positive or negative) are not included.

These basic observations seem to confirm the basic prediction from the theory, as outlined in section 2 and in Nordvig (2014), that local law bonds should be associated with an additional legal risk premium and therefore trade at higher yields than foreign law bonds. But obviously there are exceptions. 
At this stage, I cannot infer anything about the reason for this spread. It could be either due to a perceived credit risk differential or due to a perceived differential in terms of redenomination risk. In any case, the yields spreads on local and foreign law bond pairs point to the presence of a legal risk premium during the Euro-crisis.

\subsubsection{Dynamics of observable governing law premia}

One shortcoming of the analysis of levels of yields, and levels of spreads, is that there may be persistent yield differentials linked to bond characteristics I have not controlled for when selecting bond pairs. For example, bond liquidity could differ between foreign law and local law bonds, especially when there is a difference in issue size. A simple way to reduce this issue is to look at changes of spreads (since those omitted variables would to some extent be constant over time).

To investigate the dynamics of governing law premia during the Euro-crisis, I focus on the change in yield spread during the second half of 2011, which was arguably the most intense period of the crisis by many measures. ${ }^{23}$

I compare the average spread in the period of low volatility during Q2 2011 with the period of very high volatility from September to November 2011. The specific periods are selected based on the dynamics of implied volatility in EUR-USD on OTC currency options (but other indicators would have generated a similar choice of periods).

I find that there are 33 bond pairs, for which reliable price information is available during the two sub-periods I am interested in. ${ }^{24}$

- Within the full group of 33 bonds, $76 \%$ of pairs saw a rise in the local law risk premium from the calm period in early 2011 to the period of market panic in SepNov 2011.

- Within the sub-group of bond pairs with a generally positive spread, $82 \%$ saw a rise in local law risk premium from the calm period in early 2011 to the period of market panic Sep-Nov 2011.

Similar to my analysis of the level of spreads, these results are consistent with my expectation that a rise in tension should lead to wider spreads of local law bonds versus foreign law bonds. However, as before, it is not possible to infer if this rise in governing law premia is a function of increased credit risk, or a function of redenomination risk (i.e. compensation for devaluation/depreciation risk).

\footnotetext{
23 This argument is supported by a number of market indicators, including levels of sovereign spreads, the volatility in the currency market (EUR-USD implied volatility), and indicators of stress in the banking system (such as LIBOR/OIS spreads and the basis implied in FX swaps for USD funding). This number is relatively small (relative to the initial sample of 137 bond pairs) because some bonds were issued after Q2 2011 and because several bonds lack reliable pricing in the period from September to November 2011, when markets were particularly unstable.
} 
Since the results above are based on a relatively small sample of bonds (especially with regard to the changes in spreads), it is useful to look for additional data, which can provide further information about the behavior of the governing law spread during the Euro-crisis. Below we will briefly discuss findings for a sample of government guaranteed bonds. But we state up front that the results based on this sample are not particularly conclusion, except for Greece. And we discuss the findings here mainly for completeness. In sections 5, 6, 7 and 8, we will go into considerably more detail with a larger sample of agency bonds (without government guarantee).

The key challenge in creating a data set is that many issuers, including sovereigns, do not issue foreign law bonds (limiting the amount of observable yield pairs). One avenue to broaden the available information is to look for sample of foreign law bonds with characteristics very similar to standard (local law) government bonds. The closest I can get to government bonds is government guaranteed bonds.

I then compare the observed yields of the foreign law government guaranteed bonds with an equivalent point on local benchmark curves (interpolated when needed). For example, for a French foreign law government guaranteed bond with 3 years and 4 months to maturity I use a linearly interpolated point on the government par curve (2/3 weight on the 3 -year point and $1 / 3$ weight on the 4 -year curve) to provide a yield benchmark, and to compute a government law spread (partially observable) ${ }^{25}$.

The basic idea of this method is that the credit characteristics of government guaranteed bonds and plain vanilla government bonds are sufficiently similar to allow a direct comparison of their yields. That is, I do not necessarily need a more elaborate method to control for different credit characteristics (which would not be possible due to data limitations), although there will be other differences, as I discuss below.

For example, for a bond issued by the export credit bank of Spain, which is government guaranteed, I compare with a similar 'hypothetical' bond on the Spanish government curve. That is, I match the maturity characteristics of the government guaranteed foreign law bond, with an equivalent point on the government curve, which is derived from local law benchmark securities. ${ }^{26}$

\footnotetext{
25 One could argue that a non-linear interpolation might be superior, and often various spline-based methods are used for yield-curve modeling. However, for my purposes, and given the noise in the observed foreign law yields, I do not think a more complex interpolation strategy would make much of a difference. $26 \quad$ I use benchmark par curves (as opposed to zero coupon curves) provided by Bloomberg. Specifically, I use the benchmark bonds (1Y to 20Y) provided by Bloomberg, and interpolate linearly between the provided points on the curve to match the maturity of the bonds in my sample more accurately. I believe the coupon characteristics of the par curve should be sufficiently similar to the foreign law bonds in my sample to not cause any major differences from this variable.
} 
Depending of the specific point in time, my sample has 20-124 government and government guaranteed bonds under foreign law outstanding. During the Eurocrisis period there are typically $40-70$ bonds in my sample. Table A.1 in the appendix has details on the composition of the sample.

Chart A.2 to A.8 in the appendix shows the calculated foreign law premium of foreign law government and government guaranteed bonds for Greece, Austria, Belgium, Finland, France, Portugal and Spain. Unfortunately, a number of interesting countries (such as Italy) have no relevant bonds (i.e. bond in EUR) issued under foreign law. Note that spreads we show are the spreads available at a given point in time, and that the time series are affected by bonds dropping in and out of the sample. ${ }^{27}$

The clearest result is that there is very convincing evidence of a governing law premium for Greece, especially in the run-up to the March 2012 restructuring. The foreign law premium spikes very significantly during 2011 and stays above 10 percentage points until the debt restructuring is completed. This observation is consistent with other analysis of the debt crisis, including Choi, Gulati and Posner (2011)

Outside Greece, the evidence in this sample is more mixed. There seems to be evidence that the governing law spread increases in late 2011 for Belgium and France (especially on the simple average line). But the effects are small (note the charts have the same scaling except for Greece). Moreover, the results are not particularly uniform across countries.

Some of the country specific differences are logical. For example, I would not expect large governing law premia for highly rated and politically stable countries such as Austria, for which a credit event and/or exit from the Eurozone has not been a major issue. ${ }^{28}$ But the results for Spain are harder to explain in this context. Spain experienced significant tension and escalating speculation about potential exit from the Eurozone during 2012. Nevertheless, the Spanish governing law spreads (shown in Chart A.8) show surprisingly little movement within this specific sample of bonds around the tension in mid-2012, even if capital flight from Spain was at the center of Eurozone tensions at the time. ${ }^{29}$

The Spanish result is particularly surprising given that there is a theoretical argument that government guaranteed bonds may have a reason to trade at a

\footnotetext{
$27 \quad$ I could have eliminated bonds, for which data is not available for the entire sample to avoid these 'artificial jumps', but that would have left us with very few bonds to chart, and little information left to analyze. 28 As highlighted by Nordvig (2014), political risk is a key factor in connection with redenomination risk, as the departure from the Euro would ultimately be a political decision. Hence, the risk of redenomination is arguably higher in countries where the political situation is more uncertain in a way where the centrist and Euro-supportive forces are at risk of losing a majority at future elections.

29 For evidence that tension was indeed concentrated around Spain in the summer of 2012, see Nordvig (2012).
} 
premium to plain vanilla government bonds (assuming that they had the same governing laws), as explained in Choi and Gulati (2012). The basic argument is that owners of government guaranteed bonds have the right to declare an event of default, and they have discretion as to exactly when to make such a declaration. This provides an option value for the creditor, as it may be advantageous to wait with the declaration if a sovereign restructuring is under way (to obtain restructured bonds at a later stage, rather than receiving a government obligation that is about to be haircut).

This effect should make the calculated spread even more likely to spike in periods of tension (both due to a combination of the governing law premium and due to this option value embedded in the foreign law government guaranteed bonds).

This lack of observed governing law spread could be due to inefficiencies in market pricing, or due to insufficient controls for third variables. For example, there could be a liquidity premium on the foreign law bonds, if they are issued in smaller sizes. Nevertheless, it is surprising that even in changes, there is no strong evidence of a pickup in the governing law spread for Spain during 2012.

\subsection{Data limits and robustness issues}

The analysis above, which includes a dataset of directly observable governing law spreads and another dataset of partially observable spreads, illustrates the basic empirical challenge associated with putting together a sufficiently large sample of bonds that allows robust identification of the effect from the governing law parameter on bond pricing. Small sample issues means that the noise to signal ratio can be poor. In addition, it is hard to control for additional variables, which may impact the spreads. This makes it harder to draw firm conclusion. Are the results driven by inefficient pricing of legal parameters or by shortcomings of the methodology to analyze the governing law effect? It is hard to know for sure.

Nevertheless, the directly observable governing law spreads from pairs of bonds with otherwise similar characteristics generally point to the presence of a legal risk premium, and one that spikes notably during the Euro-crisis for the countries in most severe stress.

In the following section, I turn to a richer sample of bonds, issued by various agencies, in order to derive more robust conclusions using a more formal methodology.

\section{MODELLING LEGAL RISK PREMIA IN A SAMPLE OF AGENCY BONDS}

In this section, I focus on a sample of Eurozone agency bonds. This data set has sufficient sample size (even within the subset of bonds issued by Eurozone issuers 
and in EUR) to run various types of regression analyses, including in a period-byperiod cross-sectional setting.

The number of foreign law agency bonds under foreign law outstanding bonds vary from 2008 to 2014, and ranges from 7 to 78 over the sample. During the Euro-crisis, however, I have 30-50 bonds under foreign law outstanding, which is enough data to extract information about the role of the governing law parameter.

I merge the sample of foreign law bonds with a richer sample of 42-264 local law agency bonds, so as to identify the role of the governing law parameter in the yield differences between the two subgroups of bonds. Since the universe of local law agency bonds is fairly large (amounting to several hundred bonds at any point in time) I have the luxury of focusing on the more liquid bonds, for which price information is more reliable.

The composition of the data set is provided in Table A.2 in the appendix.

The universe of agency bonds includes debt issued by special purpose banks, government backed utility providers, and certain social security institutions. Importantly, this is a sample of bonds without explicit government guarantees attached to them. In order to obtain a larger sample of bonds for my analysis (as opposed to focusing on sovereign bonds only), I have to move out the credit curve.

Hence, to isolate the component of yields that is directly linked to the governing law parameter, it is necessary to control for the differing credit characteristics of the individual bond in the sample, as well as other control variables.

\subsection{A regression model to identify the governing law premium}

The basic idea is to model the yield of the bonds in the sample at a given point in time as a function of standard drivers of the yield, and a dummy variable for the governing law parameter. This basic method is consistent with the regression framework applied in Eichengreen and Mody $(2000,2004)$ to investigate the role of CACs and the regression analysis done by Clare and Schmidlin (2014) to investigate the role of the governing law parameter during the Euro-crisis. ${ }^{30}$

However, I try to take the analysis a step further and pinpoint the key drivers of the governing law premium (as opposed to simply confirming its presence).

Since the legal parameter becomes important only in the face of significant risks to the creditor, either in the form of credit risk or redenomination risk, I interact the

\footnotetext{
$30 \quad$ Häseler (2009) lists additional papers that apply related methodologies to investigate the role of CACs.
} 
governing law dummy variable with a another variable that capture those specific risks. ${ }^{31}$

Hence, I work with regressions of the type:

$$
\text { Yield },=a+b_{1} \text { RiskRating }+b_{2} \text { Liquidity }+b_{3} C D S+b_{4} \text { Legal }+u
$$

The RiskRating variable is an index based on a numerical scoring of the ratings from the three major ratings agencies for the specific issuer in question. I use a relative rating concept since I already control for the sovereign component of credit risk in the specification (through the sovereign CDS term in the regression). Hence, my RiskRating variable is constructed as follows:

- I assign a numerical Ratings Score between 1 and 22 to each level of rating in the credit ratings grid for Moody's, S\&P and Fitch. A higher score indicates higher credit risk, and 1 is assigned to the AAA rated issuers), as specified in Table A.3 in the appendix.

- I average the ratings scores between the three ratings agencies. ${ }^{32}$

- I subtract the average ratings score of the relevant sovereign, to obtain a relative risk ratings concept.

I expect the coefficient on the credit rating term to be positive. In the tables in the appendix, this variable is labeled 'ratingspread'.

The liquidity variable is simply the issue size of each bond. I would expect bonds of small size to trade at higher yields, given their lower liquidity (and higher trading costs). As such, I expect the coefficient on the liquidity variable to be negative (higher liquidity, lower yield). In the tables in the appendix, this variable is labeled 'issuesize'. ${ }^{33}$

The $C D S$ variable is the country level sovereign CDS (hence, it is a variable that is country specific, but not issuer specific). This variable is meant to capture system wide (at the country level) credit concerns at a given point in time beyond that captured in the credit rating variable, which is slower moving and issuer specific. ${ }^{34}$

$31 \quad$ Clare and Schmidlin (2014) achieve a similar identification of the role of the dummy in situations of elevated credit risk by splitting the sample into sub-samples high grade and low grade issuers, while Chamon, Schumancher \& Trebesch (2014), explicitly model the governing law spreads as a function of CDS. possible with a single rating measure (which often moves infrequently).

33 I also experimented with alternative specifications, including a bid-ask spread, to capture timevarying liquidity. However, that variable seemed excessively noisy, and I opted for the more conservative liquidity proxy (issue size).

34 One could argue that a multiplicative specification (interacting the rating of the issuer with the system wide credit tension, as captured by the sovereign CDS variable) might in theory be better. There is some evidence that this may improve the fit of the model in certain specifications. But such a specification does not have a major impact on the other parameters in the model. I show an alternative specification of this type in the appendix (Table A.9). But my benchmark specification is kept as the linear one. 
The Legal term is a term that interacts the legal parameter (my governing law dummy) with either a credit risk variable at the country level (proxied by the CDS spread) or a proxy for redenomination risk at the country level (as detailed in section 6). Our governing law dummy is one for the local law bonds, and zero for foreign law bonds. Hence, I expect the coefficient on the legal interaction term to be positive. In other words, I expect the local law bonds to be more exposed to both credit risk and/or redenomination risk than their foreign law counterparts. In the tables in the appendix, the dummy variable is labeled 'govlaw'.

\section{MEASURING REDENOMINATION RISK}

One of the key goals in this paper is to identify the role of redenomination risk as a driver of legal risk premia embedded in Eurozone bonds denominated in Euros. The basic empirical challenge is that redenomination risk is not directly observable in any market prices. One way or the other, I have to rely on proxies of redenomination risk, and those proxies are likely to be correlated to the credit risk at the country level (I will discuss how this makes it harder to identify the role of redenomination risk in section 8).

In the empirical analysis, I am going to work with two specific proxies of redenomination risk. ${ }^{35}$ The first (Section 6.2) proxy for redenomination risk is based on the quantity of certain news stories in the financial press. The second (Section 6.3) is based on so-called quanto swaps, which is the based on pricing differential of CDS contracts in USD and EUR. But before I turn to the specific empirical proxies, it is instructive to think about how redenomination risk in theory could be measured

\subsection{Contingent forward contracts for Eurozone countries}

In theory, redenomination risk would be observable from contingent currency forward contract, defined as currency forward contracts written with reference to the currency of country X from time to time, rather than the Euro. Such forwards would directly to capture redenomination risk, since the forward would have to take into account the pricing of both the 'normal' contingency of no exit from the Eurozone, and the special case of exit from the Eurozone and a shift to a new currency. In fact, Nomura Securities had designed such a product, structured as non-

\footnotetext{
35 Other proxies for redenomination risk have been proposed in the literature. De Santis (2015) provides a list. One of the proxies is from spread betting agency InTrade, which is no longer in operation. I have compared my news based redenomination variable to the exit probability from InTrade (for Greece). The correlation is not strong, although there is a spike in both series around May 2012, when the Greek election produced elevated concern about an imminent Greek exit from the Eurozone. That said, the spread betting metric is based on a small amount of betting by retail investors, and it may not produce very efficient estimates of the actual probabilities involved. Hence, I am not putting too much weight on the correlation being fairly weak. The other possible measures listed by De Santis (2015) seem too far removed from actual market expectations to be relevant for my purposes, and do not have the frequency needed to be relevant for my empirical analysis.
} 
deliverable forward contract, and it was registered and approved by the UK FSA in 2012.

Specifically, the product behaved as a normal EURUSD forward contract in the scenario of no exit. But in the contingency involving exit from the Eurozone and redenomination from EUR into new currency NEW, it would switch to pay out as NEWUSD, based on the central bank fixing of NEWUSD at a specific future date.

Similarly to the bond pricing in the context of redenomination risk (as presented in section 2.3) the forward pricing would be essentially a probability-weighted average of the forward pricing in the two separate scenarios.

In the scenario of no exit from the Eurozone, the contingent non-deliverable currency forward would simply price as the EURUSD forward:

$$
C N D F_{t+1}=E U R U S D_{t} \frac{\left(1+r_{U S D}\right)}{\left(1+r_{E U R}\right)}
$$

Where $\mathrm{r}_{\text {USD }}$ and $\mathrm{r}_{\text {EUR }}$ are the one-period money market interest rate in the US and the Eurozone, respectively.

In the scenario of exit from the Eurozone and redenomination into a new currency, the currency forward should price to the following.

$$
C N D F_{t+1}=E_{t}\left(N E W U S D_{t+1}\right)
$$

Where NEWUSD is the exchange rate between the new currency and the USD, and $\mathrm{r}_{\mathrm{NEW}}$ is the one-period money market interest rate on the new currency.

Overall, the CNDF should price as a probability weighted average of the two possible scenarios, with probability $p$ attached to the exit/redenomination scenario:

$$
C N D F_{t+1}=p \times E_{t}\left(N E W U S D_{t+1}\right)+(1-p) \times E U R U S D_{t} \frac{\left(1+r_{U S D}\right)}{\left(1+r_{E U R}\right)}
$$

Assuming that the interest rate differential between USD and EUR is small (perhaps because the period length is short), then the percentage difference between the CNDF rate and EURUSD is given by:

$$
\frac{C N D F_{t+1}}{E U R U S D_{t}}-1=p \times\left[\frac{E_{t}\left(N E W U S D_{t+1}\right)}{E U R U S D_{t}}-1\right]
$$


That is, the percentage difference of the CNDF rate over the EURUSD spot rate is approximately equal to the probability of exit times the expected percentage redenomination in the event of exit.

If I had observed prices on CNDF, they would be a direct measure of redenomination risk. The product of the probability of redenomination and the expected currency move in the event of redenomination is what matters. The split between the two effects is less important for asset pricing. ${ }^{36}$

This product was offered to institutional market participants during 2012 when there were elevated fears about exit(s) from the Eurozone. But there was never sufficient demand from market participants to create a liquid market in the product (i.e. it was not possible to find a market clearing price in the product).

As such, I have to find ways to measure the redenomination risk indirectly.

\subsection{A news based proxy of redenomination}

Given that there was a huge public focus on the issue of Euro breakup and on certain countries potentially leaving the Eurozone, I can use the quantity of news stories in the financial press as a proxy for the amount of (perceived) redenomination risk at a given point in time.

For example, I can count the number of new stories per month, which talks about "Exit" and "break up" together with "Euro" and that news count clearly provides some measure of the amount of focus on the issue. Specifically, I use the NT function on Bloomberg to provide the counting of such stories over time, and I think this is a good starting point as it is the financial news that is most relevant in this context (and that type of news is well represented on the Bloomberg News Service).

Specifically, I search for new stories, which mention country X, in conjunction with the terms "Euro breakup" or "Euro exit". I also attempted to search for specific terms, such as 'Grexit', or "Spexit", but those terms tended to be overlapping with the simpler word searches, and hence did not add anything notable to the simpler measure.

The goal is to construct a variable that can be used in the cross-sectional regression of bond yields. Hence, I need a variable that captures the 'relative redenomination risk'. To facilitate this, it is necessary to make two adjustments to the raw news count variable.

$36 \quad$ The probability of exit could be estimated under an assumption (estimated using a separate model) of the magnitude of currency depreciation in the event of exit. Ignoring the interest rate differential related aspect of forward pricing, the probability would be given by: $p=($ CNDF/EURUSD-1)/( NEWUSD/EURUSD 1 ), where NEWUSD is the expected exchange rate of new currency XXX relative to the USD after exit. 
First, there is a need to normalize the news-count to take into account that large countries tend to receive more news coverage. Hence, I normalize the recorded counts for country $i$ by the average monthly counts for that same country in 2008 (before the Euro-crisis erupted and exit and break up of the Eurozone were discussed in the press). Hence, my variable can be viewed as a multiple of what was a 'normal amount of news' with the specific key words before the Euro-crisis erupted.

$$
\text { RedenominationRis }_{i, t}=\frac{\text { Newscount }_{i, t}}{\text { Newscount }_{i, \text { pre-Euro-crisis }}}
$$

Chart 2 below shows the 'redenomination risk' variable.

\section{Chart 2: Normalized News Count Redenomination Risk Proxy}

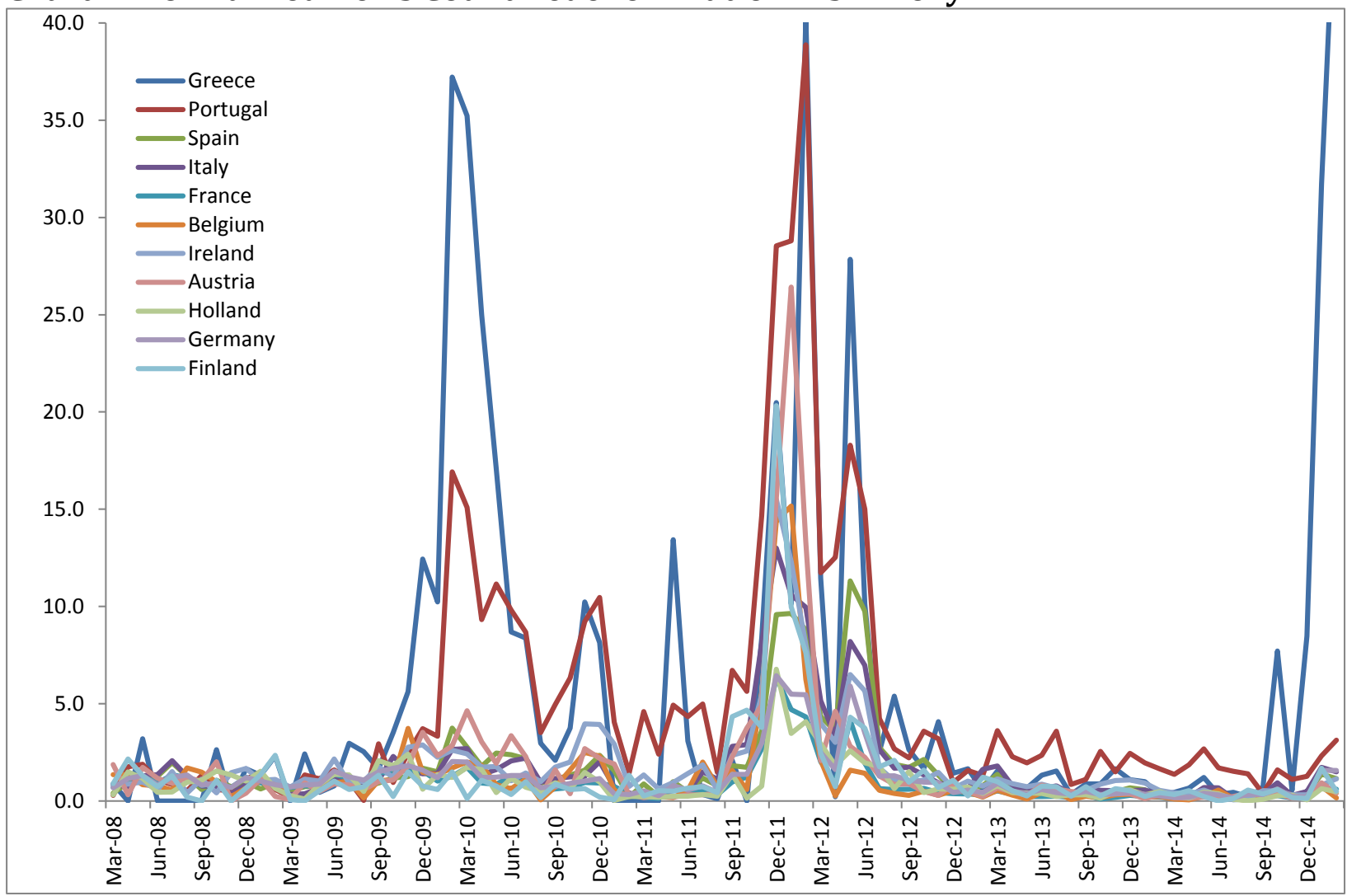

Source: Bloomberg and authors calculations.

Note: Chart shows the normalized news count for 11 Eurozone countries. Early in the crisis (early 2010) the news count for Greece spikes dramatically to 35 times normal. Portugal is the only other country with a significant spike in the news count early in the sample. In late 2011, the news-count spikes notably for a number of countries, including Greece, Portugal, Finland, Italy and Spain. In mid-2012 the news spikes are most significant for Greece, Portugal and Spain, followed by Italy.

Second, there is a need to adjust the news-count variable for Germany. Since Germany is often mentioned in connection with other countries (because of Germany's role in directing policy during the Euro-crisis), it will have an inflated 
news count. But more importantly, since Germany, in the event of exit, would have been expected to see its currency appreciate, I need to view the news count variable differently. In my standard specification, I simply set the count to zero for Germany, to essentially remove the interaction term for the German bonds. But alternative specifications are also possible. ${ }^{37}$

A couple of observations are worth making from the chart:

- The redenomination risk clearly spikes in 2010 for Greece and Portugal, and for Spain and Italy in 2011. In addition, there is a further spike for Greece, Spain (and Portugal) in 2012. All these moves are very consistent with the general narrative of the financial press. Hence, a visual inspection seem to confirm that the methodology based on counting news stories does capture the risk factor I am looking for. - The relative ranking of the countries (which is crucial in my cross-sectional regressions), seem to correspond to what you would expect. The metric shows consistently high risk for Greece, and very low risk for the Netherlands, and so fourth, broadly consistent with my priors.

Since I am measuring a risk factor, which in inherently unobservable, it is by definition hard to have full confidence that the variable is capturing exactly what I am looking for. The financial press may be slow at catching on to a theme for example. The key analytical issue is that news coverage may spike in line with sovereign tension, so that the news variable is highly correlated to solvency risk, as proxied by sovereign CDS pricing (as I will discuss in section 8).

\subsection{Quanto-CDS as proxy of redenomination risk}

As an alternative to the news based proxy of redenomination risk, I can use so-called quanto CDS pricing. ${ }^{38}$ The basis idea of using quanto CDS is inspired by De Santis (2015). But I apply the concept differently. ${ }^{39}$

\footnotetext{
37 In theory, one could argue that local law German instruments should have traded at a premium to foreign law government instruments (the opposite of other Eurozone countries). However, such a 'negative yield premium' on German local law instruments has not been easy to observe, and the reason may be that investors may have feared that Germany would have chosen not to redenominate its EUR liabilities into stronger DEM liabilities in an exit Scenarios. Based on these considerations, I think zeroing out the news count for Germany is preferable to trying to use an inverted (i.e. with a negative sign) version of the variable. 38 For those unfamiliar with the quanto CDS market, the financial times provided a primer back in 2010. The link is here: http://www.ft.com/intl/cms/s/2/725d679e-545e-11df-b75d00144feab49a.html\#axzz3YzqDEC66

$39 \quad$ De Santis (2015) uses the quanto CDS proxy of redenomination risk to argue that redenomination risk played a significant role in the pricing of CDS, and implicitly in bonds. He applies a relative concept of quanto CDS (ie. quanto CDS Italy minus quanto CDS Germany) to proxy redenomination risk. Given that the quanto CDS from Germany should be interpreted with caution in relation to country specific redenomination risk, I would argue that the method in De Santis (2015) creates an unnecessarily biased estimate. In my opinion, the absolute quanto CDS level is a preferable proxy compared to the concept relative to Germany. In any case, his paper does not touch on the governing law dimension of bond pricing.
} 
Quanto CDS is defined as the difference between USD and EUR denominated CDS pricing. Quanto CDS exists (i.e. there is demand for the product) because investors who are looking to protect themselves against a credit event in a given Eurozone country may also look to protect themselves against EUR depreciation in that scenario. Hence, sovereign CDS is often traded in USD. But contracts also exist in EUR terms. In essence, the quanto CDS will capture the expected correlation between a credit event and EURUSD.

Time series of Quanto CDS are plotted in Chart 3 below. It shows the significant pickup in quanto CDS spreads during the crisis, with Portugal showing the largest increases early in the crisis, while Spain takes over as showing the widest quanto CDS spreads in the middle of 2012.

\section{Chart 3: Quanto CDS time series}

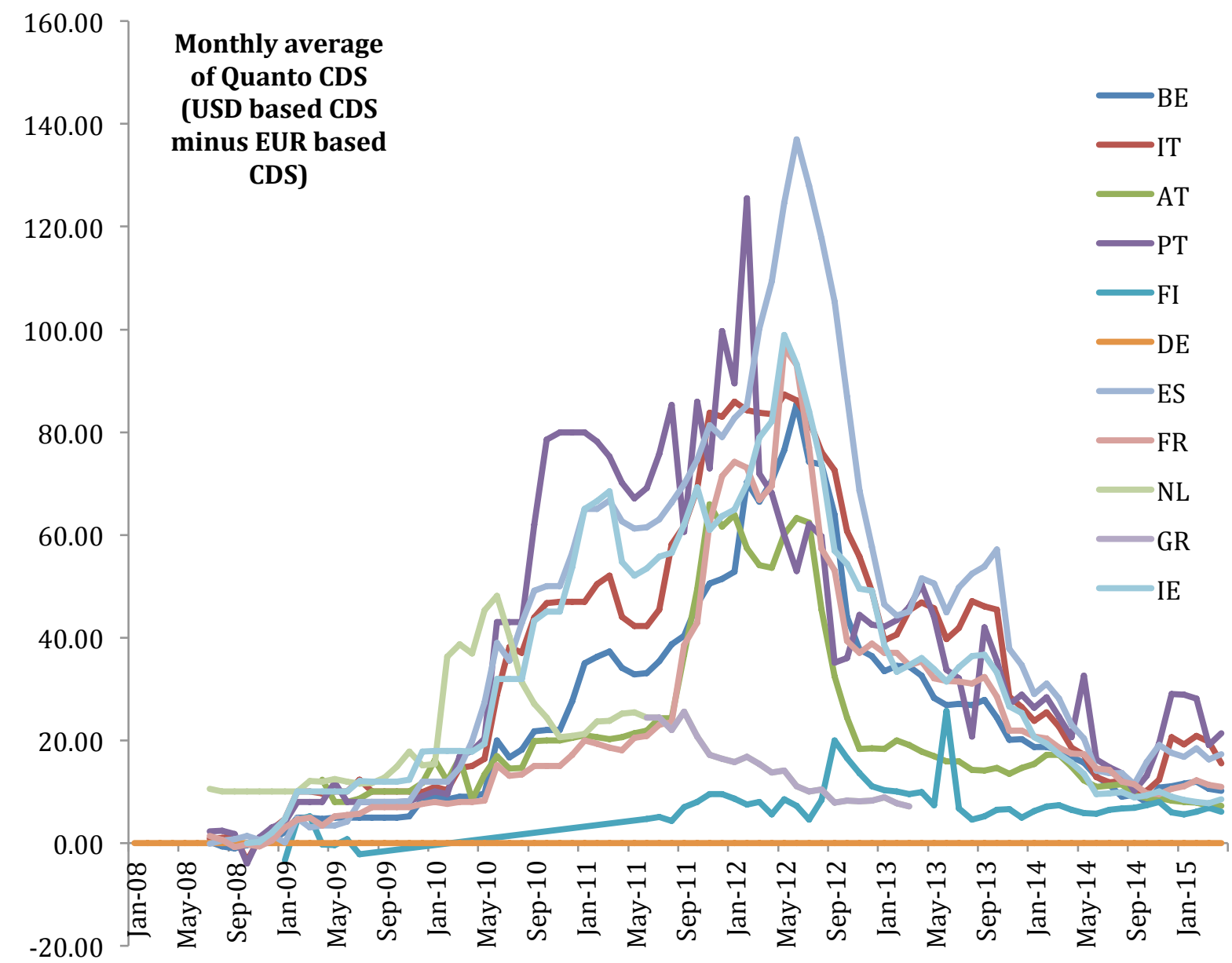

Source: Thomson Reuters

Note: Quanto CDS plotted in basis points. Data for Germany is set to zero. Data is not available for Greece (since no CDS pricing in EUR is generally available). 
However, the Quanto CDS will not directly capture the potential depreciation of a successor currency versus the Euro. As such, it will only proxy redenomination risk well, if there is a strong correlation between the expected move in the successor currency and EURUSD in a credit event.

There are instances where this would indeed be expected to be the case. For example, the quanto CDS for Spain may signal that EURUSD is expected to depreciate in a Spanish credit event, and it would seem logical that this would be the case given Spain's size. Moreover, since Spain's new currency would presumably devalue versus the Euro (see Nordvig (2013), Chapter 13), there is reason to believe that the quanto CDS is a reasonable proxy for redenomination risk in Spain's case.

On the other hand, a credit event in a small country, such as Cyprus, may not impact the Euro much, even if it is expected to generate a large depreciation of the new currency of Cyprus. ${ }^{40}$ We do not have quanto CDS for Cyprus in our sample (due to lack of data). But a similar argument could be made for Greece or Portugal, especially in the latter stages of the crisis, when various backstop facilities had been put in place to limit contagion.

Another example in which the quanto CDS may be a poor proxy for country specific redenomination risk is Germany. Many analysts would expect that German exit from the Euro would lead to Euro depreciation against the USD, but appreciation of the new German currency versus the Euro. ${ }^{41}$ Hence, the fact that the quanto CDS for Germany signals expected Euro depreciation in the event of a German credit event, may be a very poor proxy of the redenomination risk inherent in German assets. ${ }^{42}$

From this perspective, the Quanto CDS is clearly an imperfect proxy of country specific redenomination risk. But it may be a respectable proxy, especially for the larger countries, for which currencies would be expected to depreciate in the event of exit (i.e. Spain, Italy, France). In terms of a markets based observed variable, it is probably the best available.

To deal with the special issues around Germany, I use a version of the quanto CDS in the empirical work, where I make an adjustment for Germany. Specifically, I tailor the quanto CDS vector to better capture redenomination risk at the country level, rather than the correlation to EURUSD (which is the underlying concept at work in the instrument) by manually setting the quanto CDS to zero for Germany. ${ }^{43}$

\footnotetext{
40 The fact that severe tension in Cyprus in early 2013, including the historical imposition of capital controls in and EU country, did not have any notable spillover effects to the rest of the Eurozone or to the Euro supports this basic conclusion.

41 See Nordvig(2013, Chapter 13) for projection of potential currency moves in an exit scenario for 11 Eurozone countries.

42 Since it is not easy to imagine a scenario of German default/debt restructuring, perhaps it is better to view German CDS pricing as broadly following global CDS pricing trends.

43 This is comparable to the adjustment I have to make in the news-based proxy of redenomination for Germany.
} 


\section{REGRESSION RESULTS FOR THE AGENCY BOND SAMPLE}

I now turn to the regression results. I start with the results from the benchmark version of the model that focus on the credit risk (as proxied by CDS) as the driver of the governing law premium. I then move on to the results from the versions of the model that focus on redenomination risk as the driver of the governing law premium (using the two proxies of redenomination risk defined in section 6).

Since the price information (i.e. the yields) can be noisy during periods of stress, I use monthly averages of the yields. Such averaging across months achieves a degree of smoothing, which can be helpful in the event of temporary inaccuracies in the pricing data (as observed in Chart 1 and Chart A.1). In addition, since the explanatory variables are mostly slow moving, this approach seems to fit the specification best.

To enhance the robustness of the results, I estimate both fairly restrictive panel versions of the model and more flexible single period cross-sectional versions of the model. In terms of the estimation procedure, I apply both OLS and GLS ${ }^{44}$. Moreover, I also experiment with various adjustment of the estimation of standard errors, again to enhance robustness.

As highlighted by Häseler (2009), previous studies that have used a regression of the type I am applying, including Eichengreen and Moody (2004), use an instrumental variable approach to minimize effects from endogeneity in the choice of governing law. However, this effect is mainly an issue when you investigate spread around the time of issuance (based on primary market data). I use secondary market data, and the yields are materially different during the Euro-crisis than at issue (except for the few bonds issued during the crisis itself). Hence, there is less need to account for this potential endogeneity of the choice of governing law in my sample, and for this reason I do not apply an IV estimator.

In what follows, I focus on estimation in levels. I have experimented with estimation in changes too. But the explanatory power of the regression drops notably in changes form, likely because some of my control variables are constant (such as my liquidity proxy) and given that others are fairly slow moving (such as the ratings variable). Hence, I will not focus on the changes specification in what follows.

To give an initial impression of the dataset, key descriptive statistics are tabulated in Table A.4 in the appendix.

$44 \quad$ The basic rationale behind using the GLS estimator is that the sequence of cross-sectional regressions can be viewed as a system of seemingly unrelated regressions (SUR). Hence, it can be argued that more efficient estimates can be obtained using GLS. In our estimations, we also compute t-statistics using robust standard errors, as estimated using White's method. For further details on estimating standard errors in panel regressions, see Petersen (2005). 


\subsection{The governing law premium and credit risk for agency bonds}

In this section, I focus on a specification where the legal term is the governing law dummy interacted with the country specific CDS variable, to capture (primarily) credit risk.

As I will discuss in more detail in section 8, I note that while CDS stands for Credit Default Swap, it is worth recognizing that 'credit' in this context involves various types of losses that can happen as a function of various triggers of the CDS.

Typically, investors and commentators in financial markets focus on the risk of a 'haircut' on the principal of the underlying instruments, as a function of a default or debt restructuring. But risk of losses can also derive from currency redenomination, which reduces real value of payment on the bond for a foreign investor. I will discuss this issue in more detail below, but I use the term 'credit risk' to refer to the risk that is related to haircuts on principal or coupon payments, while I use the terms 'redenomination risk' to refer to reduction in the value of such payments through currency depreciation. At best, the CDS variable can be viewed as a proxy for the credit risk that is linked to haircuts on coupon and principal payments.

The version of the regression equation, which focus on credit risk, looks as follows:

$$
\begin{aligned}
\text { Yield },=a+ & b_{1} \text { RiskRating }+b_{2} \text { Liquidity }+b_{3} \text { CDS } \\
& +b_{4} \text { GovLawDummy } \times C D S+b_{5} \text { GovLawDummy }+u
\end{aligned}
$$

I initially run the regression in panel form. Table A.5 and Table A.6 in the appendix shows the results for the period 2009-2013 (my benchmark sample) and Table A.7 and Table A.8 show the results for the Euro-crisis period (2010-2012).

The various panels show that all the variables are highlight significant (at the $5 \%$ or better) and have the expected signs. ${ }^{45}$ The coefficient I am most interested in, the one associated with the legal term interacting the governing law dummy with the CDS variable, is positive and highly significant. Moreover, I note that the magnitude of the coefficient increases (also as expected) as I zoom in on the Euro-crisis years.

During those years, the coefficient is 0.0059 when estimated with panel OLS and 0.0069 when estimated with panel GLS (reported in Table A.6). This implies that for a $100 \mathrm{bp}$ increase in the country specific CDS variable the yields on local law agency bonds will increase by 59-69bp. Given that CDS variables spiked several hundred basis points in key countries during the crisis, the effect has potential to add several percentage points to the yields of local law bonds.

Given that legal risk premia may change over time (including due to variation in parameters), it is interesting to also allow the coefficients to vary more freely over

$45 \quad$ This conclusion holds both in the simple OLS specification and in specifications with robust standard errors, using the White correction (not shown in appendix). 
time. Hence, I run single period (i.e. monthly) cross-sectional regression of the yields on the explanatory variables for each month from January 2009 to December 2014. The regression output is a time series of the regression coefficients (or $\mathrm{t}$ statistics). I focus initially on the results using simply OLS. But I also cross check the results using GLS estimation, which may be more efficient.

Based on the OLS regression, the explanatory variables generally (i.e. in the large majority of estimation periods) have the expected sign, and the explanatory power of the regression rises notably during the most intense period of the Euro-crisis (late 2011 and early 2012). The CDS variable is generally always significant at the $5 \%$ level, while the liquidity variable has the right sign but not always significant.

The variable I am most interested in, the interaction term between the local law dummy variable and country specific sovereign CDS spreads, is not always significant. But during the key phases of the crisis, the variable becomes highly statistically significant. That is, in periods of elevated tension, it matters if a bond has local or foreign government law, if there is significant credit risk (as proxied by the CDS variable).

\section{Chart 4: t-statistic of interaction term (governing law interacted with CDS): OLS estimation}

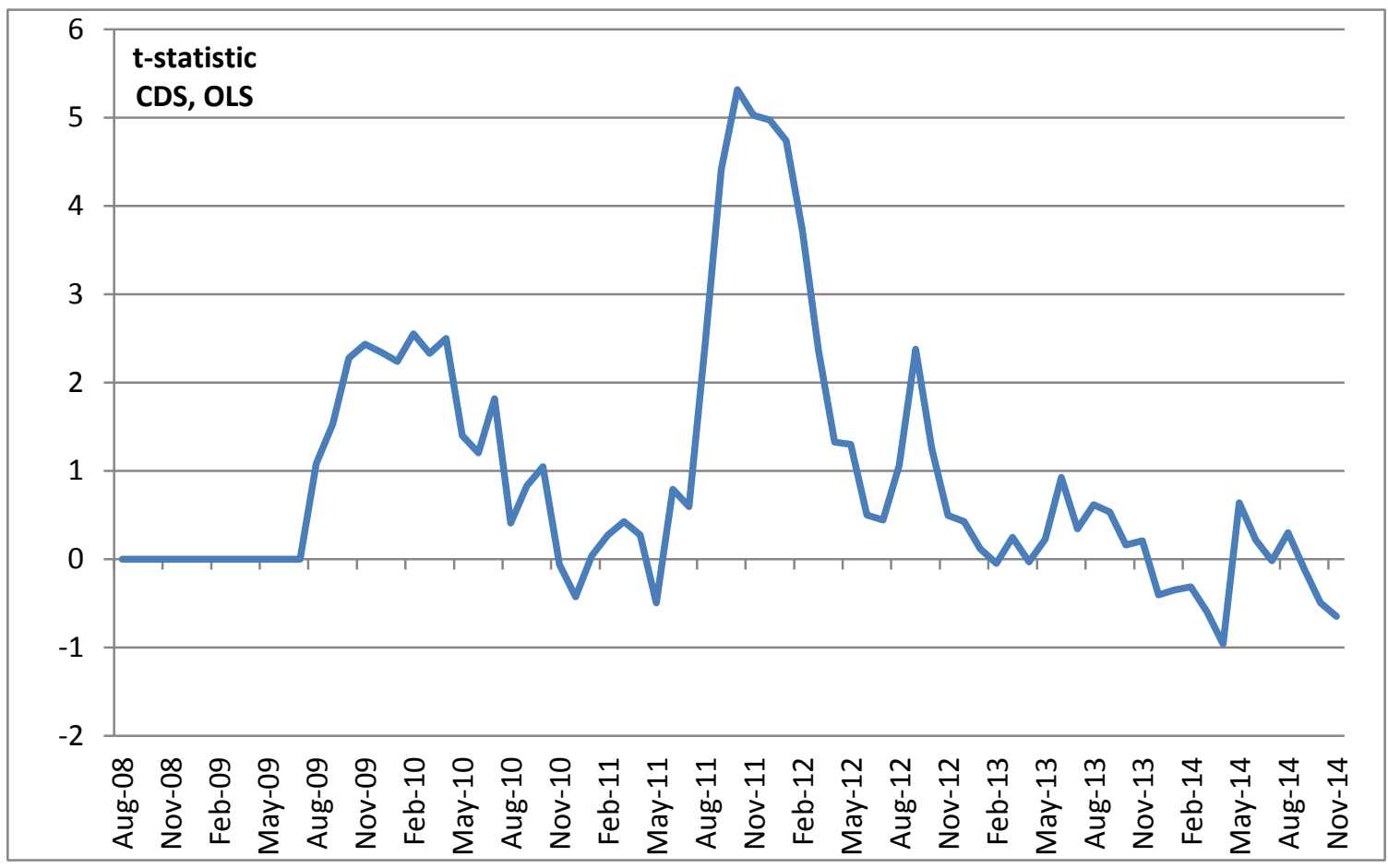

Note: t-statistic spikes to above 2 early in the Euro-crisis (late 2009 and early 2010). It moves towards zero in early 2011 (when markets were calmer, and the ECB hiked rates), and it spikes even further to above 4 in late 2011, when systemic tension resurfaced. Finally we have a spike in the t-statistic around September 2012, to above 2. In other periods, especially in 2013 and 2014 , the t-statistic hovers around zero. 
Chart A.9 in the appendix shows the actual coefficients on both the CDS variable and the interaction variable. During the intense period of the Euro-crisis the interaction coefficient was generally in the region $0.010-0.015$. Hence, if CDS spreads spike by $100 \mathrm{bp}$, this would have added 1.0-1.5 percentage points to yields of local law bonds. There is a further temporary spike in the coefficient in September 2012 (to higher level). That coincides with the time at which the ECB clarified the details of its OMT program, which was meant to reduce redenomination risk. ${ }^{46}$

The GLS estimation may be more appropriate if there is a linkage between the error terms in the individual cross-sectional regressions. Both OLS and GLS are unbiased, but OLS may be inefficient in a SUR system. When I estimate the system of crosssectional equations using GLS, I generally find very similar coefficient estimates, but the standard errors are substantially reduced, and the t-statistics are substantially higher. The general conclusions are the same, however. The explanatory power of the regression increases in the crisis period, and the governing law dummy becomes highly significant during the most intense period of the crisis. T-statistics from the GLS estimation are shown in Chart A.10.

7.2 The governing law premium and redenomination risk for agency bonds

I now turn to the version of the model that tries to explain the governing law premium mainly with redenomination risk. Since redenomination risk is not directly observable, I use my proxies of the redenomination risk at the country level. ${ }^{47}$

The regression model now takes this form:

$$
\begin{aligned}
\text { Yield },=a+ & b_{1} \text { RiskRating }+b_{2} \text { Liquidity }+b_{3} \text { CDS } \\
& +b_{4} \text { GovLawDummy } \times \text { RedenominationProxy }+b_{5} \text { GovLawDummy } \\
& +u
\end{aligned}
$$

The difference from the previous section is that I interact the governing law dummy variable with my measure of county specific redenomination risk.

\subsubsection{News variable as redenomination proxy}

As previously, I start with a regression in panel form. Over both the 2009-2013 sample, and the Euro-crisis years (2010-2014) the regression shows that the interaction term (redenomination news proxy interacted with governing law

\footnotetext{
46 De Santis (2015) makes a similar observation regarding the dynamics of quanto CDS. Hence, this is a feature of several different data sets.

To be more precise, what I am interested in (in terms of asset pricing) is the expectations of market participants. In other words, I am not interested in an objective measure of redenomination risk, but rather the subjective perception of redenomination risk at a given point in time. It is this 'average perception' among market participants, combined with risk preference, which should determine asset pricing (i.e. yields on the bonds).
} 
dummy) has the wrong sign (Table A.10 and Table A.11). However, the more flexible cross-sectional regressions reveal a different picture.

In the cross-sectional specification, all the variables in the regression have the expected signs on the control variables (the CDS variable is generally always significant at the $5 \%$ level, while the liquidity variable has the right sign but not always significant, similar to above)

Chart A.11 shows the t-statistic on the interaction term as estimated by OLS. The tstatistic is positive in all periods but a few months. Importantly, during the intense period of the Euro-crisis, it becomes significant and positive. This indicates that the yield demanded on the bonds is rising with perceived redenomination risk for local law bonds, as expected. Moreover, this specification has very similar explanatory power over time, compared to the regression interacting with credit risk.

Chart A.12 shows the equivalent results the same regression estimated with GLS. The t-statistics are higher, but the dynamics and the inference is the same.

The redenomination risk variable is imperfect by construction (there is no market variable capturing the risk II am interested in). Nevertheless, it does a good job in the regression, explaining the premium on foreign law bonds during period of severe stress and focus on Euro breakup. Specifically, the coefficient on the interaction term spikes (and becomes highly statistically significant) in late 2011 and mid-2012, similar to the conclusion based on the credit risk variable.

Chart A.15 shows the actual coefficients on both the CDS variable and the interaction term (this time interacted with redenomination risk as proxied by news). During the intense period of the Euro-crisis the interaction coefficient was generally in the region $0.5-1.0$. Hence, in periods where the news count variable spikes to 2 times normal, this would have added 1-2 percentage points to yields of local law bonds during that period. ${ }^{48}$

As outlined above, I can use GLS estimation to provide an alternative set of coefficient estimates, and importantly standard errors. But again, the general conclusions are the same. The point estimates are very similar to the OLS estimates, but the standard errors are smaller. The explanatory power of the regression increases in the crisis period, and the governing law dummy becomes highly significant during the most intense period of the crisis (and even more significant than when estimated using OLS).

$48 \quad$ Similarly, to the findings in the regression setup with the dummy variable interacted with credit risk, there is a temporary spike in the coefficient in September 2012. 


\subsubsection{Quanto CDS as redenomination proxy}

Our panel regressions show that the raw Quanto CDS variable is not significant (in the interaction term) when estimated over the full sample (Table A.12). However, during the Euro-crisis, the interaction term (Quanto CDS and governing law dummy) becomes significant (Table A.13). ${ }^{49}$

As mentioned in section 6.3, the raw quanto CDS variable, is likely to lead to biased results for Germany, however. Hence, I apply a version of the quanto CDS vector, which is corrected for Germany (Quanto CDS set to zero). Interestingly, this version of the regression has somewhat higher explanatory power, and a significantly larger coefficient on the interaction term (Quanto CDS interacted with the governing law dummy). This version of the model is shown in Table A.14 in the appendix.

In the corrected panel specification, the coefficient on the interaction term is 0.019 . This implies that for a $100 \mathrm{bp}$ increase in the quanto CDS, as observed in Spain for example during the summer of 2012, the contribution to local law yields would be in the region of almost $200 \mathrm{bp}$.

Turning to the cross-sectional regressions, the interaction term, based on quanto CDS, is borderline significant early in the sample, but becomes highly significant during the second half of 2011 (Chart A.13). After that, the significance peters out again.

This result is consistent with the notion that 2011 was characterized by the most 'systemic' period in the crisis, in which breakup of the Euro was viewed as a real risk and a process that would take the value of the Euro down. Hence, the quanto CDS captures this systemic aspect of the crisis. Later on (in H2 2012) when the focus turned more to single country exits, the QCDS variable is only borderline significant.

\subsection{Overall regression result}

Overall, I find strong evidence of a governing law premium in my sample of agency bonds. For the large majority of specifications, I find evidence of a significant governing law premium. I.e. there is strong evidence that foreign law bond trade at a premium to local law bonds.

Moreover, there is also strong evidence that the premium increases during the Eurocrisis, especially in late 2011 and the summer of 2012. Specifically, there is evidence that the coefficient on the interaction term increased during the Euro-crisis, implying not only that the governing law premium increase, but that the sensitivity

$49 \quad$ This conclusion holds both in the simple OLS specification and in specifications with robust standard errors, using the White correction (not shown in appendix). 
of the governing law premium to a given amount of credit or redenomination risk increased.

I note that this result is not driven by data for Greece. In fact, there is not a single agency bond for Greece in the specific sample I focus on in this section. Hence, my agency bond data confirms that the governing law premium is present at the regional level in the Eurozone, rather being specific to Greece. In this sense, the analysis of agency bonds complements the other data sets discussed in this paper (as discussed in section 4) and in other papers (such as Chamon, Schumancher \& Trebesch [2014]), which showed a very large governing law premium for Greece, but less clear results for other countries.

The results also provide some evidence that redenomination risk may be a factor driving the governing law premium. This conclusion is supported both in crosssectional specifications with the news-based redenomination proxy and in panel and cross-sectional specifications with the quanto-CDS variable. Interpreting these statistical findings in a more causal sense is difficult given that the underlying (latent) drivers of both the CDS variable (itself a proxy for risk related to haircuts) and the redenomination proxies are overlapping. It is inherently hard to separate the two concepts, as I will discuss further below.

\section{WHICH FACTOR DOMINATES: CREDIT VS. REDENOMINATION RISK}

As previously noted, the CDS variable and the redenomination risk proxies (both the news count variable and the quanto CDS variable) are correlated. For example, the (cross-sectional) correlation between the country specific CDS variables and my news based redenomination proxy becomes high and persistent during the Eurocrisis, generally in the region 0.6-0.8. Similarly, the cross-sectional correlation between the CDS variable and the quanto CDS variable is 0.4-0.8. The time series of these correlations are shown in chart A.16 in the appendix.

The high correlations tell us little about the underlying causality between the two. But it does make it hard to separate the effects from credit risk versus redenomination risk in our modeling of the governing law premium. There are various techniques for model selection in such a setting. One common process, as advocated by Hendy (1995) for example, involves a general to specific approach in my regression analysis. Such an approach generally favors the CDS variable, and renders the other variables insignificant (or with the wrong sign). A few examples of such regressions are shown in the table in the appendix (Table A.15 and Table A.16). 50

$50 \quad$ Another way to test the importance of the CDS variables relative to the redenomination proxies in relation to driving the legal risk premium would be to conduct a McKinnon J-test for non-nested hypothesis. However, the basic idea behind this test is not too dissimilar to that implicit in the general to specific procedure, and I do not report such a test explicitly here. 
Against this background it is tempting to conclude that the redenomination risk proxies simply pick up credit risk. However, I note that there are conceptual reasons why the correlation may run the other way too, as I will explain below.

\subsection{CDS pricing and redenomination risk}

CDS is generally viewed as a proxy for credit risk. And credit risk is generally linked to insolvency, and related haircuts on coupon and principal payments. But this is not the only factor involved in CDS pricing.

Importantly, in relation to the question I ask in this paper, currency redenomination qualifies as a trigger of sovereign CDS for non-G7 countries. That is, for a country such as Spain (not a G7 member), the CDS pricing should directly reflect the risk of redenomination.

The International Swaps and Derivatives Association specifies CDS triggers as follows:

The listed events are: reduction in the rate of interest or amount of principal payable (which would include a "haircut"); deferral of payment of interest or principal (which would include an extension of maturity of an outstanding obligation); subordination of the obligation; and change in the currency of payment to a currency that is not legal tender in a G7 country or a AAA-rated OECD country. ${ }^{51}$

From this perspective, it is important to think hard about the possibility of two-way causality between the CDS variable and my redenomination proxies.

One could argue that exit and redenomination is highly unlikely in the absence of a debt restructuring default. In other words, the two concepts may be entirely coinciding in the context of CDS triggers. In the end, it depends on the country in question, and in theory at least it should be possible to redenominate without defaulting on sovereign debt. 52

Nevertheless, even if redenomination is expected to coincide with default/restructuring, redenomination risk would still impact CDS pricing indirectly. This is so because protection sellers would need compensation not only for losses due to explicit haircuts, but also due to currency depreciation in the scenario of sovereign default and redenomination. As such, CDS pricing should incorporate an element of redenomination risk even for G7 countries. ${ }^{53}$

\footnotetext{
$51 \quad$ This quote is taken from the ISDA website's Q\&A on the Greek debt restructuring.

52 Different analyst may have different views on this issue. While it is hard to image redenomination in Greece without sovereign default/restructuring, it is possible to imagine redenomination in France that does not coincide with debt default/restructuring, as argued in Nordvig (2013), chapter 13.

$53 \quad$ For G7 countries, CDS pricing should be based on the probability of a credit event (excluding redenomination) but incorporate losses from redenomination in the event of default. For non-G7 countries, CDS pricing should be based on the probability of a credit event (including redenomination) and incorporate losses from redenomination both in the scenario where redenomination happens in conjunction with haircuts
} 
The role of credit risk (defined as the risk linked to reduced/delayed coupon and principal payments) and redenomination risk in CDS pricing can be summarized as follows when differentiating between G7 and non-G7 countries:

\section{Table 2: Factors Affecting Sovereign CDS pricing}

\begin{tabular}{|l|c|c|}
\hline & G7 & non-G7 \\
\hline Credit event* & YES & YES \\
\hline Credit event* and currency redenomination & YES & YES \\
\hline Currency redenomination & NO & YES \\
\hline
\end{tabular}

* Credit event defined as event involving haircuts/delay in coupon or principal payment

\subsection{Testing the direction of causality to and from the CDS variable}

To obtain an objective (even if not definitive) metric of the direction of the causality between the CDS variable (meant to proxy credit risk) and my proxies for redenomination risk, I run a series of granger-causality tests. The detailed results are shown in Tables A.17 to A.26 in the table appendix.

The most interesting set of tests are those concerning the news-based redenomination risk proxy. I find that for the countries in which exit from the Eurozone has been actively debated (as evidenced by high news counts on the redenomination proxy), I can reject the null hypothesis of no granger causality running from the redenomination proxy to the CDS variable. This is the case for Portugal, Spain and Italy (all at 5\% significance level or better), and partially the case for Greece (at $10.6 \%$ p-value). In other words, there is evidence that perceptions of heightened redenomination risk may be feeding into CDS pricing, as they theoretically should (given that redenomination is a trigger event for CDS, and potential cause of additional losses for CDS sellers), for the countries at the epicenter of the exit debate. These results are summarized in Table 3 below.

For the G7 countries, where redenomination is not a trigger of CDS, the results are more mixed. I cannot reject the null of no granger causality for France. But for Italy the hypothesis is rejected. This finding provides evidence that even for a G7 country (where the devaluation risk is perceived significant) the redenomination risk may still impact CDS pricing. ${ }^{54}$

(debt restructuring/default) and in the scenario in which redenomination happens independently of any haircuts on debt payments.

$54 \quad$ This makes conceptual sense in that even if redenomination is not a direct trigger of CDS (does not qualify as trigger event according to ISDA for G7 countries), it will nevertheless impact the pricing of the CDS contract, as in the event of default and redenomination, the CDS protection seller will be facing losses linked to both factors. Hence, these potential losses should be embedded in the CDS pricing, even if redenomination is not in itself a direct trigger of CDS. 
Table 3: Summary of Country-specific Granger Causality Tests (p-values)

\begin{tabular}{lccc} 
& \multicolumn{2}{c}{ Testing the hypothesis of no granger-causality } & Normalized \\
From Redenom to CDS & From CDS to Redenom & News Count \\
Greece & $10.6 \%$ & $8.0 \%$ & 9.3 \\
Portugal & $2.6 \% * *$ & $5 \% * *$ & 9.3 \\
Austria & $54.8 \%$ & $9.99 \% *$ & 3.2 \\
Ireland & $15.4 \%$ & $18.1 \%$ & 3.0 \\
Spain & $0.2 \% * *$ & $26.8 \%$ & 2.9 \\
Italy & $1.32 \% * *$ & $10.3 \%$ & 2.9 \\
Finland & $23.9 \%$ & $12.9 \%$ & 2.3 \\
Belgium & $53.0 \%$ & $0.48 \% * *$ & 2.0 \\
France & $52.6 \%$ & $2.27 \% * *$ & 1.3 \\
Netherlands & $63.0 \%$ & $60.1 \%$ & 1.3
\end{tabular}

Note: Table shows p-values from granger causality tests done on monthly observations of a country-specific VAR with 12 lags of both the CDS variable and the news-based redenomination proxy. Cases where the hypothesis can be rejected at $5 \%$ level are marked with ${ }^{* *}$. Cases where the hypothesis can be rejected at the $10 \%$ level are marked with *. The Normalized news counts (average for 2010-2012) are displayed for reference.

For the countries that have observed little debate about exit and/or in which exit would not necessarily trigger substantial currency depreciation, the results show that I cannot reject the null of no granger causality running from the redenomination proxy to CDS. This holds for Austria, Finland, Holland, as well as Belgium and Ireland.

This highlights, that the high correlations observed between the CDS variable and the redenomination risk proxy may at least partly be a function of redenomination risk having an impact on the CDS variable, as opposed to causality running the other way.

I ran similar granger causality tests for the CDS variable and the Quanto CDS variable (selected results shown in Table A.27 to Table A.30 in the appendix). But for the quanto CDS variable it is harder to reject the hypothesis of no granger causality funning from quanto CDS to CDS. For example, I cannot reject this hypothesis (at 5\% or 10\% level) for Italy, Spain and France, while I can reject it for Portugal. ${ }^{55}$ I note that these findings may be driven in part by the quanto CDS variable capturing mainly 'systemic redenomination risk' rather than country specific exit fears. Hence, the full sample granger-causality test may provide weak evidence against the null of no granger causality because there was little systemic breakup risk later in the sample.

\footnotetext{
55 Quanto CDS data is not available for Greece, except for very short periods of time, which means that granger-causality tests are not feasible.
} 


\subsection{The governing law premium for G7 Eurozone countries}

Finally, I can divide my sample of agency bonds into G7 and non-G7 countries. The purpose of this is to investigate if there is more differentiation between the effects from the CDS variable and the redenomination risk proxies in the countries for which CDS cannot be triggered by redenomination (and therefore presumably less causation running from redenomination risk to the CDS variable). ${ }^{56}$

Tables A.31 to A.34 shows such panel regressions..$^{57}$ Interestingly, these regressions now have the redenomination risk proxy (based on news count) seemingly dominating the CDS variable. Specifically, in Table A.32, which runs the estimation for the more interesting Euro-crisis years (2010), I see that the interaction term between the governing law dummy and the news-based redenomination proxy is the driving force in the governing law premium, as opposed to the interaction with the CDS variable, when tested down using a general to specific approach. ${ }^{58}$

In other words, in the specification, which has the best chance of separating credit risk and redenomination risk (the one focusing on G7 Eurozone countries), the news-based redenomination risk proxy can be shown to be superior to the CDS variable. In the specification with Quanto CDS as proxy for redenomination risk, the CDS variable still seems to dominate, however.

\section{CONCLUSION}

There are two main takeaways from the analysis in this paper.

First, the analysis confirms the importance of legal parameters for asset pricing, including the variability of such effects over time.

- In calmer periods, legal parameters (the governing law parameter in this study) do not seem to have any clear impact on bond pricing. This is consistent with previous findings in the legal literature, as discussed in Choi and Gulati (2014), which tend to conclude that legal parameters are ex ante under-appreciated by investors.

- In periods of stress, however, legal parameters embedded in financial contracts, can be important for asset pricing. In the context of the Eurocrisis, my findings are consistent with Choi, Gulati and Posner (2011), Clare and Schmidlin (2014), and Chamon, Schumancher \& Trebesch (2014). These

\footnotetext{
56 We note, as outlined in Table A.2 that the G7 sample, since we exclude Germany, is dominated by Italy.

I note that these regressions are dominated by Italy, since Italy accounts for a far larger amount of bonds than France, and given that Germany is excluded from this exercise given Germany's special status in the context of redenomination risk (i.e. either not present, or potentially with the opposite sign of other countries).

$58 \quad$ This conclusion holds both in the simple OLS specification and in specifications with robust standard errors, using the White correction (not shown in appendix).
} 
papers also analyze the role of the governing law parameter in asset pricing during the Euro-crisis, and find a significant premium attached to foreign law bonds during periods of severe stress (although with different samples of bonds).

Relative to previous studies, I would argue that my results add a level of robustness and are easier to interpret. This is so, because my results are derived from a larger sample of bonds, including corporate bonds, government guaranteed bonds, and agency bonds (as opposed to sovereign bonds only). In addition, my sample is focused on bonds in Euro issued by Eurozone residents, for which I have to worry less about whether identification comes spuriously from currency specific effects, as opposed to the governing law parameter itself.

Second, this paper highlights that in the context of the Euro-crisis the legal risk premium can a function of both credit risk and redenomination risk. Previous studies have (explicitly or implicitly) assumed that the legal risk premium is linked only to credit risk (defined in a way that ignores redenomination risk). As such, my paper is the first to investigate the effect from redenomination risk empirically (at least in the context of the governing law parameter). ${ }^{59}$ I have previously shown, based on legal analysis, that the governing law parameter should be a key factor determining redenomination risk embedded in specific assets and liabilities, Nordvig (2014). This paper takes this line of reasoning a step further, by providing empirical evidence from bond market dynamics during the Euro-crisis that legal parameters did indeed interact with redenomination risk to impact bond pricing.

I acknowledge that my findings on the importance of redenomination risk are not fully conclusive. The basic challenge for empirical work on redenomination risk has two components. First, there is no direct way to observe redenomination risk (since there are no traded prices for contingent forward contacts, which in theory would offer a direct measure). Second, it is hard to separate credit risk from redenomination risk with the proxies available for empirical work. Even the CDS variable, which is generally viewed as a credit risk variable, itself contains an element of redenomination risk, especially in non-G7 countries.

Overall, I find tentative evidence that redenomination risk was an driving force of asset prices during the Euro-crisis, over and above the influence from credit risk (as emphasized in previous studies of the governing law premium). I note that this is also the conclusion from the recent study by De Santis (2015), using an entirely different methodology.

The results are potentially important for both investors and policy makers.

\footnotetext{
59 De Santis (2015), in work done in parallel with this paper, discuss redenomination risk, and its impact on sovereign bond pricing generally (although not differentiating between local and foreign law bonds).
} 
For investors, the Euro-crisis has illustrated that legal parameters within bond documentation can matter crucially for asset pricing (and therefore for returns). This was the case during the Greek debt restructuring, and my analysis shows that legal parameters mattered at the regional level too. Going forward, if the Eurozone were to see departures from the common currency (being it Greek exit or another country exiting) it will again be worthwhile for investors to focus the legal dimension of their portfolios. In this context, appropriate focus should be given to the governing law parameter, which matters both for credit risk and redenomination risk.

For policy makers in the Eurozone, the presence of redenomination risk (from time to time) is an important issue given that monetary policy is still focused on reducing fragmentation of financial markets (and avoiding contagion effects from tension in Greece). Tools that quantify the presence of redenomination risk embedded in asset prices could be valuable for policy makers looking to respond to market tension, especially systemic tension linked to breakup fears. Such tools to track redenomination risk could take the form of a governing law spread index, using a suitable sample of bond pairs (local and foreign law bond pairs). Alternatively, policy makers could track the movements over time in the coefficients in a crosssectional regression setup, such as that utilized in section 6 (including a foreign law dummy variable). Such tools would allow policy makers to monitor the dynamics of legal risk premia in real-time, and design needed policy responses in a timely manner.

Turning to avenues for future research, I propose two:

1) While my results are based on a broader sample of bonds than previously analyzed (and more tailored to address the role of redenomination risk), there is room for further expansion of the data. Specifically, there is a large sample of corporate bonds, which has not been analyzed formally up to this point (although I did analyze pairs of similar bonds in Section 4). Formal analysis will require substantial filtering of price information (or combination of pricing information from multiple sources), to reduce noisy price signals distorting the analysis and the conclusions. In addition, more manual processes for inputting governing law information may be necessary. But there are tens of thousands of bonds available with potentially valuable information. Hence, this is something to explore further.

2) There may be potential to derive information about redenomination risk from looking at the basis between CDS spreads and cash bond yields. My preliminary analysis suggests that the basis may differ between G7 and non-G7 countries. Specifically, the basis is smaller for France and Italy than for non-G7 Eurozone countries. The difference could be due to the fact that redenomination is dealt with differently for G7 and non-G7 countries (in the context of CDS triggers). This is indirect evidence that redenomination risk matters for the pricing of CDS and cash bond pricing. This is an issue to explore in more detail in future research. 


\section{REFERENCES}

Bolton, Patrick and Olivier Jeanne. 2007. Structuring and restructuring sovereign debt: The role of a bankruptcy regime, Journal of Political Economy, 115(6), 901-924.

Chamon, Schumancher \& Trebesch (2014), Unpublished Manuscript, "Foreign Law Bonds: Can They Reduce Sovereign Borrowing Cost", October 2014

Choi, Stephen, Mitu Gulati and Eric Posner, "Pricing Terms in Sovereign Debt Contracts: A Greek Case Study with Implications for the European Crisis Resolution Mechanism”, JOHN M. OLIN LAW \& ECONOMICS WORKING PAPER NO. 541 (2D SERIES), The University of Chicago, February 2011.

Choi, Stephen J. and Mitu Gulati, , "From Pigs to Hogs”, Manuscript, Sep 2014

http://scholarship.law.duke.edu/cgi/viewcontent.cgi?article=5986\&context=faculty_scholarship

Clare, Andrew \& Nicolas Schmidlin, "The Impact of Foreign Governing Law on European Government Bond Yields", March 2014.

Coffrey, Niall, Warren B. Hrung, and Asani Sarkar, Capital Constraints, Counterparty Risk, and Deviations from Covered Interest Rate Parity, Federal Reserve Bank of New York Staff Report No 393, Sep 2009.

De Santis, Roberto,

Eichengreen, B. and Mody, A. (2004). Do collective action clauses raise borrowing costs? The Economic Journal. 114 (April). p.247-264.

Häseler, Sönke, COLLECTIVE ACTION CLAUSES IN INTERNATIONAL SOVEREIGN BOND CONTRACTS - WHENCE THE OPPOSITION?, Journal of Economic Surveys (2009) Vol. 23, No. 5, pp. 882-923

Hendry, David F., Dynamic Econometrics, Oxford University Press, 1995

IMF, "A Survey of Experiences with Emerging Market Sovereign Debt Restructurings", IMF Monetary and Capital Markets Department, June 2012

Nordvig, Jens, Charles St-Arnaud, and Nick Firoozye, "Currency risk in a Eurozone break-up - Legal Aspects", November 2011. Fixed Income Strategy Special Topic, Nomura Securities.

Nordvig, Jens, "Currency risk in a Eurozone break-up: Valuing potential new national currencies", December 2011. Nomura Securities Fixed Income Strategy.

Nordvig, Jens, "Currency Risk in the Eurozone: Accounting for break-up and redenomination risk", January 2012(a). Nomura FX Strategy, Nomura Securities.

Nordvig, Jens, Ylva Cederholm, and Yujiro Goto, "Eurozone March capital flows”, May 2012(a). Nomura FX Strategy, Nomura Securities.

Nordvig, Jens, and Nick Firoozye, "Rethinking the European monetary union", Finalist paper for the Wolfson Economics Prize, June 2012(b).

Nordvig, Jens, The Fall of the Euro: Reinventing the Eurozone and the Future of Global Investing, McGraw Hill, October 2013.

Nordvig, Jens, "Cost and Benefits of Eurozone Breakup: The role of contract redenomination and balance sheet effects in policy analysis", unpublished manuscript, September 2014.

Petersen, Mitchell A., "Estimating standard errors in finance panel data sets: comparing approaches", NBER Working Paper \#11280, April 2005. http://www.nber.org/papers/w11280.pdf

Proctor, Charles, "The Euro- fragmentation and the financial markets", October 2010. Capital Markets Law Journal.

Proctor, Charles, “The Greek Crisis and the Euro - A Tipping Point?”, June 2011. Client Advisory, Edwards Angell Palmer \& Dodge.

Ratha, Dilip, "Emerging market sovereign bonds: Does it cost more to issue a bond under the English law?", World Bank People Move Blog, May 2014 
Roubini, Nouriel. 2000. Bail-in, burden-sharing, private sector involvement (PSI) in crisis resolution and constructive engagement of the private sector. a primer: Evolving definitions, doctrine, practice and case law, Mimeo, New York University.

Scott, Hal S., "When the Euro Falls Apart", 1998. Working paper, Program on International Financial Systems, Harvard Law School.

Scott, Hal S., "When the Euro Falls Apart - A Sequel", January 2011. Working paper, Program on International Financial Systems, Harvard Law School.

Vrugt, Evert B. "Estimating Implied Default Probabilities and Recovery Values: The Case of Greece during the 2010 European Debt Crisis, Journal of Fixed Income, Fall 2011, p. 5 - 14 [lead article]

Zettelmeyer, Jeromin, Christoph Trebesch, and Mitu Gulati. "The Greek Debt Restructuring: An Autopsy”, Peterson Institute of International Economics, Working Paper Series, WP 13-8, August 2013 


\section{Table and Chart Appendix}

\section{Chart A.1: Enel Spa Governing Law Spread}

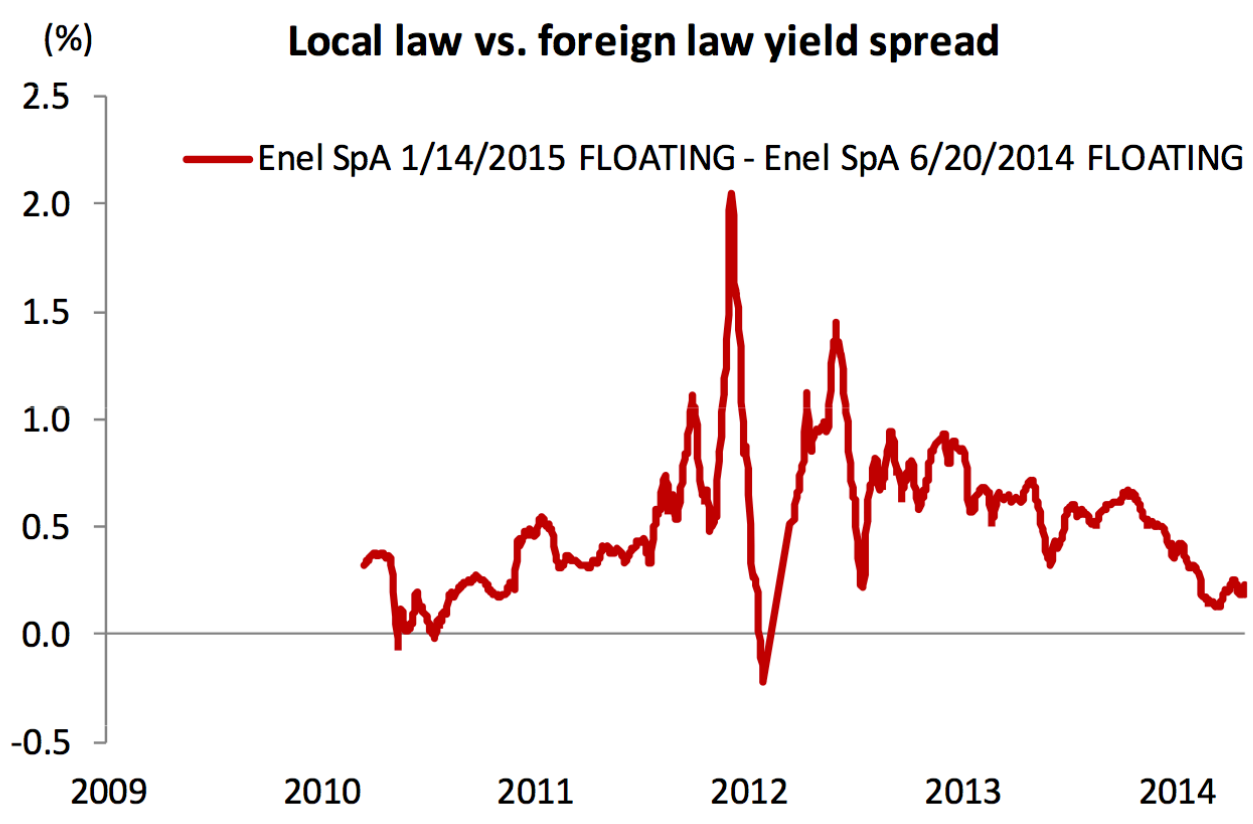

Source: Bloomberg, Nomura Securities. Note: The spread is generally positive and has an intuitive trajectory, with spreads spiking in late 2011 and mid-2012. However, the temporary negative spread in early 2012 is hard to explain fundamentally. As explained in the main text, based on the individual yields in Chart 1, the negative spread in early 2012 is likely due to a pricing in-efficiency on the local law bond.

\section{Table A.1: Summary of Sovereign and Government Guaranteed Bond Sample} (Number of bonds)

\begin{tabular}{|c|c|c|c|c|c|c|c|c|c|c|c|c|}
\hline \multicolumn{13}{|c|}{ Sovereign and Government Guaranteed Agency Bonds } \\
\hline & Austria & Belgium & Finland & France & Germany & Greece & Ireland & Italy & Netherlands & Portugal & Spain & Total \\
\hline Min & 5 & 0 & 0 & 9 & 0 & 0 & 0 & 0 & 0 & 0 & 4 & 20 \\
\hline Max & 20 & 1 & 4 & 38 & 0 & 24 & 0 & 0 & 0 & 6 & 39 & 124 \\
\hline \multicolumn{13}{|c|}{ Sovereign Bonds } \\
\hline & Austria & Belgium & Finland & France & Germany & Greece & Ireland & Italy & Netherlands & Portugal & Spain & Total \\
\hline Min & 1 & 0 & 0 & 0 & 0 & 0 & 0 & 0 & 0 & 0 & 0 & 1 \\
\hline Max & 5 & 1 & 2 & 0 & 0 & 24 & 0 & 0 & 0 & 4 & 1 & 37 \\
\hline \multicolumn{13}{|c|}{ Government Guaranteed Agency Bonds } \\
\hline & Austria & Belgium & Finland & France & Germany & Greece & Ireland & Italy & Netherlands & Portugal & Spain & Total \\
\hline Min & 4 & 0 & 0 & 9 & 0 & 0 & 0 & 0 & 0 & 0 & 4 & 19 \\
\hline Max & 16 & 0 & 2 & 38 & 0 & 0 & 0 & 0 & 0 & 3 & 38 & 88 \\
\hline
\end{tabular}

Source: Bloomberg and Nomura Securities Note: The three tables show the minimum and maximum number of bonds in the sample at a given point in time, starting January 2008 and ending December 2014. 
Chart A.2: Governing Law Spread: Greek government or government guaranteed bonds

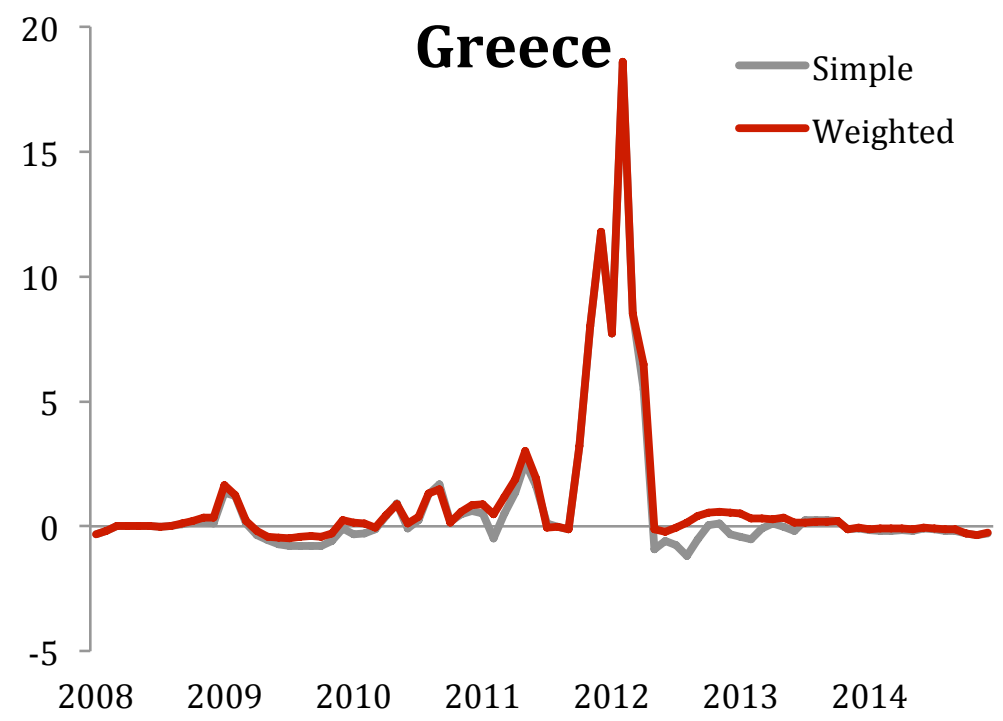

Note: Chart, which is based on a sample of exclusively sovereign bonds, shows the governing law premium edging higher during 2010 and 2011 and spiking dramatically in the run-up to the debt restructuring in 2012 . Note also Greece has a different scale than the $-2 \%$ to $+2 \%$ used in other charts.

\section{Chart A.3: Governing Law Spread: Austrian government or government guaranteed bonds}

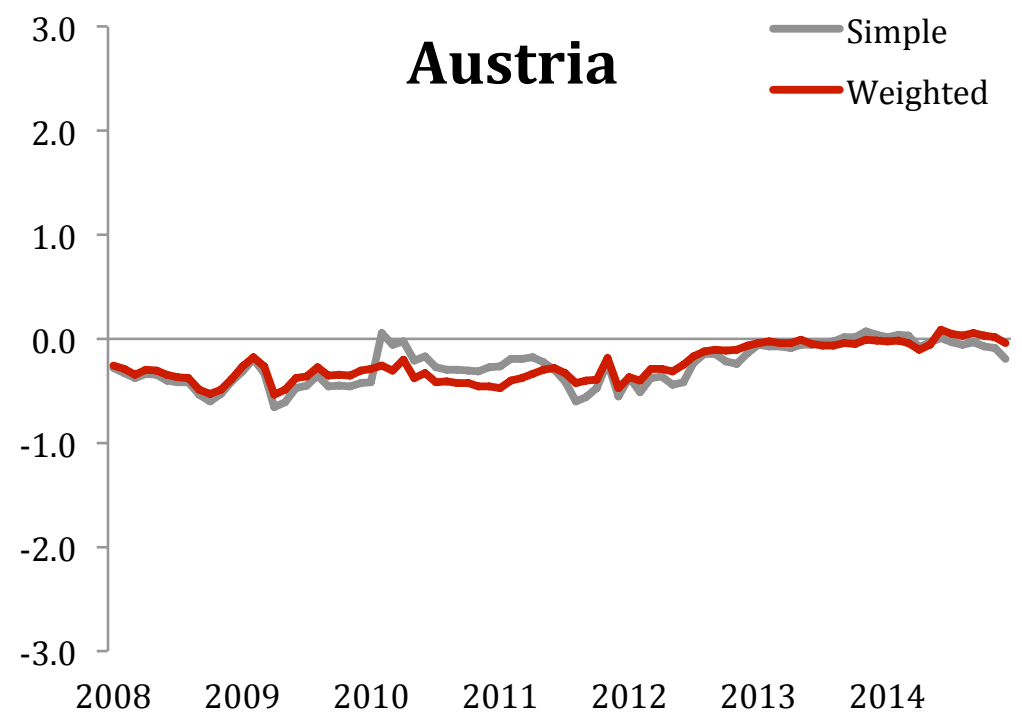

Note: Austrian sample based on a mix of sovereign and government guaranteed bonds. But the governing law spread is very stable across the period, and never far from zero. 
Chart A.4: Governing Law Spread: Belgian government or government guaranteed bonds

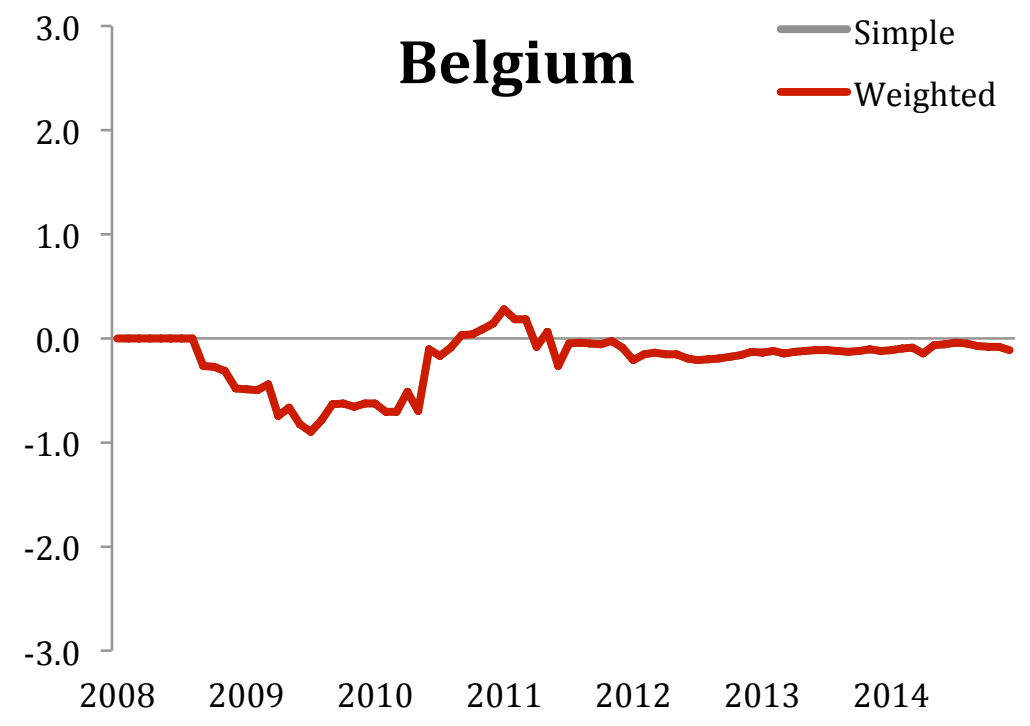

Note: There is some movement in the spread, with some evidence of a spike in late 2011 (at the peak of the Euro-crisis). The sample is based on one single government bond issued under foreign law (hence the simple and weighted concepts are identical).

\section{Chart A.5: Governing Law Spread: Finnish government or government guaranteed bonds}

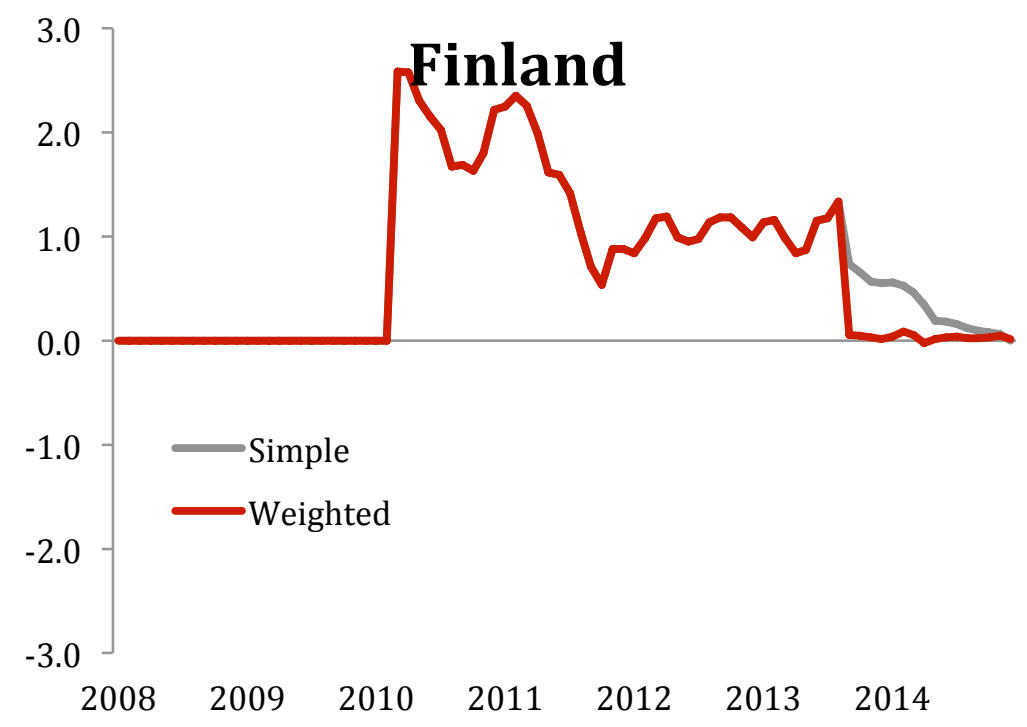

Note: During the Euro-crisis the Finnish sample is driven by 2 government bonds issued under foreign law. We observe those bonds trading at a positive premium, which stays elevated in 2010 and 2011 and then declines. 


\section{Chart A.6: Governing Law Spread: French government or government guaranteed}

bonds

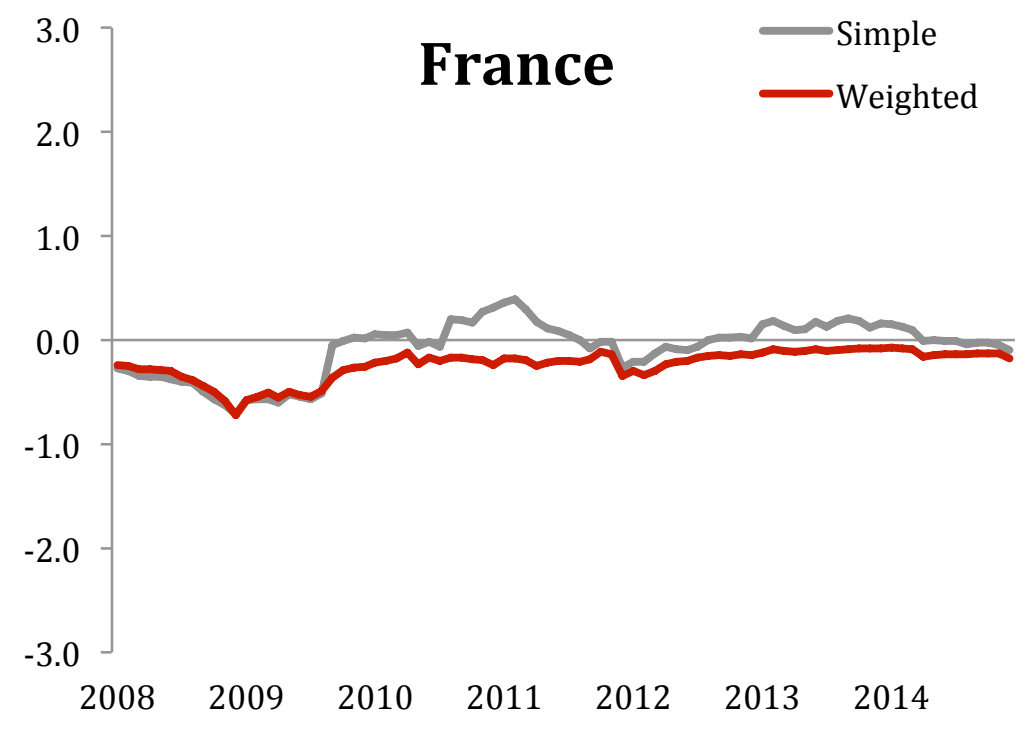

Note: France has no sovereign bonds issued under foreign law. The data set for France is comprised of agency bonds (15-28 of them during the 2010-2012 period). It can be observed that the governing law premium is often negative over the sample as a whole, but the premium does drift higher during 2010 and 2011, although in absolute terms by a moderate amount.

\section{Chart A.7: Governing Law Spread: Portuguese government or government guaranteed bonds}

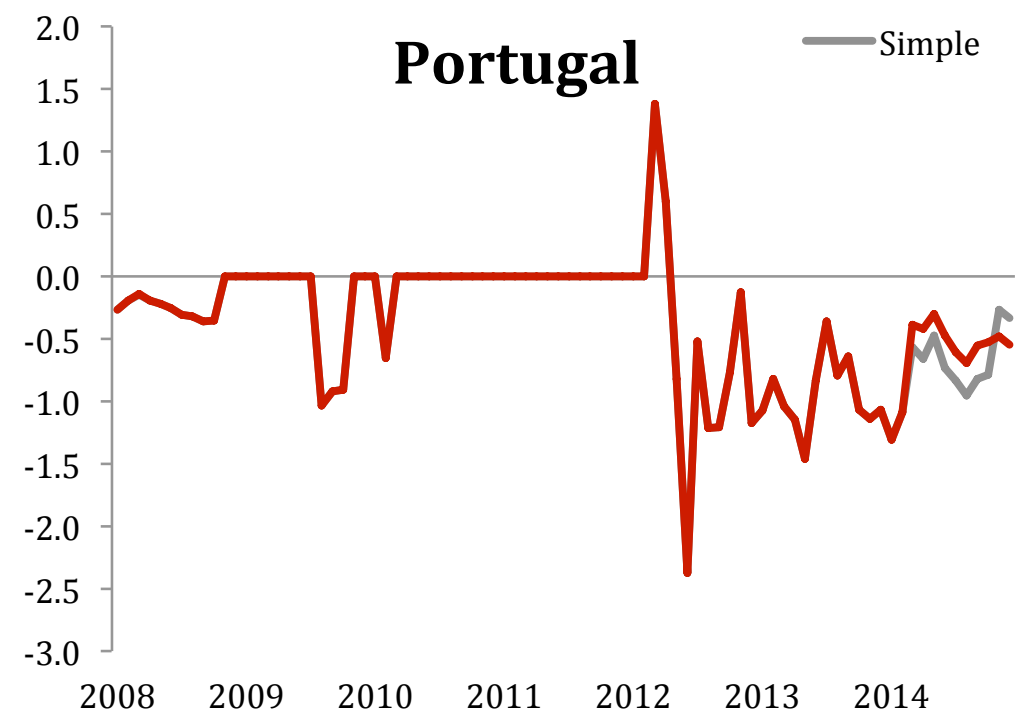

Note: Portugal has no data until the later part of the Euro-crisis, during which the governing law premium has a negative sign. In 2012 and 2013, the sample is comprised of 1-2 government guaranteed bonds. 


\section{Chart A.8: Governing Law Spread: Sample of Spanish government or government guaranteed bonds}

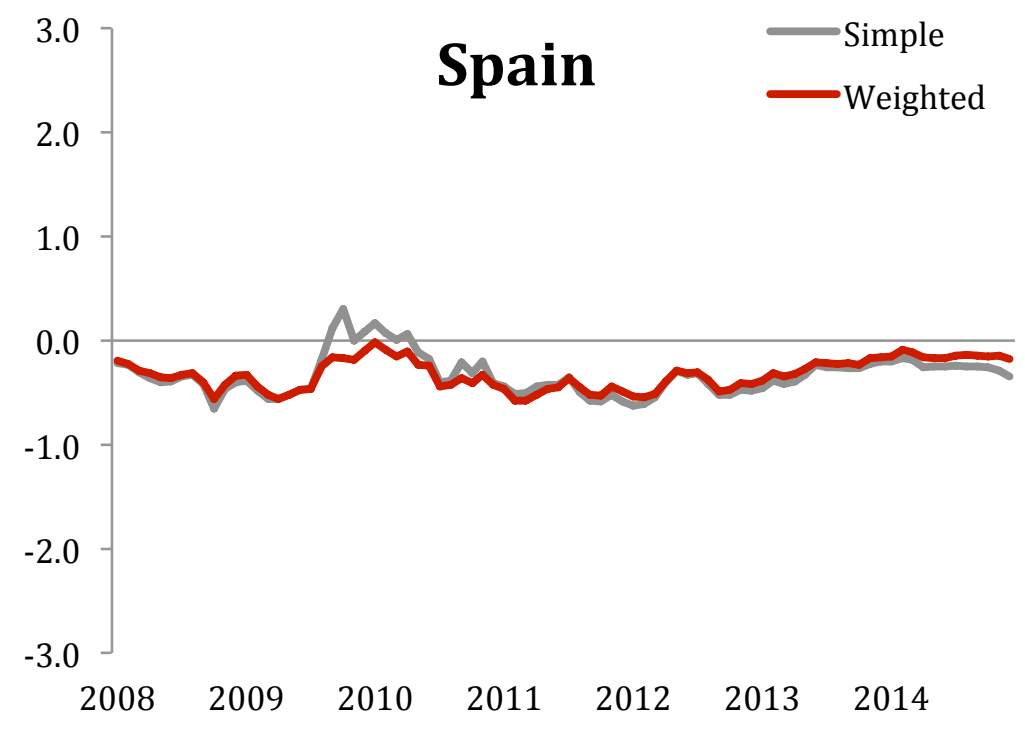

Note: Spain has one government bonds (in Euro) issued under foreign law in the sample. But Spain has a sizeable number of government guaranteed bonds. During the Euro-crisis, the sample ranges from 12 to 37 bonds (gradually increasing). As such, the spread shown in the chart is derived from government guaranteed bonds, as opposed to vanilla sovereign bonds. We observe that the spread is generally negative, and fairly stable not too far from zero. 
Table A.2: Sample of Agency Bonds (Foreign Law Breakdown and Total)

\begin{tabular}{|c|c|c|c|c|c|c|c|c|c|c|c|c|c|}
\hline & $\mathrm{GR}$ & IE & PT & ES & IT & $F R$ & $\mathrm{BE}$ & $\mathrm{DE}$ & AT & $\mathrm{FI}$ & $\mathrm{NL}$ & SUM FL & Total Sum \\
\hline Jan-09 & 0 & 0 & 0 & 4 & 3 & 0 & 0 & 0 & 0 & 2 & 0 & 9 & 52 \\
\hline Feb-09 & 0 & 0 & 0 & 3 & 4 & 0 & 0 & 0 & 0 & 2 & 0 & 9 & 51 \\
\hline Mar-09 & 0 & 0 & 0 & 3 & 3 & 0 & 0 & 0 & 0 & 2 & 0 & 8 & 54 \\
\hline Apr-09 & 0 & 0 & 0 & 3 & 3 & 0 & 0 & 0 & 0 & 2 & 0 & 8 & 54 \\
\hline May-09 & 0 & 0 & 0 & 4 & 3 & 0 & 0 & 0 & 0 & 2 & 0 & 9 & 54 \\
\hline Jun-09 & 0 & 0 & 0 & 5 & 3 & 0 & 0 & 0 & 0 & 3 & 0 & 11 & 61 \\
\hline Jul-09 & 0 & 0 & 0 & 5 & 3 & 0 & 0 & 0 & 0 & 3 & 0 & 11 & 65 \\
\hline Aug-09 & 0 & 0 & 0 & 7 & 3 & 0 & 0 & 0 & 0 & 3 & 0 & 13 & 73 \\
\hline Sep-09 & 0 & 0 & 0 & 8 & 7 & 0 & 0 & 0 & 0 & 3 & 0 & 18 & 94 \\
\hline Oct-09 & 0 & 0 & 0 & 8 & 7 & 0 & 0 & 0 & 0 & 3 & 0 & 18 & 96 \\
\hline Nov-09 & 0 & 0 & 0 & 6 & 9 & 0 & 0 & 0 & 0 & 3 & 0 & 18 & 83 \\
\hline Dec-09 & 0 & 0 & 0 & 6 & 10 & 0 & 1 & 0 & 0 & 3 & 0 & 20 & 77 \\
\hline Jan-10 & 0 & 0 & 0 & 5 & 10 & 0 & 1 & 0 & 0 & 3 & 0 & 19 & 89 \\
\hline Feb-10 & 0 & 0 & 0 & 5 & 9 & 0 & 1 & 0 & 0 & 3 & 0 & 18 & 91 \\
\hline Mar-10 & 0 & 0 & 0 & 5 & 9 & 0 & 1 & 0 & 0 & 3 & 0 & 18 & 97 \\
\hline Apr-10 & 0 & 0 & 0 & 9 & 9 & 0 & 1 & 0 & 0 & 3 & 0 & 22 & 91 \\
\hline May-10 & 0 & 0 & 0 & 8 & 15 & 0 & 1 & 0 & 0 & 3 & 0 & 27 & 99 \\
\hline Jun-10 & 0 & 0 & 0 & 8 & 15 & 0 & 1 & 0 & 0 & 3 & 0 & 27 & 93 \\
\hline Jul-10 & 0 & 0 & 0 & 10 & 15 & 0 & 1 & 0 & 0 & 3 & 0 & 29 & 106 \\
\hline Aug-10 & 0 & 0 & 0 & 11 & 15 & 0 & 1 & 0 & 0 & 3 & 0 & 30 & 109 \\
\hline Sep-10 & 0 & 0 & 1 & 13 & 15 & 0 & 1 & 0 & 0 & 3 & 0 & 33 & 115 \\
\hline Oct-10 & 0 & 0 & 1 & 14 & 15 & 0 & 1 & 0 & 0 & 3 & 0 & 34 & 123 \\
\hline Nov-10 & 0 & 0 & 1 & 13 & 15 & 0 & 1 & 0 & 0 & 3 & 0 & 33 & 119 \\
\hline Dec-10 & 0 & 0 & 1 & 15 & 15 & 0 & 1 & 0 & 0 & 3 & 0 & 35 & 127 \\
\hline Jan-11 & 0 & 0 & 1 & 14 & 15 & 0 & 1 & 0 & 0 & 3 & 0 & 34 & 121 \\
\hline Feb-11 & 0 & 0 & 1 & 14 & 15 & 0 & 1 & 1 & 0 & 3 & 0 & 35 & 129 \\
\hline Mar-11 & 0 & 0 & 1 & 16 & 17 & 0 & 1 & 1 & 0 & 3 & 0 & 39 & 148 \\
\hline Apr-11 & 0 & 0 & 1 & 17 & 16 & 0 & 1 & 1 & 0 & 3 & 0 & 39 & 151 \\
\hline May-11 & 0 & 0 & 1 & 17 & 15 & 0 & 1 & 1 & 0 & 3 & 0 & 38 & 138 \\
\hline Jun-11 & 0 & 0 & 1 & 18 & 15 & 0 & 1 & 1 & 0 & 3 & 0 & 39 & 140 \\
\hline Jul-11 & 0 & 0 & 1 & 16 & 15 & 0 & 1 & 1 & 0 & 3 & 0 & 37 & 141 \\
\hline Aug-11 & 0 & 0 & 1 & 14 & 15 & 0 & 1 & 1 & 0 & 3 & 0 & 35 & 141 \\
\hline Sep-11 & 0 & 0 & 1 & 14 & 15 & 0 & 1 & 1 & 0 & 3 & 0 & 35 & 144 \\
\hline Oct-11 & 0 & 0 & 1 & 14 & 15 & 0 & 1 & 1 & 0 & 3 & 0 & 35 & 143 \\
\hline Nov-11 & 0 & 0 & 1 & 14 & 15 & 0 & 1 & 1 & 0 & 3 & 0 & 35 & 133 \\
\hline Dec-11 & 0 & 0 & 1 & 13 & 15 & 0 & 1 & 1 & 0 & 3 & 0 & 34 & 133 \\
\hline Jan-12 & 0 & 0 & 1 & 12 & 15 & 0 & 1 & 1 & 0 & 3 & 0 & 33 & 137 \\
\hline Feb-12 & 0 & 0 & 1 & 14 & 15 & 0 & 1 & 1 & 0 & 3 & 0 & 35 & 144 \\
\hline Mar-12 & 0 & 0 & 1 & 14 & 15 & 0 & 1 & 1 & 0 & 3 & 0 & 35 & 149 \\
\hline Apr-12 & 0 & 0 & 1 & 13 & 15 & 0 & 1 & 1 & 0 & 3 & 0 & 34 & 149 \\
\hline May-12 & 0 & 0 & 1 & 14 & 15 & 0 & 1 & 1 & 0 & 3 & 0 & 35 & 154 \\
\hline Jun-12 & 0 & 0 & 1 & 14 & 15 & 0 & 1 & 1 & 0 & 3 & 0 & 35 & 155 \\
\hline Jul-12 & 0 & 0 & 1 & 15 & 15 & 0 & 1 & 1 & 0 & 3 & 0 & 36 & 161 \\
\hline Aug-12 & 0 & 0 & 1 & 14 & 30 & 0 & 1 & 1 & 1 & 3 & 0 & 51 & 196 \\
\hline Sep-12 & 0 & 0 & 1 & 15 & 30 & 0 & 1 & 1 & 1 & 3 & 0 & 52 & 198 \\
\hline Oct-12 & 0 & 0 & 1 & 15 & 30 & 0 & 1 & 1 & 1 & 3 & 0 & 52 & 199 \\
\hline Nov-12 & 0 & 0 & 1 & 17 & 31 & 0 & 1 & 1 & 1 & 3 & 0 & 55 & 218 \\
\hline Dec-12 & 0 & 0 & 1 & 18 & 30 & 0 & 1 & 1 & 1 & 3 & 0 & 55 & 220 \\
\hline Jan-13 & 0 & 0 & 1 & 18 & 32 & 0 & 1 & 1 & 1 & 3 & 0 & 57 & 236 \\
\hline Feb-13 & 0 & 0 & 1 & 19 & 31 & 0 & 1 & 1 & 1 & 3 & 0 & 57 & 253 \\
\hline Mar-13 & 0 & 0 & 1 & 17 & 31 & 0 & 1 & 1 & 1 & 3 & 0 & 55 & 251 \\
\hline Apr-13 & 0 & 0 & 1 & 17 & 31 & 0 & 1 & 1 & 1 & 3 & 0 & 55 & 256 \\
\hline May-13 & 0 & 0 & 1 & 17 & 32 & 0 & 1 & 1 & 1 & 3 & 0 & 56 & 260 \\
\hline Jun-13 & 0 & 0 & 1 & 17 & 32 & 0 & 2 & 1 & 1 & 3 & 0 & 57 & 266 \\
\hline Jul-13 & 0 & 0 & 1 & 17 & 33 & 0 & 2 & 1 & 1 & 3 & 0 & 58 & 267 \\
\hline Aug-13 & 0 & 0 & 1 & 17 & 31 & 0 & 2 & 1 & 1 & 3 & 0 & 56 & 269 \\
\hline Sep-13 & 0 & 0 & 1 & 17 & 32 & 0 & 2 & 1 & 1 & 3 & 0 & 57 & 269 \\
\hline Oct-13 & 0 & 0 & 1 & 17 & 31 & 0 & 2 & 1 & 1 & 3 & 0 & 56 & 272 \\
\hline Nov-13 & 0 & 0 & 1 & 17 & 32 & 0 & 2 & 1 & 1 & 3 & 0 & 57 & 278 \\
\hline Dec-13 & 0 & 0 & 1 & 17 & 33 & 1 & 2 & 1 & 1 & 3 & 0 & 59 & 283 \\
\hline Jan-14 & 0 & 0 & 1 & 17 & 33 & 1 & 2 & 1 & 1 & 3 & 0 & 59 & 288 \\
\hline Feb-14 & 0 & 0 & 1 & 16 & 34 & 1 & 3 & 1 & 1 & 3 & 0 & 60 & 294 \\
\hline Mar-14 & 0 & 0 & 1 & 16 & 33 & 1 & 3 & 1 & 1 & 3 & 0 & 59 & 296 \\
\hline Apr-14 & 0 & 0 & 1 & 15 & 33 & 1 & 3 & 1 & 1 & 3 & 0 & 58 & 297 \\
\hline May-14 & 0 & 0 & 1 & 16 & 34 & 2 & 3 & 1 & 1 & 5 & 0 & 63 & 309 \\
\hline Jun-14 & 0 & 0 & 1 & 16 & 35 & 3 & 3 & 1 & 1 & 5 & 0 & 65 & 309 \\
\hline Jul-14 & 0 & 0 & 1 & 16 & 35 & 3 & 3 & 1 & 1 & 7 & 0 & 67 & 315 \\
\hline Aug-14 & 0 & 0 & 1 & 16 & 35 & 3 & 3 & 1 & 1 & 7 & 0 & 67 & 318 \\
\hline Sep-14 & 0 & 0 & 1 & 16 & 35 & 3 & 3 & 1 & 1 & 9 & 0 & 69 & 324 \\
\hline Oct-14 & 0 & 0 & 1 & 16 & 37 & 4 & 3 & 1 & 2 & 9 & 0 & 73 & 326 \\
\hline Nov-14 & 0 & 0 & 1 & 16 & 41 & 4 & 3 & 1 & 2 & 10 & 0 & 78 & 331 \\
\hline Dec-14 & 0 & 0 & 1 & 17 & 41 & 5 & 3 & 1 & 2 & 10 & 0 & 80 & 344 \\
\hline
\end{tabular}

Note: The sample of foreign law bonds (Sum FL column) starts at just nine in January 2009. By January 2010 it is 19 , and during 2010-2012 it averages 35. The total sample (Total Sum column), including local law agency bonds averages 139 bonds during 2010-2012 
Table A.3: Mapping Credit Ratings into a numerical Ratings Score

\begin{tabular}{|l|l|l|r|l|}
\hline Moody's & S\&P & Fitch & & rating description \\
\hline Aaa & AAA & AAA & 1 & Prime \\
\hline Aa1 & AA+ & AA+ & 2 & High grade \\
\hline Aa2 & AA & AA & 3 & High grade \\
\hline Aa3 & AA- & AA- & 4 & High grade \\
\hline A1 & A+ & A+ & 5 & Upper medium grade \\
\hline A2 & A & A & 6 & Upper medium grade \\
\hline A3 & A- & A- & 7 & Upper medium grade \\
\hline Baa1 & BBB+ & BBB+ & 8 & Lower medium grade \\
\hline Baa2 & BBB & BBB & 9 & Lower medium grade \\
\hline Baa3 & BBB- & BBB- & 10 & Lower medium grade \\
\hline Ba1 & BB+ & BB+ & 11 & Non-investment grade \\
\hline Ba2 & BB & BB & 12 & speculative \\
\hline Ba3 & BB- & BB- & 13 & speculative \\
\hline B1 & B+ & B+ & 14 & Highly speculative \\
\hline B2 & B & B & 15 & Highly speculative \\
\hline B3 & B- & B- & 16 & Highly speculative \\
\hline Caa1 & CCC+ & CCC & 17 & Substantial risks \\
\hline Caa2 & CCC & & 18 & Extremely speculative \\
\hline Caa3 & CCC- & & 19 & Default imminent with little prospect for recovery \\
\hline Ca & CC & & 20 & Default imminent with little prospect for recovery \\
\hline & C & & 21 & Default imminent with little prospect for recovery \\
\hline C & D & DDD & 22 & In default \\
\hline Na: Tab & shows the & \\
\hline
\end{tabular}

Note: Table shows the ratings scales from Moody's, S\&P and Fitch. The fourth column shows the numerical Ratings Score that we map to each rating in the grid. 
Table A.4: Descriptive Statistics of Agency Bond Data Set

\begin{tabular}{|c|c|c|c|c|c|c|c|}
\hline & YIELD & SYSTEMIC & REDENOM & CDS & RATINGSPRD & ISSUESIZE & GOVLAW \\
\hline Mean & 3.565541 & 179.7105 & 1.504865 & 146.1758 & 0.841805 & 470.3649 & 0.780911 \\
\hline Median & 3.239190 & 160.4364 & 0.956840 & 92.66890 & 0.666667 & 230.0000 & 1.000000 \\
\hline Maximum & 15.99605 & 511.6469 & 28.49102 & 1210.215 & 7.333333 & 2638.483 & 1.000000 \\
\hline Minimum & -13.06900 & -6.587676 & 0.000000 & 4.373000 & -6.666667 & 1.000000 & 0.000000 \\
\hline Std. Dev. & 2.539764 & 138.8913 & 1.937095 & 136.7609 & 1.778753 & 492.2719 & 0.413634 \\
\hline Skewness & 0.877372 & 0.656870 & 4.030380 & 1.598040 & 0.059958 & 1.337578 & -1.358275 \\
\hline Kurtosis & 4.506975 & 2.546329 & 24.46836 & 6.559941 & 6.125744 & 4.759787 & 2.844912 \\
\hline Jarque-Bera & 2986.916 & 2894.213 & 848485.4 & 36929.96 & 6636.443 & 16543.72 & 11945.87 \\
\hline Probability & 0.000000 & 0.000000 & 0.000000 & 0.000000 & 0.000000 & 0.000000 & 0.000000 \\
\hline Sum & 47774.68 & 6462031. & 58274.37 & 5660510. & 13702.91 & 18214411 & 30240.00 \\
\hline Sum Sq. Dev. & 86422.49 & $6.94 \mathrm{E}+08$ & 145301.7 & $7.24 \mathrm{E}+08$ & 51499.82 & $9.38 \mathrm{E}+09$ & 6625.249 \\
\hline Observations & 13399 & 35958 & 38724 & 38724 & 16278 & 38724 & 38724 \\
\hline
\end{tabular}

Note: Table shows that the minimum yield is negative (at -13.07 ), this is due to some very noisy yield series during 20008. Since we are mainly regressing 2009-2013 (and specifically 2010-2012) this is generally not impacting our results.

\section{Table A.5: Benchmark panel regression (CDS, OLS, 2009-2013)}

Dependent Variable: YIELD

Method: Panel Least Squares

Date: 05/03/15 Time: 15:57

Sample: 2009M01 2013M12

Periods included: 60

Cross-sections included: 281

Total panel (unbalanced) observations: 6990

\begin{tabular}{lrlrr}
\hline \multicolumn{1}{c}{ Variable } & Coefficient & Std. Error & t-Statistic & Prob. \\
\hline \hline C & 2.106945 & 0.088156 & 23.90022 & 0.0000 \\
RATINGSPREAD_A & 0.262550 & 0.011214 & 23.41237 & 0.0000 \\
ISSUESIZE_A & -0.000400 & $3.86 E-05$ & -10.36736 & 0.0000 \\
CDS_A & 0.011609 & 0.000296 & 39.23692 & 0.0000 \\
CDS_A*GOVLAW_A & 0.004670 & 0.000355 & 13.16549 & 0.0000 \\
GOVLAW_A & -1.001505 & 0.096928 & -10.33248 & 0.0000 \\
\hline \hline & & & \\
R-squared & 0.663312 & Mean dependent var & 4.119273 \\
Adjusted R-squared & 0.663071 & S.D. dependent var & 2.713755 \\
S.E. of regression & 1.575215 & Akaike info criterion & 3.747519 \\
Sum squared resid & 17329.41 & Schwarz criterion & 3.753400 \\
Log likelihood & -13091.58 & Hannan-Quinn criter. & 3.749545 \\
F-statistic & 2751.850 & Durbin-Watson stat & 0.139721 \\
Prob(F-statistic) & 0.000000 & & \\
\hline \hline
\end{tabular}

Note: The benchmark regression for the sample 2009-2013, using Panel OLS, shows that all the variables have the expected sign and that the interaction term (governing law and CDS) has a positive sign as expected. Note that the governing law dummy enters alone with a negative sign, reflecting a lower average yield over the sample than the foreign law bonds (potentially reflecting selection bias, pressured issuers have to issue under foreign law). 
Table A.6: Benchmark panel regression (CDS, GLS/SUR, 2009-2013)

\begin{tabular}{|c|c|c|c|c|}
\hline \multicolumn{5}{|c|}{$\begin{array}{l}\text { Dependent Variable: YIELD_A } \\
\text { Method: Panel EGLS (Cross-section weights) } \\
\text { Date: 05/03/15 Time: } 16: 05 \\
\text { Sample: } 2009 \mathrm{M} 012013 \mathrm{M} 12 \\
\text { Periods included: } 60 \\
\text { Cross-sections included: } 281 \\
\text { Total panel (unbalanced) observations: } 6990 \\
\text { Linear estimation after one-step weighting matrix }\end{array}$} \\
\hline Variable & Coefficient & Std. Error & $\mathrm{t}$-Statistic & Prob. \\
\hline $\mathrm{C}$ & 2371319 & 0084145 & 281 & 0.00 \\
\hline RATINGSPREAD_A & 0.254045 & 0.009757 & 26.03723 & 0.0000 \\
\hline ISSUESIZE_A & -0.000292 & 2.89E-05 & -10.10593 & 0.0000 \\
\hline CDS_A & 0.010364 & 0.000293 & 35.33861 & 0.0000 \\
\hline CDS_A*GOVLAW_A & 0.005095 & 0.000331 & 15.38708 & 0.0000 \\
\hline$\overline{G O V L A W \_A}$ & -1.336014 & 0.087856 & -15.20691 & 0.0000 \\
\hline \multicolumn{5}{|c|}{ Weighted Statistics } \\
\hline R-squared & 0.763048 & \multirow{5}{*}{\multicolumn{2}{|c|}{$\begin{array}{l}\text { Mean dependent var } \\
\text { S.D. dependent var } \\
\text { Sum squared resid } \\
\text { Durbin-Watson stat }\end{array}$}} & 4.581463 \\
\hline Adjusted R-squared & 0.762878 & & & 2.829723 \\
\hline S.E. of regression & 1.562008 & & & 17040.04 \\
\hline F-statistic & 4498.056 & & & 0.148420 \\
\hline Prob(F-statistic) & 0.000000 & & & \\
\hline \multicolumn{5}{|c|}{ Unweighted Statistics } \\
\hline R-squared & 0.658443 & \multirow{2}{*}{\multicolumn{2}{|c|}{$\begin{array}{l}\text { Mean dependent var } \\
\text { Durbin-Watson stat }\end{array}$}} & 4.119273 \\
\hline Sum squared resid & 17580.03 & & & 0.130786 \\
\hline
\end{tabular}

Note: The GLS estimation shows very similar coefficient estimates, compared to the OLS estimation. The standard errors are different, but not sufficiently different to impact t-statistics meaningfully. 
Table A.7: Benchmark panel regression (CDS, OLS, 2010-2012)

Dependent Variable: YIELD_A

Method: Panel Least Squares

Date: 05/03/15 Time: 16:10

Sample: 2010M01 2012M12

Periods included: 36

Cross-sections included: 222

Total panel (unbalanced) observations: 3944

\begin{tabular}{lrlrr}
\hline \multicolumn{1}{c}{ Variable } & Coefficient & Std. Error & t-Statistic & Prob. \\
\hline \hline \multicolumn{1}{c}{ C } & 2.156983 & 0.121684 & 17.72608 & 0.0000 \\
RATINGSPREAD_A & 0.338562 & 0.017660 & 19.17097 & 0.0000 \\
ISSUESIZE_A & -0.000187 & $5.56 E-05$ & -3.363777 & 0.0008 \\
CDS_A & 0.010940 & 0.000369 & 29.64072 & 0.0000 \\
CDS_A*GOVLAW_A & 0.005885 & 0.000452 & 13.01693 & 0.0000 \\
$\quad$ GOVLAW_A & -1.527620 & 0.138485 & -11.03092 & 0.0000 \\
\hline \hline & & & \\
R-squared & 0.679870 & Mean dependent var & 4.511516 \\
Adjusted R-squared & 0.679463 & S.D. dependent var & 2.980680 \\
S.E. of regression & 1.687540 & Akaike info criterion & 3.885941 \\
Sum squared resid & 11214.60 & Schwarz criterion & 3.895495 \\
Log likelihood & -7657.076 & Hannan-Quinn criter. & 3.889330 \\
F-statistic & 1672.650 & Durbin-Watson stat & 0.191013 \\
Prob(F-statistic) & 0.000000 & & \\
\hline \hline
\end{tabular}

Note: The regression results are similar to the results from 2009-2013 (the benchmark period). However, the coefficient on the interaction term is somewhat higher (by 28\%), indicating the greater importance of the governing law parameter during the Euro-crisis. 
Table A.8: Benchmark panel regression (CDS, GLS/SUR, 2010-2012)

Dependent Variable: YIELD_A

Method: Panel EGLS (Cross-section weights)

Date: 05/03/15 Time: 16:16

Sample: 2010M01 2012M12

Periods included: 36

Cross-sections included: 222

Total panel (unbalanced) observations: 3944

Linear estimation after one-step weighting matrix

\begin{tabular}{lrlrr}
\hline \hline \multicolumn{1}{c}{ Variable } & Coefficient & Std. Error & t-Statistic & Prob. \\
\hline \hline C & 2.451485 & 0.110899 & 22.10561 & 0.0000 \\
RATINGSPREAD_A & 0.323930 & 0.016072 & 20.15479 & 0.0000 \\
ISSUESIZE_A & -0.000162 & $3.60 E-05$ & -4.499400 & 0.0000 \\
CDS_A & 0.009689 & 0.000354 & 27.39698 & 0.0000 \\
CDS_A*GOVLAW_A & 0.006912 & 0.000391 & 17.70077 & 0.0000 \\
GOVLAW_A & -1.895140 & 0.116701 & -16.23930 & 0.0000 \\
\hline \hline & Weighted Statistics & & \\
\hline \hline R-squared & 0.843033 & Mean dependent var & 4.962418 \\
Adjusted R-squared & 0.842834 & S.D. dependent var & 5.457260 \\
S.E. of regression & 1.675030 & Sum squared resid & 11048.95 \\
F-statistic & 4230.029 & Durbin-Watson stat & 0.197087 \\
Prob(F-statistic) & 0.000000 & & \\
\hline \hline
\end{tabular}

Note: Coefficient and standard error estimates are not materially different from the OLS regression. 
Chart A.9: Coefficients from benchmark cross-sectional regression. CDS based, and OLS estimation:

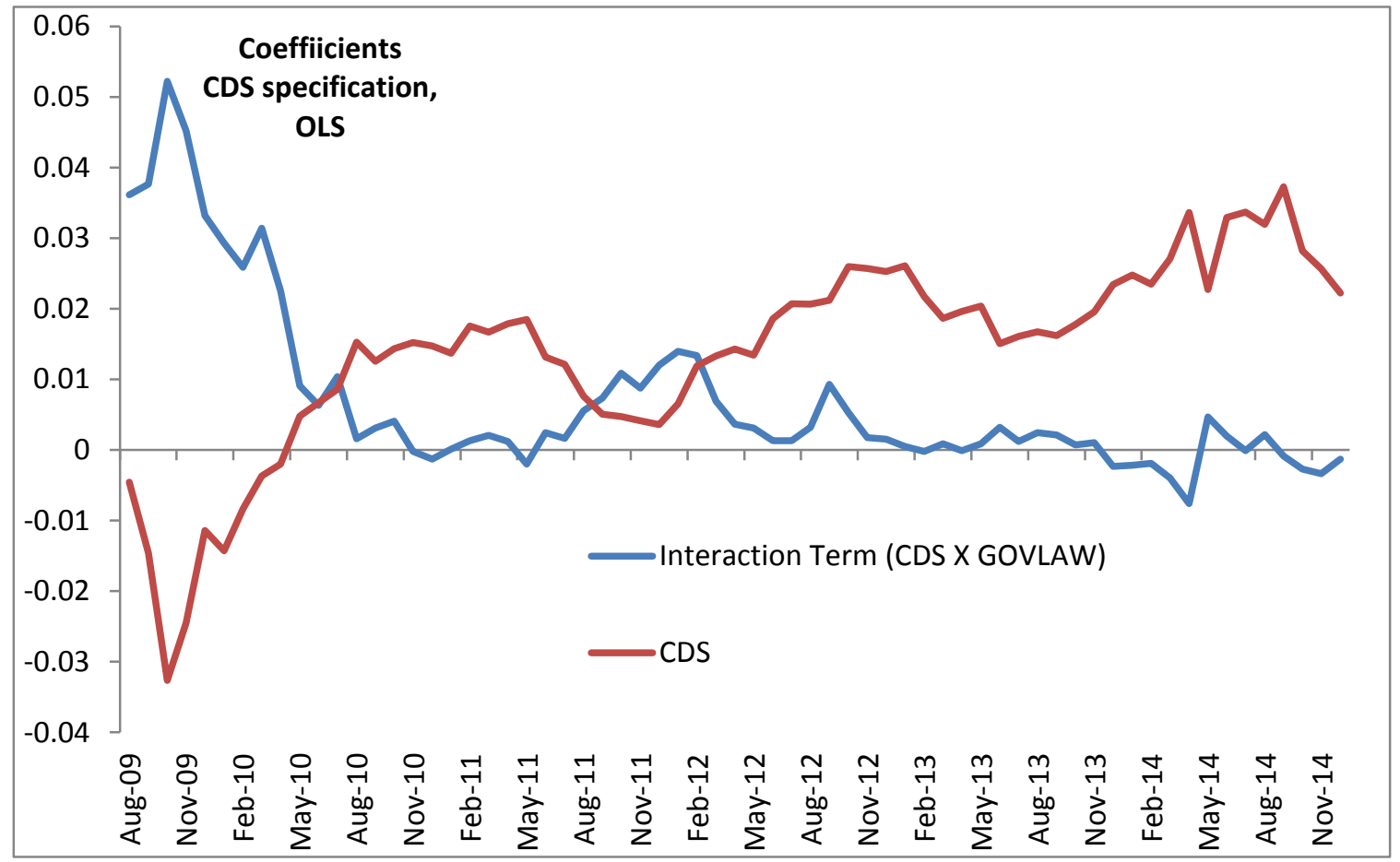

Note: During the period where the coefficients are the most significant, i.e. late 2011, we observe values of the interaction parameter of $0.010-0.015$. This implies that a $100 \mathrm{bp}$ spike in the country specific CDS variable can generate a $100-150 \mathrm{bp}$ increase in the governing law premium in those periods. 
Chart A.10: T-statistic of interaction term (governing law interacted with CDS): GLS estimation

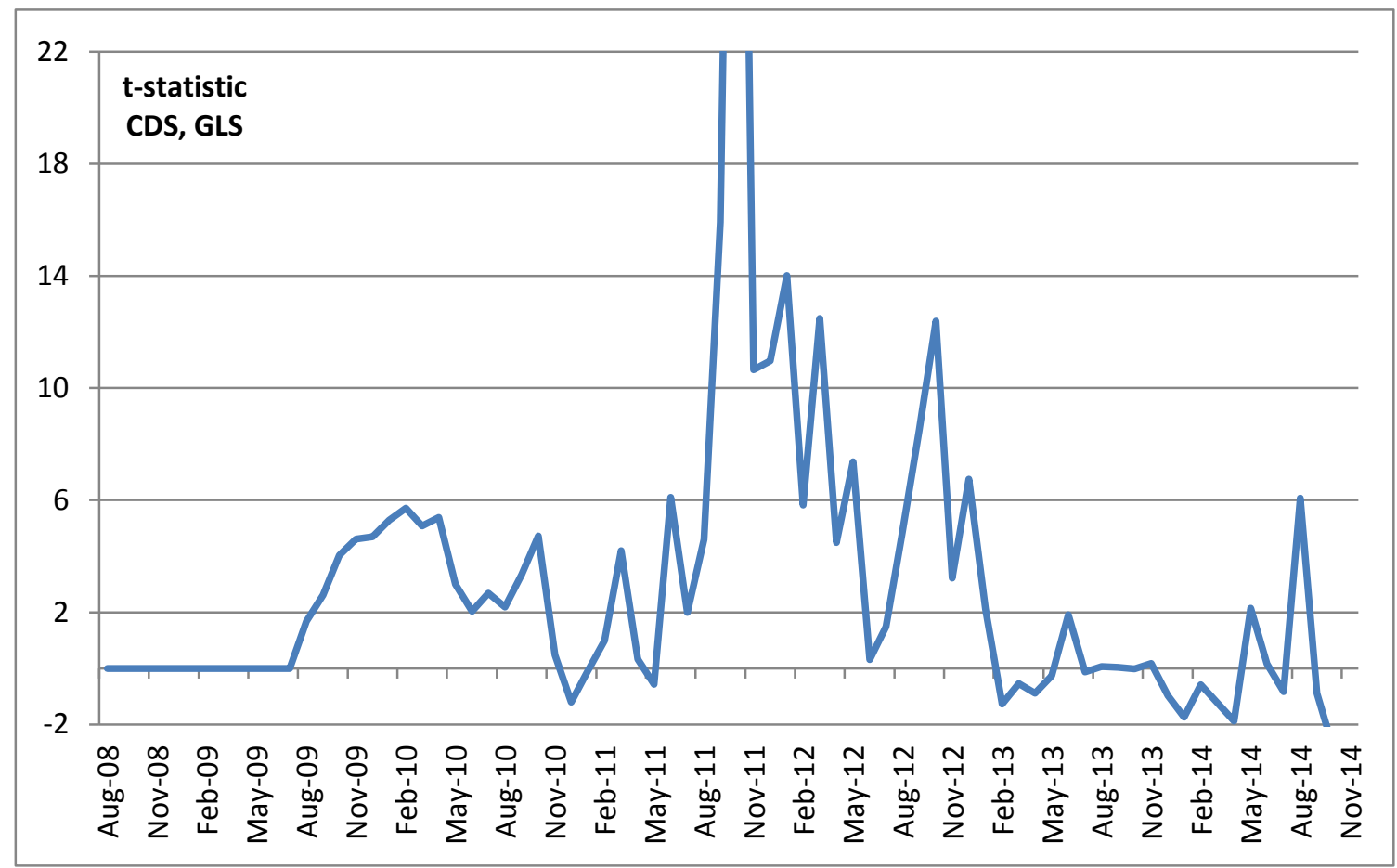

Note: The trajectory of the t-statistics is similar to the ones obtained with OLS estimation, but they are shifted higher. The t-statistics spike to above 2 early in the Euro-crisis (late 2009 and early 2010). It then moves towards zero in early 2011 (when markets were calmer, and the ECB hiked rates), and it spikes even further to above 10 in late 2011, when systemic tension resurfaced. Finally, we have elevated tstatistic in most of 2012. In other periods, especially in 2013 and 2014, the t-statistic hovers around zero. 
Table A.9 Panel regression (CDS, with ratings and CDS interaction, OLS, 2009-2013)

Dependent Variable: YIELD_A

Method: Panel Least Squares

Date: 05/06/15 Time: 17:23

Sample: 2009M01 2013M12

Periods included: 60

Cross-sections included: 281

Total panel (unbalanced) observations: 6990

\begin{tabular}{lrlrr}
\hline \multicolumn{1}{c}{ Variable } & Coefficient & Std. Error & t-Statistic & Prob. \\
\hline \hline C & 2.442399 & 0.086446 & 28.25360 & 0.0000 \\
RATINGSPREAD_A*CDS_A & 0.001012 & $3.91 \mathrm{E}-05$ & 25.87546 & 0.0000 \\
ISSUESIZE_A & -0.000435 & $3.83 \mathrm{E}-05$ & -11.36484 & 0.0000 \\
CDS_A & 0.010164 & 0.000304 & 33.41837 & 0.0000 \\
CDS_A*GOVLAW_A & 0.005484 & 0.000357 & 15.35842 & 0.0000 \\
$\quad$ GOVLAW_A & -1.130359 & 0.096131 & -11.75854 & 0.0000 \\
\hline \hline & & & \\
R-squared & 0.668653 & Mean dependent var & 4.119273 \\
Adjusted R-squared & 0.668416 & S.D. dependent var & 2.713755 \\
S.E. of regression & 1.562672 & Akaike info criterion & 3.731529 \\
Sum squared resid & 17054.53 & Schwarz criterion & 3.737411 \\
Log likelihood & -13035.70 & Hannan-Quinn criter. & 3.733556 \\
F-statistic & 2818.717 & Durbin-Watson stat & 0.150813 \\
Prob(F-statistic) & 0.000000 & & \\
\hline \hline
\end{tabular}

Note: Compared to Table A.5, we see that the main results are very similar. However, the R-squared is marginally higher and the t-statistics is also higher for the ratingspread term (i.e. the CreditScore). Moreover, the coefficient on the legal term is somewhat higher, by $17 \%$ (compared to the benchmark regression). 
Table A.10: Panel regression (Redenomination (news proxy), OLS, 2009-2013)

Dependent Variable: YIELD_A

Method: Panel Least Squares

Date: 05/03/15 Time: 17:36

Sample: 2009M01 2013M12

Periods included: 60

Cross-sections included: 281

Total panel (unbalanced) observations: 6990

\begin{tabular}{lrlrr}
\hline \multicolumn{1}{c}{ Variable } & Coefficient & Std. Error & t-Statistic & Prob. \\
\hline \hline C & 1.145481 & 0.068041 & 16.83513 & 0.0000 \\
RATINGSPREAD_A & 0.242622 & 0.011148 & 21.76302 & 0.0000 \\
ISSUESIZE_A & -0.000510 & $3.78 E-05$ & -13.50006 & 0.0000 \\
CDS_A & 0.015524 & 0.000173 & 89.53643 & 0.0000 \\
GOVLAW_A & 0.351180 & 0.056448 & 6.221309 & 0.0000 \\
GOVLAW_A*REDENOM_A & -0.123153 & 0.013460 & -9.149916 & 0.0000 \\
\hline \hline R-squared & 0.659043 & Mean dependent var & 4.119273 \\
Adjusted R-squared & 0.658799 & S.D. dependent var & 2.713755 \\
S.E. of regression & 1.585169 & Akaike info criterion & 3.760118 \\
Sum squared resid & 17549.13 & Schwarz criterion & 3.765999 \\
Log likelihood & -13135.61 & Hannan-Quinn criter. & 3.762144 \\
F-statistic & 2699.909 & Durbin-Watson stat & 0.145939 \\
Prob(F-statistic) & 0.000000 & & \\
\hline \hline
\end{tabular}

Note: The interaction term has the wrong sign in this specification. 
Table A.11: Panel regression (Redenomination (news proxy), OLS, 2010-2012)

Dependent Variable: YIELD_A

Method: Panel Least Squares

Date: 05/03/15 Time: 17:41

Sample: 2010M01 2012M12

Periods included: 36

Cross-sections included: 222

Total panel (unbalanced) observations: 3944

\begin{tabular}{lrlrr}
\hline \multicolumn{1}{c}{ Variable } & Coefficient & Std. Error & t-Statistic & Prob. \\
\hline \hline C & 1.144955 & 0.091789 & 12.47378 & 0.0000 \\
RATINGSPREAD_A*CDS_A & 0.000863 & $5.00 E-05$ & 17.26768 & 0.0000 \\
ISSUESIZE_A & -0.000448 & $5.39 E-05$ & -8.306470 & 0.0000 \\
CDS_A & 0.014852 & 0.000231 & 64.32622 & 0.0000 \\
GOVLAW_A*REDENOM_A & -0.107583 & 0.016037 & -6.708213 & 0.0000 \\
GOVLAW_A & 0.409661 & 0.079390 & 5.160106 & 0.0000 \\
\hline \hline R-squared & 0.674006 & Mean dependent var & 4.511516 \\
Adjusted R-squared & 0.673592 & S.D. dependent var & 2.980680 \\
S.E. of regression & 1.702925 & Akaike info criterion & 3.904092 \\
Sum squared resid & 11420.02 & Schwarz criterion & 3.913646 \\
Log likelihood & -7692.870 & Hannan-Quinn criter. & 3.907481 \\
F-statistic & 1628.397 & Durbin-Watson stat & 0.200907 \\
Prob(F-statistic) & 0.000000 & & \\
\hline \hline
\end{tabular}

Note: The governing law interaction term has the wrong sign even in the Euro-crisis specification, when estimated with OLS. 
Table A.12: Panel regression (QCDS, OLS, 2009-2013)

Dependent Variable: YIELD_A

Method: Panel Least Squares

Date: 05/03/15 Time: 17:27

Sample: 2009M01 2013M12

Periods included: 60

Cross-sections included: 281

Total panel (unbalanced) observations: 6946

\begin{tabular}{lrlrr}
\hline \hline \multicolumn{1}{c}{ Variable } & Coefficient & Std. Error & t-Statistic & Prob. \\
\hline C & 1.419486 & 0.080651 & 17.60046 & 0.0000 \\
RATINGSPREAD_A*CDS & 0.000893 & $3.94 \mathrm{E}-05$ & 22.66661 & 0.0000 \\
ISSUESIZE_A & -0.000539 & $3.81 \mathrm{E}-05$ & -14.15992 & 0.0000 \\
CDS_A & 0.014260 & 0.000253 & 56.39008 & 0.0000 \\
GOVLAW_A & 0.176975 & 0.083301 & 2.124524 & 0.0337 \\
GOVLAW_A*QCDS_A & 0.000446 & 0.001266 & 0.352210 & 0.7247 \\
\hline \hline R-squared & 0.660157 & Mean dependent var & 4.123346 \\
Adjusted R-squared & 0.659913 & S.D. dependent var & 2.720806 \\
S.E. of regression & 1.586693 & Akaike info criterion & 3.762045 \\
Sum squared resid & 17472.11 & Schwarz criterion & 3.767958 \\
Log likelihood & -13059.58 & Hannan-Quinn criter. & 3.764083 \\
F-statistic & 2696.243 & Durbin-Watson stat & 0.149318 \\
Prob(F-statistic) & 0.000000 & & & \\
\hline \hline
\end{tabular}

Note: QCDS interacted with governing law variable not significant in the longer sample. 
Table A.13: Panel regression (QCDS, OLS, 2010-2012, No German adjustment)

Dependent Variable: YIELD_A

Method: Panel Least Squares

Date: 05/03/15 Time: 17:18

Sample: 2010M01 2012M12

Periods included: 36

Cross-sections included: 222

Total panel (unbalanced) observations: 3910

\begin{tabular}{lrlrr}
\hline \hline \multicolumn{1}{c}{ Variable } & Coefficient & Std. Error & t-Statistic & Prob. \\
\hline C & 1.558278 & 0.115816 & 13.45480 & 0.0000 \\
RATINGSPREAD_A*CDS & 0.000988 & $5.12 E-05$ & 19.30089 & 0.0000 \\
ISSUESIZE_A & -0.000397 & $5.44 E-05$ & -7.299101 & 0.0000 \\
CDS_A & 0.013035 & 0.000331 & 39.35939 & 0.0000 \\
GOVLAW_A & -0.386510 & 0.124151 & -3.113235 & 0.0019 \\
GOVLAW_A*QCDS_A & 0.009463 & 0.001657 & 5.710608 & 0.0000 \\
\hline \hline R-squared & 0.675725 & Mean dependent var & 4.521937 \\
Adjusted R-squared & 0.675309 & S.D. dependent var & 2.990327 \\
S.E. of regression & 1.703937 & Akaike info criterion & 3.905294 \\
Sum squared resid & 11334.89 & Schwarz criterion & 3.914917 \\
Log likelihood & -7628.850 & Hannan-Quinn criter. & 3.908709 \\
F-statistic & 1627.030 & Durbin-Watson stat & 0.196157 \\
Prob(F-statistic) & 0.000000 & & \\
\hline \hline
\end{tabular}

Note: QCDS variable significant during Euro-crisis period (even without adjustment of German data) 
Table A.14: Panel regression (QCDS, OLS, 2010-2012, German variable set to zero)

Dependent Variable: YIELD_A

Method: Panel Least Squares

Date: 05/06/15 Time: 17:35

Sample: 2010M01 2012M12

Periods included: 36

Cross-sections included: 222

Total panel (unbalanced) observations: 3910

\begin{tabular}{lrlrl}
\hline \multicolumn{1}{c}{ Variable } & Coefficient & Std. Error & t-Statistic & Prob. \\
\hline \hline C & 2.100754 & 0.115321 & 18.21659 & 0.0000 \\
RATINGSPREAD_A*CDS_A & 0.001063 & $5.01 \mathrm{E}-05$ & 21.22346 & 0.0000 \\
ISSUESIZE_A & -0.000333 & $5.37 \mathrm{E}-05$ & -6.195149 & 0.0000 \\
CDS_A & 0.011058 & 0.000334 & 33.12394 & 0.0000 \\
GOVLAW_A & -0.895010 & 0.107102 & -8.356635 & 0.0000 \\
QCDS*GOVLAW_A & 0.018696 & 0.001413 & 13.22689 & 0.0000 \\
\hline \hline R-squared & 0.687041 & Mean dependent var & 4.521937 \\
Adjusted R-squared & 0.686640 & S.D. dependent var & 2.990327 \\
S.E. of regression & 1.673943 & Akaike info criterion & 3.869774 \\
Sum squared resid & 10939.34 & Schwarz criterion & 3.879398 \\
Log likelihood & -7559.409 & Hannan-Quinn criter. & 3.873190 \\
F-statistic & 1714.092 & Durbin-Watson stat & 0.191887 \\
Prob(F-statistic) & 0.000000 & & \\
P & & & \\
\hline
\end{tabular}

Note: The coefficient on the legal term (governing law interacted with QCDS) spikes about $100 \%$ when the German QCDS is set to zero. 
Chart A.11: T-statistic of interaction term (governing law interacted with news-based redenomination proxy): OLS estimation

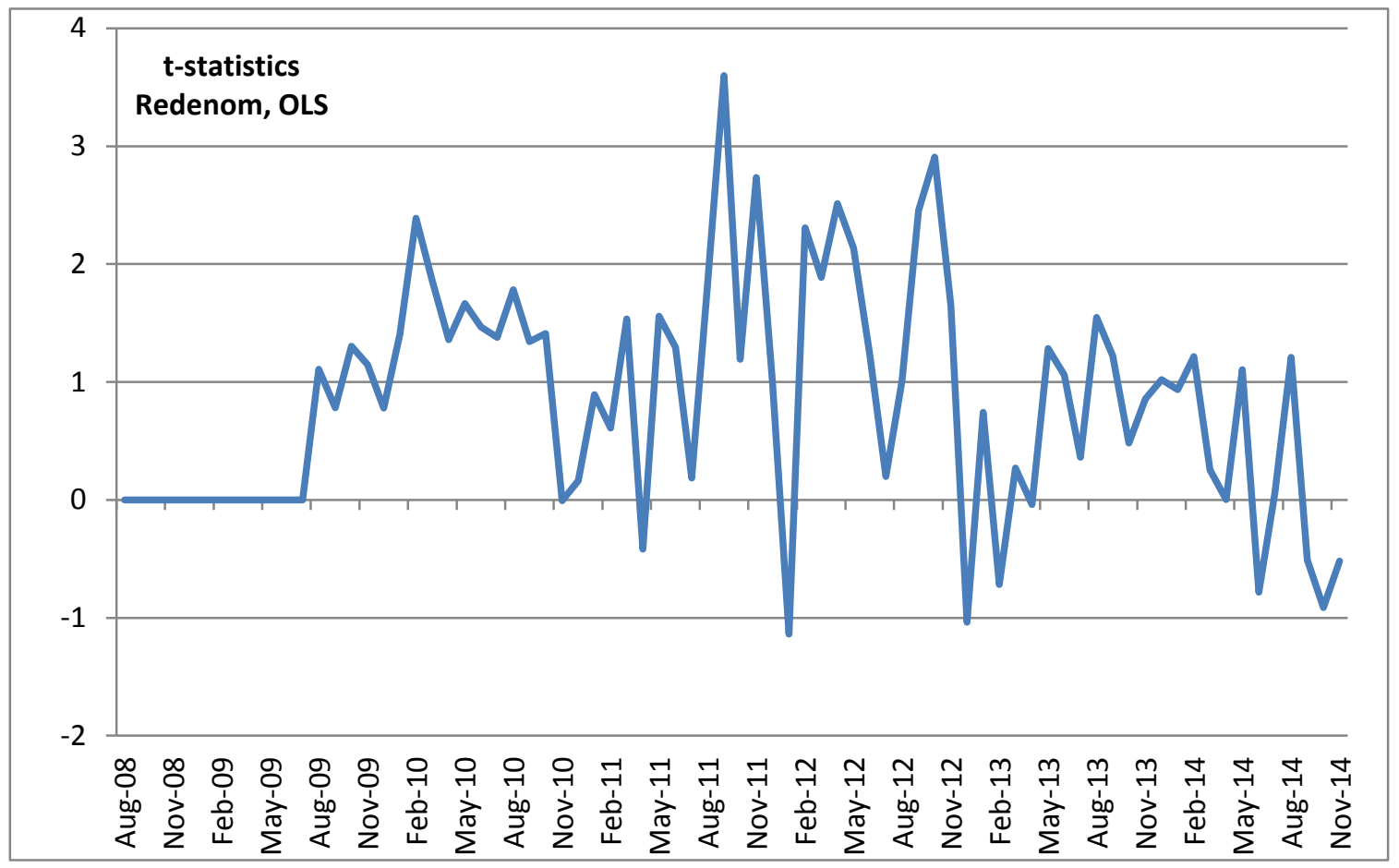

Note: t-statistic spikes to around 2 early in the Euro-crisis (Q1 2010). It moves towards zero in early 2011 (when markets were calmer, and the ECB hiked rates), and it spikes even further to above 2-3 in late 2011, when systemic tension resurfaced. Finally we have a spike in the t-statistic around AugustSeptember 2012, to above 2. In other periods, especially in 2013 and 2014, the t-statistic hovers around zero. 
Chart A.12: T-statistic of interaction term (governing law interacted with news-based redenomination proxy): GLS estimation

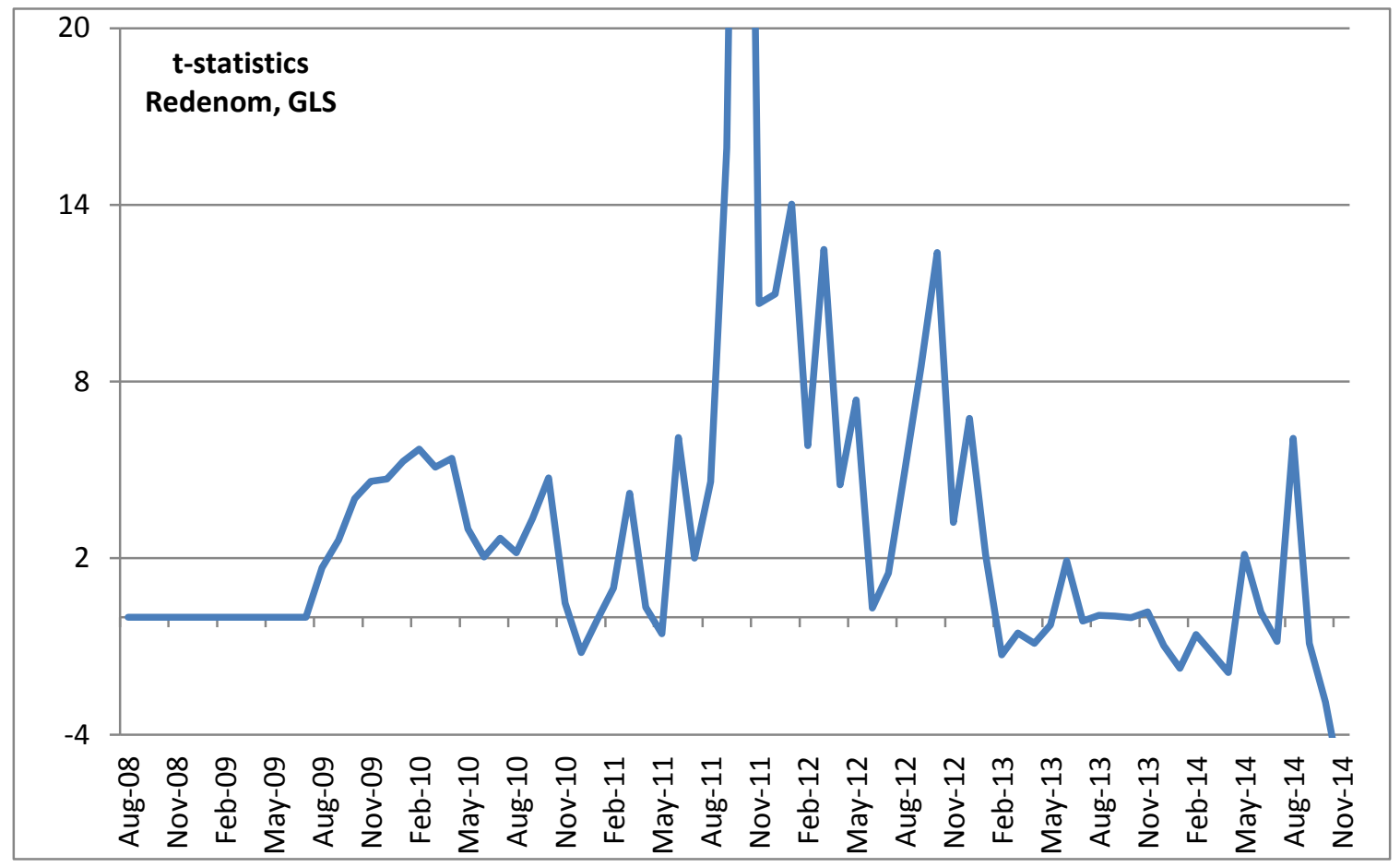

Note: t-statistic spikes to 2-6 early in the Euro-crisis (late 2009 to mid-2010). It moves towards zero in early 2011 (when markets were calmer, and the ECB hiked rates). It spikes even further to above 8 in late 2011, when systemic tension resurfaced. Finally, the t-statistic remains elevated throughout 2012, peaking around September, after which it drops, especially in 2013 and 2014, the t-statistic hovers around zero. 
Chart A.13: T-statistic of interaction term (governing law interacted with quanto-CDS): OLS estimation

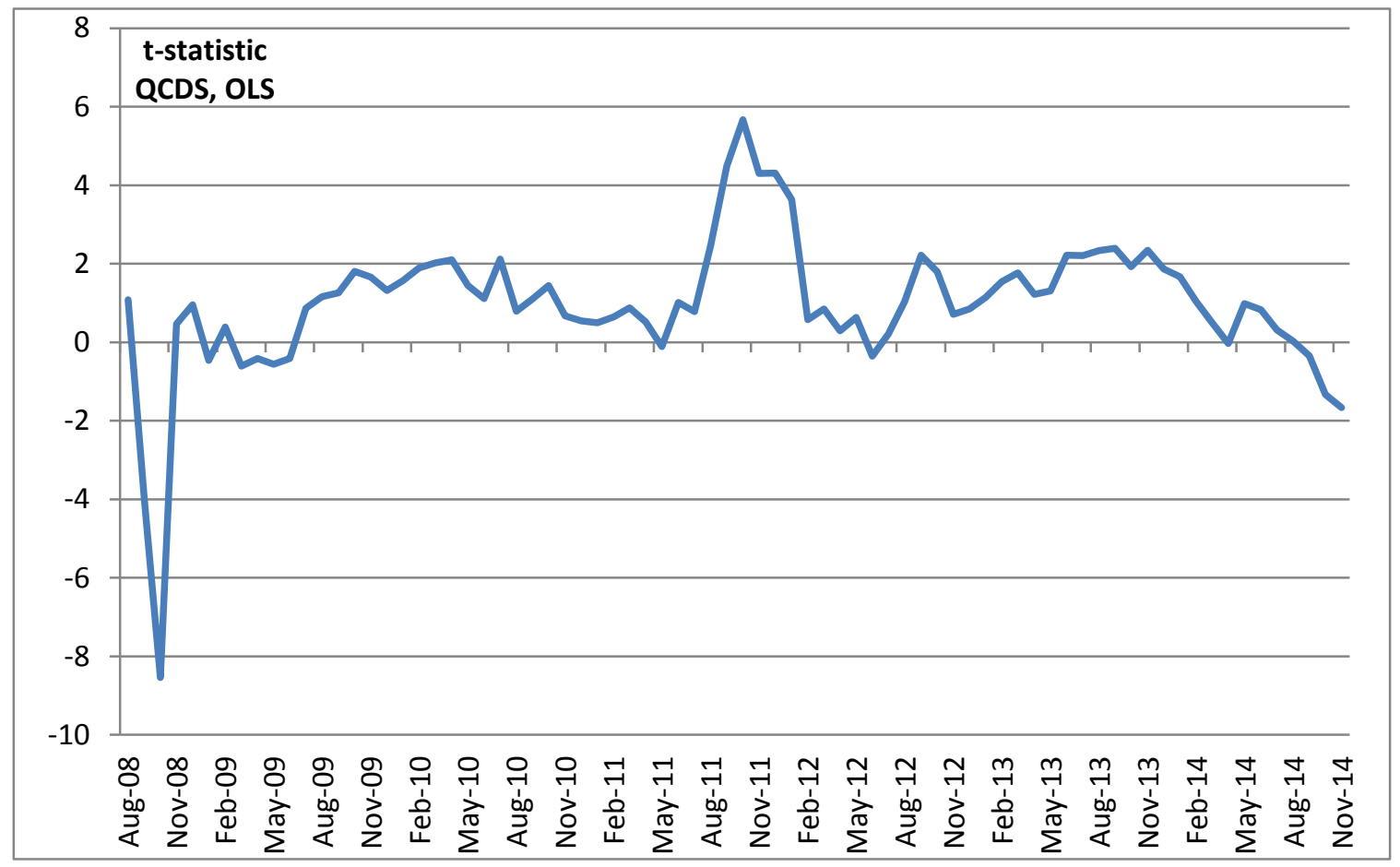

Note: t-statistic spikes just around 2 early in the Euro-crisis (late 2009 to mid-2010). It moves towards zero in early 2011 (when markets were calmer, and the ECB hiked rates), and it spikes even further to above 4 in late 2011, when systemic tension resurfaced. Finally, the t-statistic remains elevated throughout 2012 and 2013, after which it drops, especially in 2014, when the t-statistic hovers around zero. 
Chart A.14: T-statistic of interaction term (governing law interacted with quanto-CDS): GLS estimation

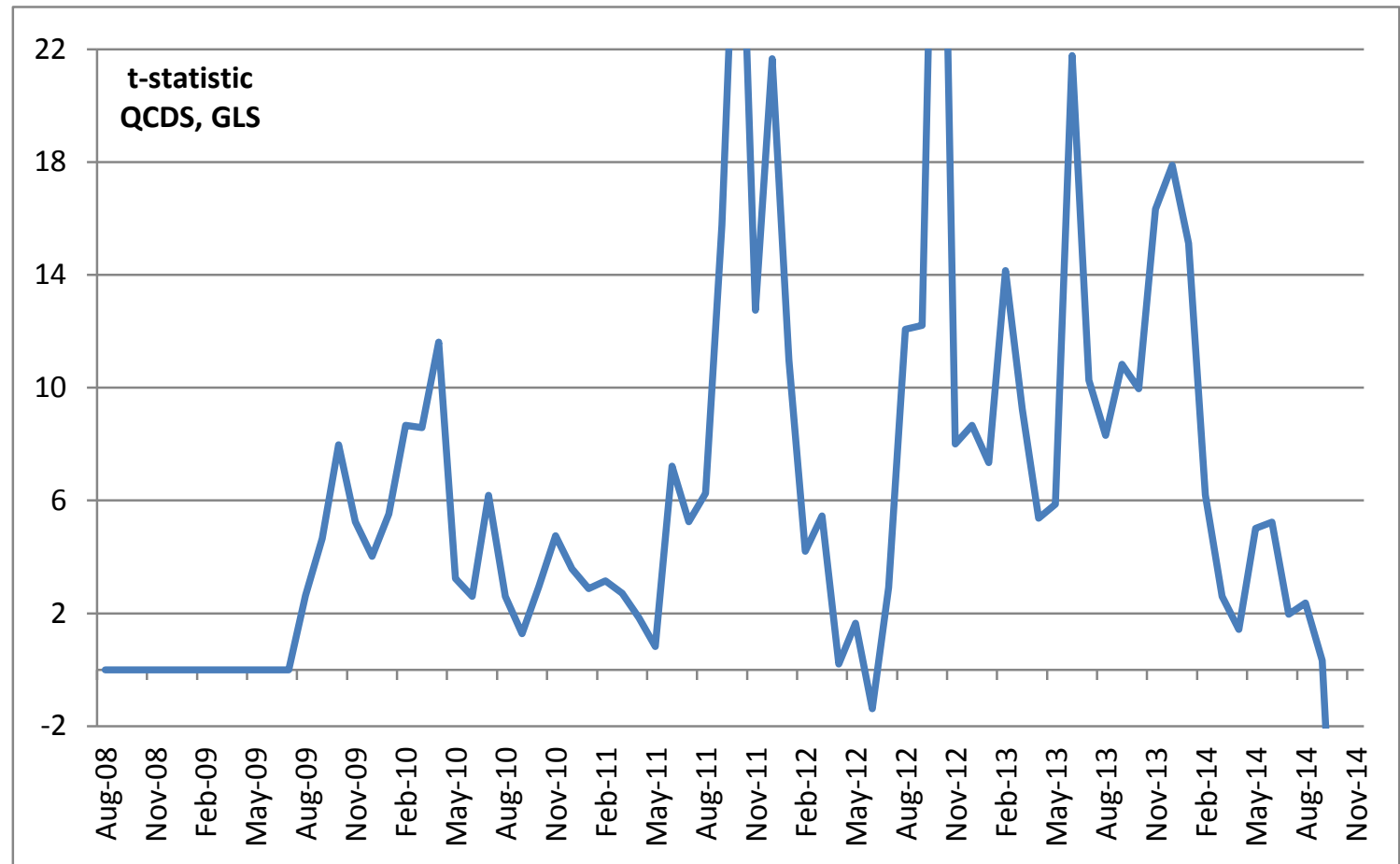

Note: t-statistic spikes 6 and higher early in the Euro-crisis (late 2009 to mid-2010). It moves towards zero in early 2011 (when markets were calmer, and the ECB hiked rates), and it spikes even further to above 10 in late 2011, when systemic tension resurfaced. Finally, the t-statistic remains elevated throughout 2012 and 2013, after which it drops, especially in 2014, when the t-statistic hovers around zero. 
Chart A.15: Coefficients from cross-sectional regression. Redenomination proxy (newsbased), and OLS estimation:

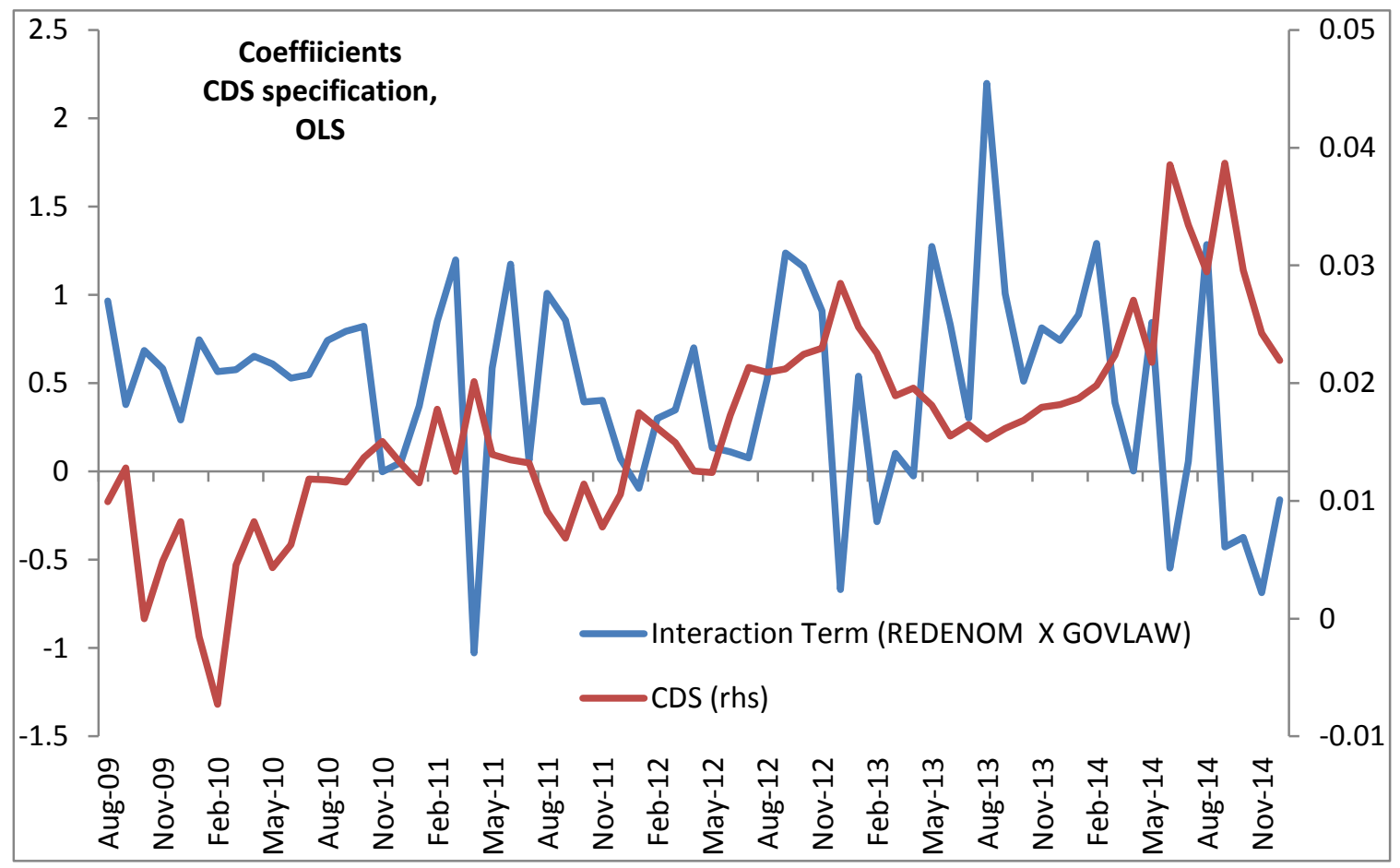

Note: During periods where the interaction term is most significant, the coefficient is around 1. 


\section{Chart A.16: Correlation between CDS and redenomination proxies (cross-section)}

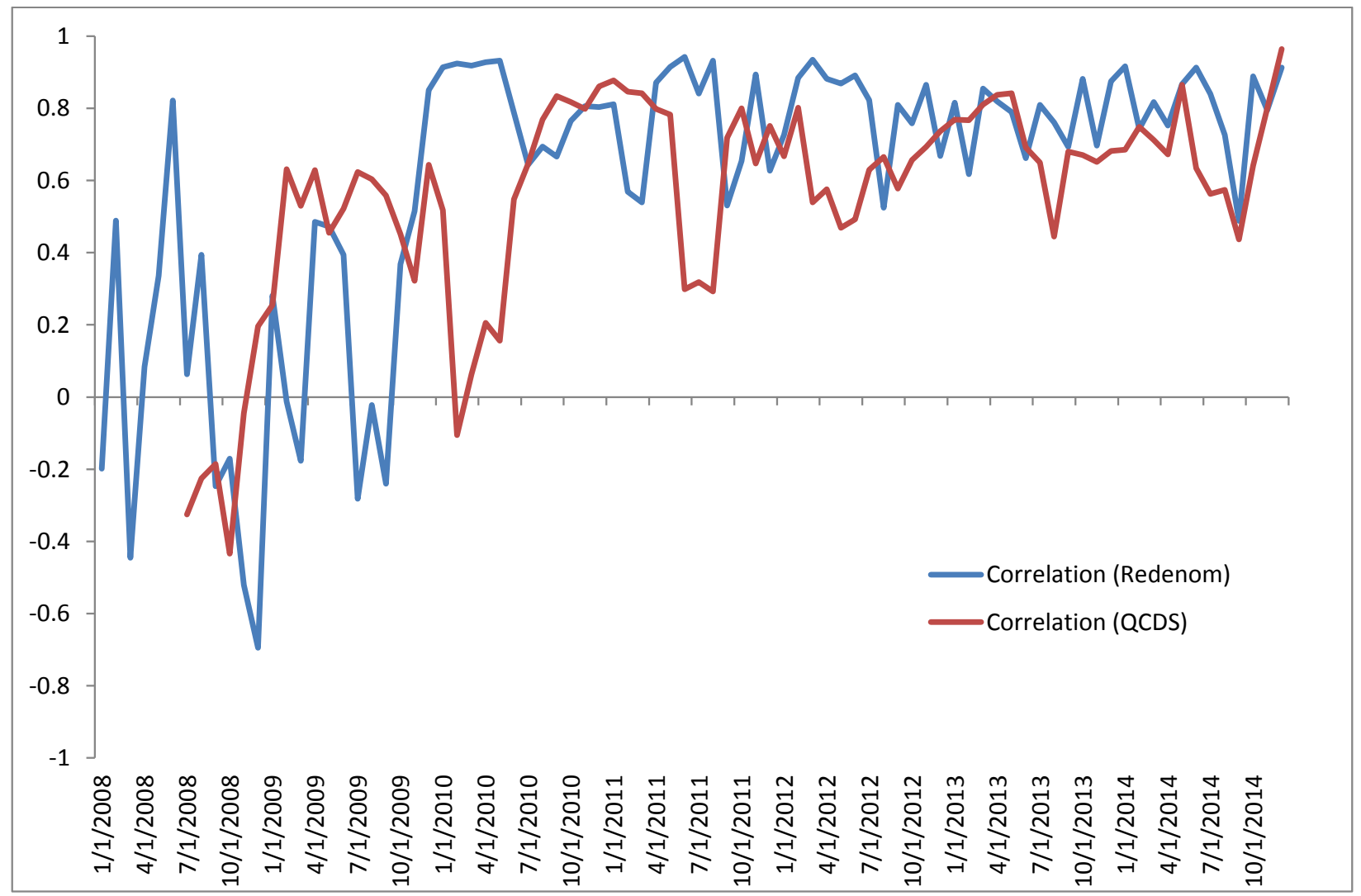

Note: Chart shows the cross-sectional correlation of the CDS variable and the two redenomination proxies. Given the limited number of countries in the Eurozone, and the occasional missing data (especially for Greece and Finland), this is based on a limited number of observations 8-11. But the trend is clear. At the on-set of the Euro-crisis, we see correlations move to 0.6-0.8 range for the news-based proxy and to $0.4-0.8$ for the quanto CDS variable. 
Table A.15: Example of general to specific approach to selecting CDS vs redenomination risk (QCDS version)

Dependent Variable: YIELD_A

Method: Panel Least Squares

Date: 05/09/15 Time: 12:05

Sample: 2010M01 2012M12

Periods included: 36

Cross-sections included: 222

Total panel (unbalanced) observations: 3944

\begin{tabular}{lrlrr}
\hline \multicolumn{1}{c}{ Variable } & Coefficient & Std. Error & t-Statistic & Prob. \\
\hline C & 1.222484 & 0.121105 & 10.09442 & 0.0000 \\
RATINGSPREAD & 0.276017 & 0.017012 & 16.22529 & 0.0000 \\
$\quad$ ISSUESIZE & -0.000193 & $5.27 E-05$ & -3.658530 & 0.0003 \\
CDS*GOVLAW & 0.014105 & 0.000554 & 25.44632 & 0.0000 \\
QCDS & 0.069216 & 0.001820 & 38.03494 & 0.0000 \\
QCDS*GOVLAW & -0.058357 & 0.002747 & -21.24416 & 0.0000 \\
$\quad$ GOVLAW & -0.456884 & 0.137530 & -3.322069 & 0.0009 \\
\hline \hline & & & & \\
R-squared & 0.715794 & Mean dependent var & 4.511516 \\
Adjusted R-squared & 0.715360 & S.D. dependent var & 2.980680 \\
S.E. of regression & 1.590241 & Akaike info criterion & 3.767422 \\
Sum squared resid & 9956.150 & Schwarz criterion & 3.778568 \\
Log likelihood & -7422.356 & Hannan-Quinn criter. & 3.771376 \\
F-statistic & 1652.601 & Durbin-Watson stat & 0.194752 \\
Prob(F-statistic) & 0.000000 & & \\
\hline \hline
\end{tabular}

Note: After testing the model down to only significant terms (at $5 \%$ level), we end up with a specification that has two interaction terms, but only the coefficient on the CDS variable is positive. 
Table A.16: Example of general to specific approach to selecting CDS vs redenomination risk (news-based variable version)

Dependent Variable: YIELD_A

Method: Panel Least Squares

Date: 05/09/15 Time: 12:23

Sample: 2010M01 2012M12

Periods included: 36

Cross-sections included: 222

Total panel (unbalanced) observations: 3944

\begin{tabular}{lrrrr}
\hline \hline \multicolumn{1}{c}{ Variable } & Coefficient & Std. Error & t-Statistic & Prob. \\
\hline C & 2.082811 & 0.122236 & 17.03924 & 0.0000 \\
RATINGSPREAD & 0.329446 & 0.017601 & 18.71698 & 0.0000 \\
ISSUESIZE & -0.000184 & $5.52 \mathrm{E}-05$ & -3.328089 & 0.0009 \\
CDS*GOVLAW & 0.006400 & 0.000572 & 11.18122 & 0.0000 \\
CDS & 0.011986 & 0.000459 & 26.11220 & 0.0000 \\
REDENOM*GOVLAW & -0.055955 & 0.029298 & -1.909818 & 0.0562 \\
$\quad$ REDENOM & -0.083315 & 0.022245 & -3.745269 & 0.0002 \\
$\quad$ GOVLAW & -1.536006 & 0.139911 & -10.97846 & 0.0000 \\
\hline \hline R-squared & 0.685242 & Mean dependent var & 4.511516 \\
Adjusted R-squared & 0.684682 & S.D. dependent var & 2.980680 \\
S.E. of regression & 1.673747 & Akaike info criterion & 3.870033 \\
Sum squared resid & 11026.42 & Schwarz criterion & 3.882771 \\
Log likelihood & -7623.705 & Hannan-Quinn criter. & 3.874551 \\
F-statistic & 1224.119 & Durbin-Watson stat & 0.207497 \\
Prob(F-statistic) & 0.000000 & & \\
\hline \hline
\end{tabular}

Note: The interaction term involving the redenomination variable becomes borderline significant, and has the wrong sign, providing evidence that CDS is dominating it in this specification. 


\section{Granger causality tests: News based redenomination proxy and CDS}

Table A.17: Granger Causality Test for Greece (CDS, Redenomination Proxy)

Pairwise Granger Causality Tests

Date: 05/04/15 Time: 23:30

Sample: 2008M01 2014M12

Lags: 12

\begin{tabular}{lcrr}
\hline \hline Null Hypothesis: & Obs & F-Statistic & Prob. \\
\hline \hline CDSGREECE does not Granger Cause GREECE & 70 & 1.78514 & 0.0802 \\
GREECE does not Granger Cause CDSGREECE & & 1.67353 & 0.1055 \\
\hline \hline
\end{tabular}

Note: We borderline reject the null of no granger-causality in both directions.

Table A.18: Granger Causality Test for Ireland (CDS, Redenomination Proxy)

Pairwise Granger Causality Tests

Date: 05/04/15 Time: 23:33

Sample: 2008M01 2014M12

Lags: 12

\begin{tabular}{lcrr}
\hline \hline Null Hypothesis: & Obs & F-Statistic & Prob. \\
\hline \hline CDSIRELAND does not Granger Cause IRELAND & 70 & 1.44671 & 0.1809 \\
IRELAND does not Granger Cause CDSIRELAND & & 1.51558 & 0.1540 \\
\hline \hline
\end{tabular}

Note: We cannot reject (at $10 \%$ level) the null of no granger causality

Table A.19: Granger Causality Test for Portugal (CDS, Redenomination Proxy)

Pairwise Granger Causality Tests

Date: 05/04/15 Time: 23:35

Sample: 2008M01 2014M12

Lags: 12

\begin{tabular}{lccc}
\hline \hline Null Hypothesis: & Obs & F-Statistic & Prob. \\
\hline \hline CDSPORTUGAL does not Granger Cause PORTUGAL & 70 & 1.97475 & 0.0500 \\
PORTUGAL does not Granger Cause CDSPORTUGAL & & 2.22654 & 0.0264 \\
\hline \hline
\end{tabular}

Note: We can reject the null of no granger causality in both directions (at $10 \%$ and $5 \%$ level) 
Table A.20: Granger Causality Test for Spain (CDS, Redenomination Proxy)

Pairwise Granger Causality Tests

Date: 05/04/15 Time: 23:36

Sample: 2008M01 2014M12

Lags: 12

\begin{tabular}{lccr}
\hline \hline Null Hypothesis: & Obs & F-Statistic & Prob. \\
\hline \hline CDSSPAIN does not Granger Cause SPAIN & 70 & 1.27175 & 0.2681 \\
SPAIN does not Granger Cause CDSSPAIN & & 3.17715 & 0.0024 \\
\hline \hline
\end{tabular}

Note: We can reject the null of no granger causality from redenomination variable to CDS (at $10 \%$ and $5 \%$ level). But we cannot reject the null of no granger causality from CDS to redenomination.

Table A.21: Granger Causality Test for Belgium (CDS, Redenomination Proxy)

Pairwise Granger Causality Tests

Date: 05/04/15 Time: 23:39

Sample: 2008M01 2014M12

Lags: 12

\begin{tabular}{lccc}
\hline \hline Null Hypothesis: & Obs & F-Statistic & Prob. \\
\hline \hline CDSBELGIUM does not Granger Cause BELGIUM & 70 & 2.89863 & 0.0048 \\
BELGIUM does not Granger Cause CDSBELGIUM & & 0.92616 & 0.5298 \\
\hline \hline
\end{tabular}

Note: We cannot reject the null of no granger causality from redenomination to CDS. However, we can reject the null of no granger causality from CDS to redenomination (at $10 \%$ and $5 \%$ )

Table A.22: Granger Causality Test for Italy (CDS, Redenomination Proxy)

Pairwise Granger Causality Tests

Date: 05/04/15 Time: 23:43

Sample: 2008M01 2014M12

Lags: 12

\begin{tabular}{lccr}
\hline \hline Null Hypothesis: & Obs & F-Statistic & Prob. \\
\hline \hline CDSITALY does not Granger Cause ITALY & 70 & 1.68517 & 0.1025 \\
ITALY does not Granger Cause CDSITALY & & 2.49840 & 0.0132 \\
\hline \hline
\end{tabular}

Note: For Italy (a G7 country), we can reject (at $5 \%$ level) the hypothesis of no granger causality running from the news-based redenomination proxy to CDS. However, we cannot reject the hypothesis of no granger causality running from CDS to the redenomination proxy (at $10 \%$ level). 
Table A.23: Granger Causality Test for France (CDS, Redenomination Proxy)

Pairwise Granger Causality Tests

Date: 05/04/15 Time: 23:43

Sample: 2008M01 2014M12

Lags: 12

\begin{tabular}{lccr}
\hline \hline Null Hypothesis: & Obs & F-Statistic & Prob. \\
\hline \hline CDSFRANCE does not Granger Cause FRANCE & 70 & 2.28628 & 0.0227 \\
FRANCE does not Granger Cause CDSFRANCE & & 0.93007 & 0.5262 \\
\hline \hline
\end{tabular}

Note: For France (a G7 country), we cannot reject (at 10\% level) the hypothesis of no granger causality running from the news-based redenomination proxy to CDS. However, we can reject the hypothesis of no granger causality running from CDS to the redenomination proxy (at $5 \%$ level).

Table A.24: Granger Causality Test Austria (CDS, Redenomination Proxy)

Pairwise Granger Causality Tests

Date: 05/04/15 Time: 23:53

Sample: 2008M01 2014M12

Lags: 12

\begin{tabular}{lccc}
\hline \hline Null Hypothesis: & Obs & F-Statistic & Prob. \\
\hline \hline CDSAUSTRIA does not Granger Cause AUSTRIA & 70 & 1.69595 & 0.0999 \\
AUSTRIA does not Granger Cause CDSAUSTRIA & & 0.90601 & 0.5483 \\
\hline \hline
\end{tabular}

Note: We cannot reject null of no granger causality from redenomination to CDS.

Table A.25: Granger Causality Test for Finland (CDS, Redenomination Proxy)

Pairwise Granger Causality Tests

Date: 05/04/15 Time: 23:55

Sample: 2008M01 2014M12

Lags: 12

\begin{tabular}{lccc}
\hline \hline Null Hypothesis: & Obs & F-Statistic & Prob. \\
\hline \hline CDSFINLAND does not Granger Cause FINLAND & \multirow{2}{*}{70} & 1.58877 & 0.1294 \\
FINLAND does not Granger Cause CDSFINLAND & & 1.32348 & 0.2392 \\
\hline \hline
\end{tabular}

Note: We cannot reject null of no granger causality from redenomination to CDS. 
Table A.26: Granger Causality Test for Netherlands (CDS, Redenomination Proxy)

Pairwise Granger Causality Tests

Date: 05/04/15 Time: 23:57

Sample: 2008M01 2014M12

Lags: 12

\begin{tabular}{lcrr}
\hline \hline Null Hypothesis: & Obs & F-Statistic & Prob. \\
\hline \hline CDSNETHERLANDS does not Granger Cause HOLLAND & 70 & 0.85029 & 0.6005 \\
HOLLAND does not Granger Cause CDSNETHERLANDS & & 0.81957 & 0.6297 \\
\hline \hline
\end{tabular}

Note: We cannot reject null of no granger causality from redenomination to CDS.

\section{Granger causality tests: Quanto CDS redenomination proxy and CDS}

\section{Table A.27: Granger causality test (CDS, QCDS, Spain)}

Pairwise Granger Causality Tests

Date: 05/10/15 Time: 08:34

Sample: 2008M01 2014M12

Lags: 12

\begin{tabular}{lcrr}
\hline \hline Null Hypothesis: & Obs & F-Statistic & Prob. \\
\hline \hline QCDSSPAIN does not Granger Cause CDSSPAIN & 66 & 1.01091 & 0.4568 \\
CDSSPAIN does not Granger Cause QCDSSPAIN & & 2.51323 & 0.0141 \\
\hline \hline
\end{tabular}

Note: We can reject the null of CDS not granger causing QCDS for Spain, but not the other way around. Results shown with 12 lags. But result seems consistent across lag specifications.

\section{Table A.28: Granger causality test (CDS, QCDS, Italy)}

Pairwise Granger Causality Tests

Date: 05/10/15 Time: 08:38

Sample: 2008M01 2014M12

Lags: 12

\begin{tabular}{lcrr}
\hline \hline Null Hypothesis: & Obs & F-Statistic & Prob. \\
\hline \hline QCDSITALY does not Granger Cause CDSITALY & \multirow{2}{*}{66} & 1.44352 & 0.1861 \\
CDSITALY does not Granger Cause QCDSITALY & & 2.21533 & 0.0293 \\
\hline \hline
\end{tabular}

Note: We can reject the null of CDS not granger causing QCDS for Italy, but not the other way around. Results shown with 12 lags. But result seems consistent across lag specifications. 
Table A.29: Granger causality test (CDS, QCDS, Portugal)

Pairwise Granger Causality Tests

Date: 05/10/15 Time: 08:40

Sample: 2008M01 2014M12

Lags: 12

\begin{tabular}{lcrr}
\hline \hline Null Hypothesis: & Obs & F-Statistic & Prob. \\
\hline \hline QCDSPORTUGAL does not Granger Cause CDSPORTUGAL & 66 & 2.11983 & 0.0370 \\
CDSPORTUGAL does not Granger Cause QCDSPORTUGAL & & 2.64917 & 0.0101 \\
\hline \hline
\end{tabular}

Note: For Portugal, there is evidence of two-way causality at the $5 \%$ significance level. This result is robust to lag specification for the underlying VAR.

\section{Table A.30: Granger causality test (CDS, QCDS, France)}

Pairwise Granger Causality Tests

Date: 05/10/15 Time: 08:42

Sample: 2008M01 2014M12

Lags: 12

\begin{tabular}{lccc}
\hline \hline Null Hypothesis: & Obs & F-Statistic & Prob. \\
\hline \hline QCDSFRANCE does not Granger Cause CDSFRANCE & 66 & 0.91776 & 0.5383 \\
CDSFRANCE does not Granger Cause QCDSFRANCE & & 2.72676 & 0.0083 \\
\hline \hline
\end{tabular}

Note: For France, we can reject the hypothesis that CDS does not granger-cause QCDS. But we cannot reject that QCDS does not granger cause CDS. 


\section{Regressions based on $\mathbf{G 7}$ countries only:}

Table A.31: G7 only panel, both CDS and Redenom interaction (2008-2014)

Dependent Variable: DEPENDENT

Method: Panel Least Squares

Date: 05/08/15 Time: 15:11

Sample: 2008M01 2014M12

Periods included: 84

Cross-sections included: 204

Total panel (unbalanced) observations: 8597

\begin{tabular}{lrrrr}
\hline \multicolumn{1}{c}{ Variable } & Coefficient & Std. Error & t-Statistic & Prob. \\
\hline \hline C & 3.324959 & 0.099042 & 33.57113 & 0.0000 \\
RATINGSPREAD & -0.147889 & 0.021553 & -6.861502 & 0.0000 \\
$\quad$ ISSUESIZE & $-9.84 E-06$ & $2.01 E-06$ & -4.888449 & 0.0000 \\
CDS & 0.005882 & 0.000382 & 15.38745 & 0.0000 \\
GOVLAW*CDS & -0.001581 & 0.000445 & -3.553791 & 0.0004 \\
GOVLAW*REDENOM & 0.152015 & 0.014160 & 10.73539 & 0.0000 \\
$\quad$ GOVLAW & -0.742660 & 0.109686 & -6.770799 & 0.0000 \\
\hline \hline R-squared & 0.209226 & Mean dependent var & 3.783159 \\
Adjusted R-squared & 0.208674 & S.D. dependent var & 1.956064 \\
S.E. of regression & 1.740047 & Akaike info criterion & 3.946515 \\
Sum squared resid & 26008.48 & Schwarz criterion & 3.952263 \\
Log likelihood & -16957.09 & Hannan-Quinn criter. & 3.948475 \\
F-statistic & 378.7955 & Durbin-Watson stat & 0.057162 \\
Prob(F-statistic) & 0.000000 & & \\
\hline \hline
\end{tabular}

Note: For the full sample, both the CDS interaction and the redenom interaction seem significant. But the interaction with the news-based redenomination variable has the right sign. 
Table A.32: G7 only panel, both CDS and Redenom interaction (2010-2012)

Dependent Variable: DEPENDENT

Method: Panel EGLS (Cross-section weights)

Date: 05/08/15 Time: 16:07

Sample: 2010M01 2012M12

Periods included: 36

Cross-sections included: 162

Total panel (unbalanced) observations: 3593

Linear estimation after one-step weighting matrix

\begin{tabular}{lrrrr}
\hline \hline \multicolumn{1}{c}{ Variable } & Coefficient & Std. Error & t-Statistic & Prob. \\
\hline C & 3.147822 & 0.117935 & 26.69123 & 0.0000 \\
RATINGSPREAD & -0.032932 & 0.018278 & -1.801716 & 0.0717 \\
ISSUESIZE & $-1.71 \mathrm{E}-05$ & $1.57 \mathrm{E}-06$ & -10.90420 & 0.0000 \\
CDS & 0.005050 & 0.000354 & 14.27186 & 0.0000 \\
GOVLAW*CDS & 0.000175 & 0.000396 & 0.443447 & 0.6575 \\
GOVLAW*REDENOM & 0.028913 & 0.008690 & 3.327112 & 0.0009 \\
$\quad$ GOVLAW & -0.103327 & 0.129551 & -0.797575 & 0.4252 \\
\hline \hline & Weighted Statistics & & \\
\hline \hline R-squared & 0.416473 & Mean dependent var & 7.510735 \\
Adjusted R-squared & 0.415497 & S.D. dependent var & 4.434742 \\
S.E. of regression & 1.719101 & Sum squared resid & 10597.74 \\
F-statistic & 426.5650 & Durbin-Watson stat & 0.183297 \\
Prob(F-statistic) & 0.000000 & & \\
\hline \hline & Unweighted Statistics & \\
\hline \hline
\end{tabular}

Note: In the raw specification in the period $2010-2012$, the redenomination variable appears highly significant, while the CDS variable drops out of the specification. 
Table A.33: G7 only panel, Redenom interaction (2010-2012), GLS

Dependent Variable: DEPENDENT

Method: Panel EGLS (Cross-section weights)

Date: 05/08/15 Time: 15:17

Sample: 2010M01 2012M12

Periods included: 36

Cross-sections included: 162

Total panel (unbalanced) observations: 3593

Linear estimation after one-step weighting matrix

\begin{tabular}{crrrr}
\hline \hline \multicolumn{1}{c}{ Variable } & Coefficient & Std. Error & t-Statistic & Prob. \\
\hline \hline C & 3.104483 & 0.067509 & 45.98600 & 0.0000 \\
RATINGSPREAD & -0.032848 & 0.018298 & -1.795141 & 0.0727 \\
ISSUESIZE & $-1.71 \mathrm{E}-05$ & $1.56 \mathrm{E}-06$ & -10.98689 & 0.0000 \\
CDS & 0.005190 & 0.000159 & 32.63687 & 0.0000 \\
GOVLAW*REDENOM & 0.030112 & 0.008245 & 3.652341 & 0.0003 \\
GOVLAW & -0.051308 & 0.057640 & -0.890149 & 0.3734 \\
\hline \hline & Weighted Statistics & & \\
\hline \hline R-squared & 0.416399 & Mean dependent var & 7.510207 \\
Adjusted R-squared & 0.415585 & S.D. dependent var & 4.430152 \\
S.E. of regression & 1.718833 & Sum squared resid & 10597.39 \\
F-statistic & 511.8635 & Durbin-Watson stat & 0.183937 \\
Prob(F-statistic) & 0.000000 & & \\
\hline \hline
\end{tabular}

Note: For the shorter sample, if we use general to specific approach to testing model down, we end up with only the redenomination variable significant (the interaction term with CDS drops out). 
Table A.34. G7 only panel, with redenom interaction, and redenom (2010-2012)

Dependent Variable: DEPENDENT

Method: Panel EGLS (Cross-section weights)

Date: 05/08/15 Time: 16:10

Sample: 2010M01 2012M12

Periods included: 36

Cross-sections included: 162

Total panel (unbalanced) observations: 3593

Linear estimation after one-step weighting matrix

\begin{tabular}{lrrrr}
\hline \hline \multicolumn{1}{c}{ Variable } & Coefficient & Std. Error & t-Statistic & Prob. \\
\hline C & 3.311638 & 0.073837 & 44.85090 & 0.0000 \\
RATINGSPREAD & -0.031943 & 0.017495 & -1.825792 & 0.0680 \\
ISSUESIZE & $-1.66 E-05$ & $1.56 E-06$ & -10.64465 & 0.0000 \\
CDS & 0.005480 & 0.000167 & 32.88607 & 0.0000 \\
REDENOM & -0.098830 & 0.018790 & -5.259637 & 0.0000 \\
GOVLAW*REDENOM & 0.119617 & 0.018892 & 6.331740 & 0.0000 \\
$\quad$ GOVLAW & -0.333219 & 0.072042 & -4.625326 & 0.0000 \\
\hline \hline & Weighted Statistics & & \\
\hline \hline R-squared & 0.421743 & Mean dependent var & 7.528934 \\
Adjusted R-squared & 0.420776 & S.D. dependent var & 4.595397 \\
S.E. of regression & 1.716769 & Sum squared resid & 10569.01 \\
F-statistic & 435.8993 & Durbin-Watson stat & 0.184183 \\
Prob(F-statistic) & 0.000000 & & \\
\hline \hline & Unweighted Statistics & \\
\hline \hline
\end{tabular}

Note: The results are the same when including redenomination variable directly as well as in the interaction term. I.e. the interaction term that remains significant is the one including the redenomination proxy (based on news counts). 